\author{
Aus der Abteilung Neuroradiologie \\ (Prof. Dr. med. M. Knauth) \\ im Zentrum Radiologie \\ der Medizinschen Fakultät der Universität Göttingen
}

\title{
Können zervikale Lymphknoten vorhersagen, ob eine Carotisplaque vulnerabel ist?
}

\author{
INAUGURAL - DISSERTATION \\ zur Erlangung des Doktorgrades \\ der Medizinischen Fakultät \\ der Georg-August-Universität zu Göttingen
}

vorgelegt von

Joëlle S. T. Landsberger

aus

Mainz

Göttingen 2013 
Dekan: Prof. Dr. rer. nat. H. K. Kroemer

I. Berichterstatter: Prof. Dr. med. M. Knauth

II. Berichterstatter: Prof. Dr. med. G. Trendelenburg

III. Berichterstatterin: Prof. Dr. med. P. Virsik-Köpp

Tag der mündlichen Prüfung: 12.02.2014 


\section{Inhaltsverzeichnis}

$1 \quad$ Einleitung

1.1 Der Schlaganfall

1.2 Morphologische Beschreibung arteriosklerotischer Läsionen

1.3 Entzündung und Plaquegeschehen

-9 -

1.4 Lymphknoten

$-13-$

1.5 Problemstellung und Hypothese

-16 -

-18 -

2 Methoden

2.1 Material

-19 -

2.2 Datenerhebung

-19 -

2.3 Erhobene Daten

-20 -

2.4 Patienten

-21 -

2.5 CT-Angiographie (CTA)

$-21-$

2.6 Bildanalyse

-22 -

2.7 Datendokumentation

2.8 Statistische Auswertung

-31 -

3 Ergebnisse

3.1 Übersicht zur Verteilung der Patienten

3.2 Überprüfung der Hypothesen (3.2.1 - 3.2.5)

4 Diskussion

4.1 Einleitung

4.2 Alternative Identifizierungsmöglichkeiten einer vulnerablen Plaque

4.3 Bildgebung zervikaler Lymphknoten

$-59-$

4.4 Grenzen der vorliegenden Arbeit

$-60-$

5 Zusammenfassung

$6 \quad$ Anhang

6.1 Tabellen

$-65-$

6.2 Formular zum Lymphknoten-Zählen

$-91-$

6.3 Abkürzungen

7 Literaturverzeichnis 


\section{Einleitung}

\subsection{Der Schlaganfall}

Der Schlaganfall ist primär klinisch definiert. Es handelt sich um ein plötzlich einsetzendes fokalneurologisches Defizit vaskulären Ursprungs (Herold 2006).

Als Ursache findet sich in $15-20 \%$ ein hämorrhagischer Schlaganfall, in $80-85 \%$ ein ischämisches Geschehen. Von einem manifesten Infarkt wird die sogenannte TIA (transitorisch-ischämische Attacke) abgegrenzt, bei der sich die Symptome innerhalb von 24 Stunden nach Beginn vollständig zurückbilden und bei der sich keine bildmorphologischen Äquivalente zeigen (Poeck und Hacke 2006). In Deutschland treten 150-200 Schlaganfälle (ischämisch und hämorrhagisch) pro 100.000 Einwohner und Jahr auf. Es handelt sich somit um eine häufige und volkswirtschaftlich relevante Erkrankung (Poeck und Hacke 2006).

Als Ursachen des ischämischen Schlaganfalls lassen sich in 70\% der Fälle Arteriosklerose und lokale arterielle Thrombosen identifizieren (Herold 2006). Die Arteriosklerose führt aufgrund strömungsmechanischer Faktoren besonders häufig an Aufteilungsstellen von Gefäßen, so z.B. an der Carotisbifurkation, zu Stenosen. 10-20\% aller ischämischen Schlaganfälle lassen sich auf Stenosen der Arteria carotis interna zurückführen (Kastrup et al. 2008).

Zum einen können diese durch Lumeneinengung der Arteria carotis interna hämodynamisch relevant werden und führen so zu hämodynamischen Infarkten.

Zum anderen kann es aber auch zu einer Ruptur der arteriosklerotischen Plaque kommen, welche lokale arterielle Thrombosen und distale Embolien verursachen kann. Lokale arterielle Thrombosen auf dem Boden der Ruptur einer arteriosklerotischen Läsion führen zu einer akuten Einengung des betroffenen Gefäßes. Auf der anderen Seite liegt 30\% aller Schlaganfälle der embolische Verschluss einer zerebralen Arterie zugrunde. Hierbei können, wie erwähnt, arteriosklerotisch veränderte, hirnzuführende Gefäße als Emboliequellen dienen, welche durch die Plaqueruptur und nachfolgende distale cerebrale Embolie zur akuten Symptomatik führen (Poeck und Hacke 2006).

Bei der Arteriosklerose als Ursache eines ischämischen Schlaganfalles spielt neben diesen makroangiopathischen Veränderungen ferner die intrazerebrale Arteriolosklerose (Mikroangiopathie) eine Rolle bei der Genese. Als weitere, nicht arteriosklerotisch bedingte Ätiologien des ischämischen Schlaganfalls seien Embolien als Folge eines Vorhofflimmerns, Dissektionen von Wänden hirnzuführender Gefäße, paradoxe Embolien und Vaskulitiden aufgeführt (Poeck und Hacke 2006).

Ausgehend von der Arteria carotis interna lassen sich folgende Ursachen für einen ischämischen Schlaganfall zusammenfassen: 
- Arteriosklerotisch bedingte Stenosen mit hämodynamischer Relevanz

- Lokale arterielle Thrombosen auf dem Boden der Ruptur einer arteriosklerotischen Plaque

- Arterielle Embolien, auf dem Boden einer Plaqueruptur entstanden.

\subsubsection{Diagnostik des Schlaganfalls}

Am Anfang der Diagnostik des Schlaganfalls steht die Anamnese und klinische Untersuchung des Patienten. Besteht der Verdacht auf einen Apoplex, so wird die dringliche Durchführung einer Bildgebung empfohlen. Hiermit ist es möglich, zeitnah Informationen über die Ätiologie und Art (hämorrhagisch/ischämisch) eines Schlaganfalls zu erhalten, um so möglichst schnell adäquat therapeutisch interventionieren zu können, da die bis zur Therapie vergangene Zeit entscheidend für die Prognose des Patienten ist („Time is brain“). Aufgrund guter Verfügbarkeit und kurzer Untersuchungszeiten steht zur initialen bildgebenden Diagnostik die Computertomographie (CT) im Vordergrund. So sind mittels CT die Abklärung möglicher Differentialdiagnosen und die Differenzierung zwischen einem hämorrhagischen und ischämischen Schlaganfall möglich. Außerdem erhält der Untersucher Informationen über Ort, Art, Alter und Ausdehnung des Infarktes. Folgende Infarktfrühzeichen werden in der Computertomographie beschrieben:

- Hypodensität

- Hyperdenses Gefäßzeichen als Nachweis eines Thrombus in einer Hirnarterie

- Gewebeschwellung mit Verkleinerung der Sulci (Poeck und Hacke 2006, Ringleb et al. 2008).

Alternativ ist zur Diagnostik eines Schlaganfalls die apparative Bildgebung mittels Magnetresonanztomographie (MRT) möglich. Die Durchführung erfolgt jedoch nicht routinemäßig. Empfohlen wird die MRT insbesondere bei Schlaganfallpatienten mit ungewöhnlichen Symptomkonstellationen, seltenen Ätiologien und bei denen die CT den sicheren Ausschluss von relevanten Differentialdiagnosen nicht ermöglicht (Ringleb et al. 2008). Außerdem ist ein Einsatzgebiet der MRT die Identifizierung derjenigen Patienten, die außerhalb des Fensters zur Thrombolysetherapie (s.u.) in der Klinik eintreffen und möglicherweise trotzdem von einer solchen profitieren können. Hierzu kann mittels perfusions- und diffusionsgewichteter Sequenzen (PWI/DWI) im MRT dasjenige Hirngewebe dargestellt werden, das lediglich in seiner Funktion eingeschränkt, aber noch nicht irreversibel zerstört wurde und so eventuell durch eine Therapie auch außerhalb des Zeitfensters zu retten ist. Hierbei handelt es sich um die so genannte Penumbra. Dieser Bereich lässt sich über ein PWI/DWI-Missmatch identifizieren. Hierbei entspricht das PWI-gestörte Areal der Penumbra, das DWI-gestörte Hirnareal dem irreversibel geschädigten Gewebe (Poeck und Hacke 2006).

Zur Abklärung der Ätiologie eines Schlaganfalls und möglicher therapeutischer Optionen wird außerdem eine rasche Gefäßbildgebung empfohlen. Hierbei sind die farbkodierte 
Duplexsonographie der extra- und intrakraniellen Gefäße, die CT-Angiographie (CTA) und die MR-Angiographie (MRA) zu nennen. Als invasive Methode ist die digitale Subtraktionsangiographie (DSA) möglich. Insbesondere für Patienten mit stattgehabter TIA oder leichtem Schlaganfall ist die vaskuläre Diagnostik bedeutend, da ihr hohes Risiko eines Schlaganfallrezidivs (bis zu 10\% in den ersten 48 Stunden) durch eine adäquate Therapie gemindert werden kann. Außerdem sollte bei jedem Schlaganfallpatienten ein kardiales Monitoring erfolgen, um zum einen häufig bei akuten Schlaganfallpatienten auftretende EKG-Abnormalitäten zu erkennen und zum anderen um ein mögliches Vorhofflimmern als Ursache für den Schlaganfall zu identifizieren. Mittels Echokardiographie können weitere kardiale Schlaganfallursachen (z.B. persistierendes Foramen ovale mit resultierender paradoxer Embolie) ausfindig gemacht werden (Poeck und Hacke 2006, Ringleb et al. 2008).

\subsubsection{Therapie des Schlaganfalls}

\section{a. Allgemeine Therapiemaßnahmen}

Grundsätzlich wird empfohlen, alle Schlaganfallpatienten auf einer Stroke Unit zu behandeln. Zur Therapie nach Schlaganfall gehört die regelmäßige Kontrolle des neurologischen Status, der Herzfrequenz, des Blutdrucks, der Temperatur und der Sauerstoffsättigung in den ersten 72 Stunden nach dem Ereignis und das Optimieren der angeführten Parameter. Des Weiteren können eine Infektbehandlung und Fiebersenkung notwendig werden. $\mathrm{Zu}$ überwachen sind außerdem der Flüssigkeitshaushalt und der Elektrolytstatus des Patienten (Ringleb et al. 2008).

\section{b. Spezifische Therapiemaßnahmen}

$\mathrm{Zu}$ den spezifischen Therapiemaßnahmen gehört die Thrombolysetherapie mit i.v.-rtPA (rekombinanter tissue type plasminogen activator). Für diese konnte durch Hacke et al. (2008) in einer randomisierten, placebo-kontrollierten Studie gezeigt werden, dass Patienten mit einem akuten ischämischen Schlaganfall bis zu viereinhalb Stunden nach Symptombeginn profitieren. Als Komplikation der Thrombolysetherapie kommt es häufiger zu intrakraniellen Blutungen als unter Placebo, jedoch konnte kein Unterschied in der Mortalität dokumentiert werden (Hacke et al. 2008). Entsprechend wird diese Maßnahme nicht beim Vorliegen von Blutungen in der Bildgebung, schwerem neurologischem Defizit mit Bewusstseinstrübung, fixierter Kopf- und Blickwendung und Hemiplegie und ausgedehnten Infarktfühzeichen im CT empfohlen, da ein erhöhtes Risiko sekundärer Einblutungen besteht. Wie bereits oben erwähnt, erfolgt die Thrombolysetherapie außerhalb des Therapiefensters bei vorliegendem PWI/DWI-Missmatch nicht routinemäßig. Weitere spezifische Therapiemaßnahmen sind die Behandlung eines erhöhten intrazerebralen Druckes z.B. durch chirurgische Dekompression und die Behandlung bzw. Prävention von Komplikationen wie z.B. Aspiration, Beinvenenthrombose oder Krampfanfällen (Ringleb et al. 2008, Poeck und Hacke 2006). 


\section{c. Primärprävention}

Die Primärprävention verfolgt das Ziel, einen Schlaganfall im Vorhinein zu verhindern. Entsprechend den bekannten Risikofaktoren für einen Schlaganfall werden die folgenden allgemeinen Maßnahmen empfohlen:

- Blutdruck-Kontrolle bzw. -Einstellung

- Blutzucker-Kontrolle bzw. -Einstellung

- Cholesterin-Kontrolle bzw. -Einstellung

- Raucherentwöhnung

- Einstellen eines übermäßigen Alkoholkonsums

- Regelmäßige körperliche Aktivität

- Gewichtsreduktion.

Des Weiteren ist eine orale Antikoagulation bei bestehendem Vorhofflimmern und eine regelmäßige Medikation mit Acetylsalicylsäure beim Vorliegen einer asymptomatischen Carotisstenose mit über $50 \%$ sinnvoll.

Eine chirurgische Intervention mittels einer Carotis-Thrombendarteriektomie (Carotis-TEA) wird laut den Leitlinien der Europäischen Schlaganfallorganisation nicht zur Primärprävention für Patienten mit einer asymptomatischen, signifikanten (60-99\% nach NASCET) Carotisstenose empfohlen, da das perioperative Risiko für einen Schlaganfall oder Tod mit 3\% über dem jährlichen Infarktrisiko der unbehandelten Stenose von 2\% liegt. Eine Carotis-TEA kann beim Vorliegen einer asymptomatischen Stenose somit erst bei erhöhtem Schlaganfallrisiko (männlich, Stenose $>80 \%$, Lebenserwartung $>5$ Jahre) erwogen werden (Schellinger et al. 2008). In einer randomisierten, kontrollierten Studie zur Effektivitität der Carotis-TEA bei Patienten mit asymptomatischer Carotisstenose konnte nach Durchführung derselben (mit einem perioperativen Risiko unter 3\%) nach zehn Jahren die Rate von nicht-perioperativ stattgehabten ischämischen, v.a. ipsilateralen Schlaganfällen halbiert werden. Aufgrund niedrigerer Schlaganfall-Raten bei Patienten unter fettsenkender Medikation wurde der absolute Effekt einer TEA gemindert, was die Wichtigkeit der adäquaten konservativen Therapie (s.o.) verdeutlicht. Bei Patienten unter adäquater konservativer Therapie und niedriger Wahrscheinlichkeit einer anderen Todesursache innnerhalb von zehn Jahren betrug die Anzahl der notwendigen Behandlungen 20 (Number Needed to Treet, entspricht einer absoluten Risikoreduktion von 5\%). Ein Benefit der Carotis-TEA kann laut den erhobenen Daten bei Patienten mit asymptomatischer Stenose in einem Alter unter 75 Jahren erwartet werden (Halliday et al. 2010). Des Weiteren profitieren eher Männer als Frauen von einer Operation (MRC Asymptomatic Carotid Surgery Trial (ACST) Collaborative Group 2004).

Die Durchführung einer perkutanen transluminalen Angioplastie (PTA) evtl. mit Einbringen eines Stents der A. carotis wird für asymptomatische Carotisstenosen nicht zur Primärprävention empfohlen (Poeck und Hacke 2006, Schellinger et al. 2008). 


\section{d. Sekundärprävention}

Die Sekundärprävention verfolgt das Ziel, einen Schlaganfall nach zuvor bereits stattgehabter TIA oder stattgehabtem Schlaganfall zu verhindern. Hierzu erfolgt entsprechend den Maßnahmen zur Primärprävention eine Minimierung der Risikofaktoren eines Schlaganfalls (s.o.). Bei Vorliegen eines persistierenden Foramen ovale kann dieses verschlossen werden. Außerdem wird eine antithrombotische Therapie nach stattgehabtem Schlaganfall empfohlen.

Bezüglich der Carotis-TEA gelten zur Sekundärprävention, d.h. bei symptomatischer Carotisstenose, die folgenden Richtlinien: Bei Vorliegen einer Stenose von 70-99\% gemessen nach NASCET sollte eine chirurgische Intervention so bald wie möglich nach dem Ereignis, am besten innerhalb von zwei Wochen, erfolgen. Handelt es sich um eine Stenose von 50-69\% gemessen nach NASCET, so profitieren männliche Patienten mit kurzer Zeit zurückliegenden, hemisphärischen Symptomen von der Operation. Nicht empfohlen wird die TEA für Patienten mit einer Carotisstenose unter 50\% (Schellinger et al. 2008).

\begin{tabular}{|l|l|}
\hline Stenosegrad nach NASCET & Empfehlung für die Durchführung einer TEA \\
\hline $70-99 \%$ & e m p f o h l e $\mathrm{n}$ \\
\hline $50-69 \%$ & mit E i n s h r ä $\mathrm{k} \mathrm{u} \mathrm{n} \mathrm{g} \mathrm{e} \mathrm{n} \mathrm{empfohlen}$ \\
\hline$<50 \%$ & $\mathrm{n} \mathrm{i} \mathrm{c} \mathrm{h} \mathrm{t} \mathrm{empfohlen}$ \\
\hline
\end{tabular}

Tab. 1 Empfehlungen zur Durchführung einer TEA (Schellinger et al. 2008)

Alternativ ist seit einigen Jahren auch die (stentgeschützte) Angioplastie der Arteria carotis etabliert (Carotid Artery Stenting, CAS). In der SPACE-Studie (Stent-Protected Angioplasty versus Carotid Endarterectomy), einer multinationalen, prospektiven und randomisierten Studie zur NichtUnterlegenheit der CAS im Vergleich zur CEA mit Einschluss von 1214 Patienten, konnte kein signifikanter Unterschied in den Zwei-Jahres-Endpunkten zwischen CAS und CEA gefunden werden. Untersucht wurden klinische Ereignisse wie (ipsilateraler) Schlaganfall und Tod (Eckstein et al. 2008).

Hiermit steht die CAS als weniger invasive Behandlungsalternative der symptomatischen Carotisstenose zur Verfügung. 


\subsection{Morphologische Beschreibung arteriosklerotischer Läsionen}

Wie beschrieben, entstehen die meisten Schlaganfälle auf dem Boden eines arteriosklerotischen Geschehens. Hierbei entstehen Plaques an den Gefäßwänden, die entweder aufgrund ihrer hämodynamischen Auswirkungen oder aufgrund ihrer instabilen Struktur klinisch relevant werden. Nach der Klassifikation von Virmani et al. (2000) nach morphologischen Kriterien werden die

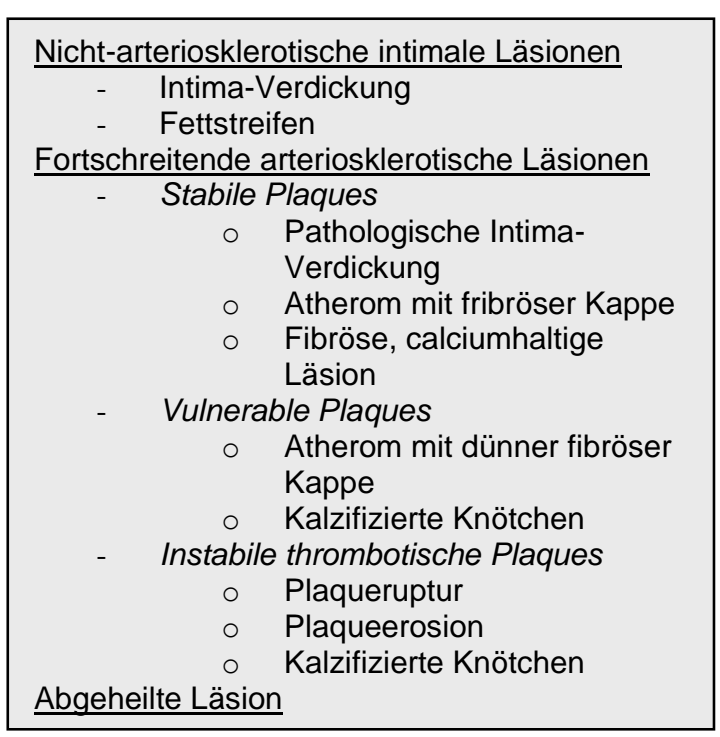

folgenden Kategorien arteriosklerotischer Läsionen unterschieden: In der Gruppe der arteriosklerotischen Läsionen werden solche identifiziert, die stabil sind, d.h. nicht zu thrombotischen Komplikationen neigen, solche, die vulnerabel sind, also mit einer gewissen Wahrscheinlichkeit thrombotische Komplikationen hervorrufen können, und solche, die instabil sind und bei denen bereits ein Thrombus vorliegt, der zur klinischen Manifestation der Arteriosklerose führen kann. Die Charakteristika der einzelnen Veränderungen seien im Folgenden aufgeführt.

\subsubsection{Nicht-arteriosklerotische intimale Läsionen}

- Intima-Verdickung (,Intimal Thickening“)

Diese Veränderung besteht aus glatten Muskelzellen in einer proteoglykanreichen Matrix. Es lassen sich keine Lipide oder Schaumzellen (s.u.) nachweisen. Plaqueerosion (s.u.) lässt sich an diesen Stellen am häufigsten finden (Virmani et al. 2000).

\section{- Fettstreifen (,Fatty Streaks“)/Intimal Xanthoma}

Hierbei handelt es sich um eine Anreicherung von Schaumzellen (s.u.) in der Gefäßintima ohne das Vorliegen eines nekrotischen Kerns oder einer fibrösen Kappe („Fibrous Cap“). Es können einige glatte Muskelzellen und T-Lymphozyten in diesen Läsionen gefunden werden. In den meisten Fällen ist diese Veränderung reversibel (Virmani et al. 2000). 


\subsubsection{Fortschreitende arteriosklerotische Läsionen}

\section{- Stabile Plaques}

\section{○ Pathologische Intima-Verdickung („Pathological Intimal Thickening“)}

Hierbei liegen wie bei der Intima-Verdickung glatte Muskelzellen in einer proteoglykanreichen Matrix vor, allerdings begleitet von Arealen bestehend aus Lipiden. Es findet sich kein nekrotischer Kern (Virmani et al. 2000). Das Vorkommen verschiedener Mengen Makrophagen und T-Lymphozyten ist möglich (Spagnoli et al. 2007).

\section{- Atherom mit fibröser Kappe („Fibrous Cap Atheroma“)}

Es findet sich ein großer lipidhaltiger nekrotischer Kern, der von einer dicken fibrösen Kappe überdeckt wird. Die fibröse Kappe besteht wiederum aus einigen glatten Muskelzellen in einer kollagen- und proteoglykanreichen Matrix. Es finden sich unterschiedliche Anteile an Makrophagen und Lymphozyten (Virmani et al. 2000). Diese Veränderung kann sich in eine calciumhaltige stabile Läsion umwandeln oder zu Komplikationen führen (Spagnoli et al. 2007).

\section{○ Fibröse, calciumhaltige Läsion („,Fibrocalcific Lesion“)}

Bei dieser Läsion liegt eine dicke fibröse Kappe vor, die über großen Ansammlungen von Calcium in der Intima liegt. Der nekrotische Kern ist klein oder nicht vorhanden (Virmani et al. 2000). Im Gegensatz zu Patienten mit einer Stenose der Koronarien haben Patienten mit einer ACI-Stenose und einer arteriosklerotischen Läsion, die viel Calcium enthält, weniger Symptome im Sinne eines Schlaganfalls oder einer TIA (Nandalur et al. 2005).

\section{- Vulnerable, gefährliche Plaques}

\section{- Atherom mit dünner fibröser Kappe („Thin Fibrous Cap Atheroma“)}

Bei diesen Läsionen liegt die Dicke der fibrösen Kappe unter $165 \mu \mathrm{m}$ bezogen auf die Arteria carotis interna vor (Spagnoli et al. 2007). Morphologisch findet man in der fibrösen Kappe wenige glatte Muskelzellen, aber reichlich entzündliche Infiltrate (Makrophagen, T-Lymphozyten). Der nekrotische Kern ist groß, es finden sich Einblutungen und/oder Kalzifikationen. Es besteht eine hohe Neigung zur Plaqueruptur (s.u.) (Virmani et al. 2000).

○ Kalzifizierte Knötchen („Calcified Nodule“) ( $\rightarrow$ s.u.) 


\section{- Instabile thrombogene Plaques}

Diese Läsionen wirken durch das Offenlegen prokoagulatorischer Substanzen, wie dem "Tissue factor", thrombogen und führen so zur Formation eines Thrombus, der für die klinischen Symptome verantwortlich sein kann (Virmani et al. 2000).

\section{○ Plaqueruptur}

Bei der Ruptur einer Plaque findet sich ein Thrombus, der an der Stelle der zerrissenen fibrösen Kappe entstanden ist und in Verbindung mit dem nekrotischen Kern der Läsion steht. Der nekrotische Kern ist meist groß. Die fibröse Kappe ist von Makrophagen und Lymphozyten infiltriert und arm an glatten Muskelzellen. Eine Plaqueruptur kann im Rahmen eines Atheroms mit dünner fibröser Kappe („Thin Fibrous Cap Atheroma“) auftreten (Virmani et al. 2000).

\section{- Plaqueerosion}

Laut Definition liegt eine Plaqueerosion dann vor, wenn in fortlaufenden histologischen Schnitten einer thrombosierten Arterie keine Plaqueruptur zu finden ist. An der Stelle der Erosion fehlt das Endothel. Die Intima, die nun freiliegt, besteht aus glatten Muskelzellen und Proteoglykanen. Entzündungszellen sind kaum vorhanden (Virmani et al. 2000). Es gibt allerdings Hinweise, dass das Vorhandensein von Mastzellen in der fibrösen Kappe mit Plaqueerosion assoziiert ist (Mayranpaa et al. 2006). Plaqueerosion kann im Zusammenhang mit einer pathologischen IntimaVerdickung („Pathological Intimal Thickening“) und einem Atherom mit fibröser Kappe („Fibrous Cap Atheroma“) auftreten (Virmani et al. 2000).

\section{○ Kalzifizierte Knötchen („Calcified Nodule“)}

Bei dieser Läsion finden sich ein Zerreißen der fibrösen Kappe und Thromben. Außerdem lassen sich kalzifizierte Knötchen identifizieren. Diese Veränderung ist selten (Virmani et al. 2000).

\subsubsection{Abgelaufene Läsion}

Es findet sich oftmals ein verschlossenes Gefäßlumen. Die Läsion besteht aus mehreren Lagen dichten Kollagens und enthält keinen nekrotischen Kern. Es ist möglich, dass sich mehrere Lagen Lipide und nekrotischer Kern identifizieren lassen, im Sinne mehrerer abgelaufener Rupturen mit nachfolgender Thrombose, die klinisch stumm verlaufen können. Diese Gruppe der Läsionen ist die häufigste bei Stenosen der Arteria carotis interna (Spagnoli et al. 2007). 


\subsubsection{Entwicklung einer Plaque}

In der im Folgenden aufgeführten Grafik werden die möglichen Entwicklungsschritte einer arteriosklerotischen Plaque zusammengefasst. Man beachte, dass die Intima-Verdickung (,Intimal Thickening“) und das intimale Xanthom („Intimal Xanthoma“, entspricht „Fatty Streak“), sich weiterentwickeln können, aber nicht müssen. Es ist auch möglich, dass sie in ihrer Form persistieren. Des Weiteren sei auf die sich möglicherweise wiederholenden Zyklen aus Ruptur/Erosion, Thrombose und Heilung hingewiesen, die sich ebenfalls morphologisch nachweisen lassen (s.o.) (Virmani et al. 2000).

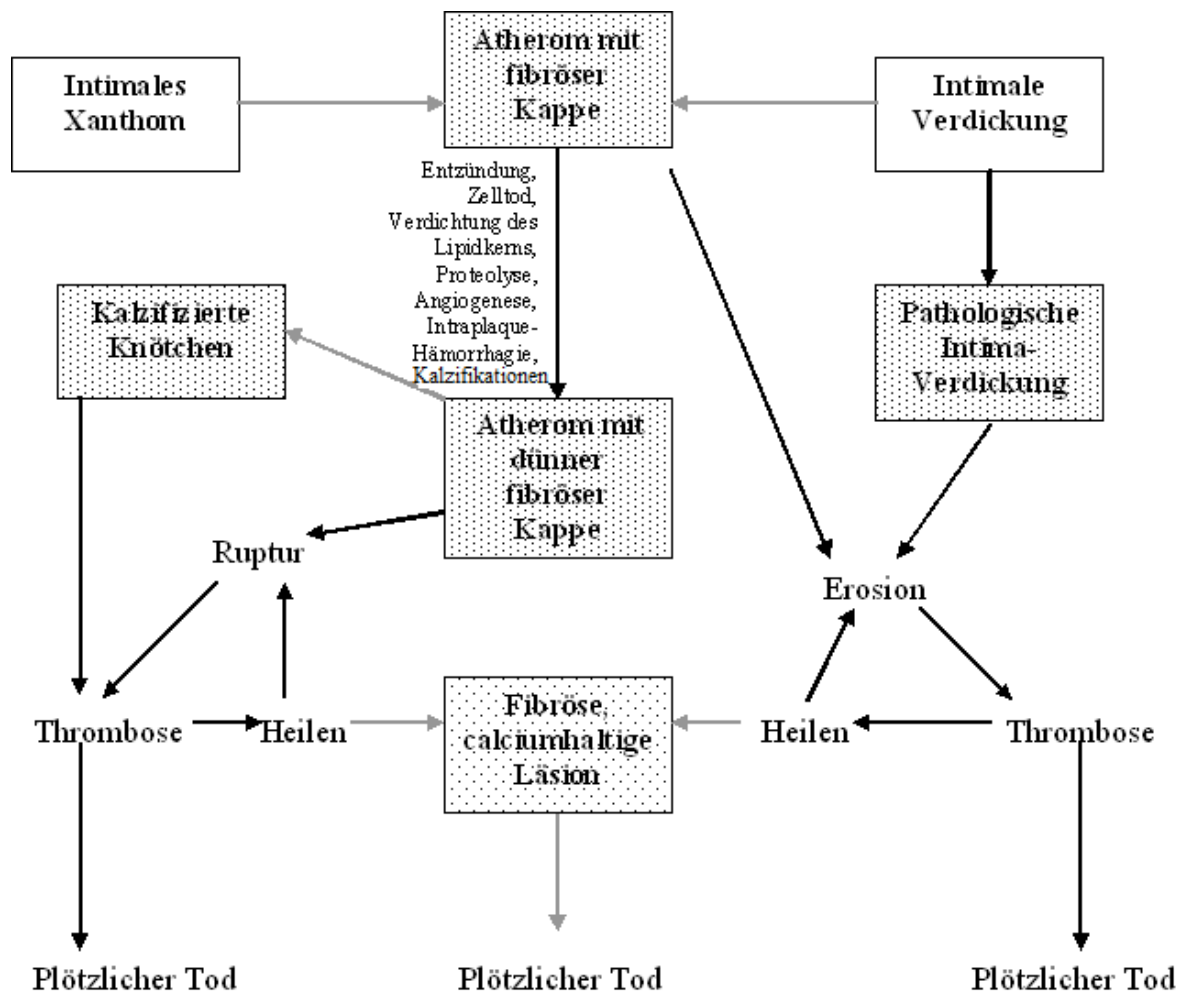

Abb. 1 Entwicklung einer Plaque, modifiziert nach Virmani et al. (2000), S. 1265 


\subsection{Entzündung und Plaquegeschehen}

\subsubsection{Grundlagen}

Mechanismen, die zu Komplikationen einer Stenose führen, sind weniger die stetige Größenzunahme einer Plaque und der daraus resultierende eingeschränkte Blutfluss im Gefäß, als vielmehr die durch entzündliche Prozesse hervorgerufene Instabilität und resultierende Ruptur oder Erosion einer arteriosklerotischen Läsion (Libby 2008). Bei den Prozessen, die hierbei eine Rolle spielen, handelt es sich um Vorgänge der angeborenen und der erworbenen Immunität. So sind Lymphozyten, Makrophagen und Mastzellen entscheidend in der Entstehung einer arteriosklerotischen Plaque und ihrer Komplikationen (Libby 2002). Im Folgenden seien die verschiedenen Abläufe und ihre zahlreichen Verknüpfungen untereinander dargestellt.

Am Anfang der Entzündungskaskade steht die Hyperlipidämie, die dazu führt, dass sich Lipoproteinpartikel in der Intima des betroffenen Gefäßes anreichern. Dieser Vorgang wird durch eine verminderte NO-Synthese des am Anfang der Läsion stehenden dysfunktionalen Endothels ermöglicht (Fuster et al. 2005a). Modifizierte Lipoproteinabkömmlinge können daraufhin zu einer Up-Regulation des VCAM-1-Rezeptors (vascular cell adhesion molecule-1-Rezeptor) am Gefäßendothel führen. Die Expression dieses Rezeptors wird außerdem über Gene reguliert, die von Scherkräften des Blutflusses beeinflusst werden. So führt ein nicht laminarer Blutfluss ebenfalls zu einer Up-Regulation. Hiermit lässt sich das vermehrte Vorkommen von Arteriosklerose an bestimmten Stellen des Gefäßbaumes (v.a. Bifurkationen) erklären.

Der VCAM-1-Rezeptor unterstützt im Folgenden die Diapedese von Leukozyten in die Gefäßintima. Der Übertritt der Leukozyten wird ferner von in arteriosklerotischen Läsionen überexprimierten Chemokinen vorangetrieben (Libby 2002).

\subsubsection{Die Rolle der Monozyten}

Nachdem Monozyten durch das Gefäßendothel in die Intima eingewandert sind, differenzieren sie zu Makrophagen und binden und internalisieren über inren Scavenger Receptor A (SRA) und CD36 modifizierte Lipoproteine (Libby 2002). Dieser Schritt vollzieht sich an und für sich in protektiver Absicht. Er soll der Minimierung der schädigenden Effekte des modifizierten LDL auf Endothel und glatte Muskelzellen dienen (Ross 1999). Unter dem Einfluss von "Granulocytemacrophage colony-stimulating factor" (GM-CSF) und "Macrophage colony stimulating factor" (M-CSF), deren Expression durch Lipoproteinpartikel vorangetrieben wird, entwickeln sich die Lipid-beladenen Makrophagen im Folgenden zu sog. Schaumzellen („Foam cells“). Diese sind charakteristisch für frühe arteriosklerotische Läsionen. 
Im weiteren Verlauf replizieren sich die Schaumzellen und setzen dabei verschiedene Substanzen frei. Zum einen handelt es sich hierbei um den „Tissue Factor“. Dieser wirkt, wenn er in Kontakt mit den Gerinnungsfaktoren des Blutes kommt, prokoagulatorisch und führt so z.B. bei einer Plaqueruptur zur Entstehung eines Thrombus. Des Weiteren werden Reaktive Sauerstoff Spezies (ROS) und Zytokine freigesetzt, die die lokale Entzündungsreaktion vorantreiben. Außerdem sezernieren die Schaumzellen Matrixmetalloproteinasen (MMPs). Diese zerstören die Integrität der subendothelialen Basalmembran und tragen auf diesem Wege zu Plaqueruptur und -erosion bei. Während des weiteren Voranschreitens der Entzündung gehen unter dem Einfluss von Interferon Y (IF-y) Schaumzellen in Apoptose und bilden den nekrotischen Kern der arteriosklerotischen Läsion (Libby 2002).

\subsubsection{Die Rolle der T-Lymphozyten}

Nachdem die T-Lymphozyten in die Intima eingewandert sind, binden sie Antigene, wie z.B. oxidiertes LDL über ihren Antigenrezeptor. Auf diesem Wege findet eine Aktivierung der Lymphozyten statt. Diese führt zur Freisetzung von Zytokinen, unter welchen sich CD154 befindet, das an den CD40-Rezeptor von Makrophagen binden kann. Diese wiederum werden so durch einen weiteren Mechanismus angeregt, „Tissue Factor", Matrixmetalloproteinasen und proinflammatorische Zytokine zu sezernieren (Effekte siehe oben).

Die T-Zellen entwickeln sich während ihrer weiteren Differenzierung verstärkt zu T-Helfer-1-Lymphozyten (TH1-Lymphozyten), welche im Folgenden ihrerseits proinflammatorische Zytokine sezernieren (Libby 2002).

\subsubsection{Die Rolle der Mastzellen}

Die Mastzellen wandern ebenfalls von Chemokinen angelockt in die Gefäßintima ein. Sobald sie sich dort befinden, kommt es zur Degranulation mit Freisetzung von Heparin, das antikoagulatorisch und wachstumshemmend auf glatte Muskelzellen wirkt, von TNF- $\alpha$, welches proinflammatorisch wirkt, und von Serinproteasen, die die Vorstufen der MMPs aktivieren, die im Folgenden das Kollagen der fibrösen Kappe spalten und katabolisieren, was zur Plaqueruptur beiträgt (s.u.) (Libby 2002). 


\subsubsection{Entzündung und Thrombusformation}

Laut der Klassifikation arteriosklerotischer Läsionen nach morphologischen Gesichtspunkten nach Virmani et al. (2000) (s.o.) entsteht eine instabile Plaque mit Thrombus v.a. auf dem Boden einer Plaqueruptur der fibrösen Kappe und einer Plaqueerosion des oberflächlichen Endothels. Des Weiteren sind selten kalzifizierte Knötchen als Basis für die Entstehung eines Thrombus möglich. Alle diese Mechanismen führen zum Kontakt von Thrombozyten und Gerinnungsfaktoren im Blut mit prokoagulatorischen Bestandteilen der arteriosklerotischen Plaque und so in ihrer Konsequenz zur Formation eines Thrombus mit Entwicklung der möglichen Komplikationen.

\section{a. Plaqueruptur}

Zum einen wird durch IF- $\gamma$ der T-Lymphozyten die Synthese von Kollagen durch glatte Muskelzellen gehemmt. Kollagen ist wichtig für die Stabilität der fibrösen Kappe. Zum anderen wird der Abbau des vorhandenen Kollagens durch Kollagenasen (MMPs, s.o.) vorangetrieben. Zuerst zerlegen die MMPs-1, -8 und -13 die Kollagenketten proteolytisch in ihre Bestandteile, die dann im Folgenden von den MMPs-2 und -9 katabolisiert werden. Hierbei tragen von Mastzellen synthetisierte Serinproteinasen zur Aktivierung der durch Makrophagen sezernierten Vorstufen der MMPs bei. Die Synthese der MMPs wird zum einen durch Aktivierung der Makrophagen durch T-Lymphozyten (über CD40, s.o.) und zum anderen durch von Mastzellen sezernierte Zytokine vorangetrieben (Libby 2008).

\section{b. Plaqueerosion}

Oberflächliche Plaqueerosion lässt sich vor allem bei Frauen und Patienten mit Hypertriglyceridämie als Ursache für die Formation eines Thrombus identifizieren. Durch aktivierte T-Killerzellen und entzündungsfördernde Mediatoren kommt es zum Zelltod der oberflächlichen Endothelzellen. Außerdem fördern die Mediatoren zusammen mit oxidierten Lipoproteinen die Aktivierung der MMPs-2 und -9, welche im Folgenden die aus Typ-IV-Kollagen bestehende subendotheliale Membran zerstören, so dass zusätzlich zum Zelltod der Endothelzellen auch deren Verankerung degradiert wird (Libby 2002, Libby 2008). 


\subsection{Lymphknoten}

\subsubsection{Aufbau und Funktion}

Lymphknoten gehören zur Gruppe der sekundären lymphatischen Organe. In den primären lymphatischen Organen (Knochenmark und Thymus) durchlaufen die B- und T-Lymphozyten verschiedene Reifungsprozesse, während die sekundären lymphatischen Organe den ausgereiften Lymphozyten einen Ort bieten, in dem zentrale Vorgänge der spezifischen Abwehr stattfinden können. So kommt es im Lymphknoten zur Antigen-Präsentation, Proliferation, Selektion und Differenzierung der Lymphozyten. Die Lymphknoten sind als Filterstationen in das Lymphgefäßsystem eingebettet. Sie erhalten über die Lymphe Antigene aus dem drainierten Gewebe. Im Lymphknoten können eine B-Zone mit Follikeln und eine T-Zone unterschieden werden. Die B-Zone befindet sich in der Rinde des Lymphknotens und besteht aus kugelförmigen Anhäufungen von B-Lymphozyten (Lymphfollikel). Man unterscheidet den Primär- vom Sekundärfollikel. Letzterer entsteht nach Applikation eines T-abhängigen Antigens. Es findet hierin die Proliferation, negative Selektion und Differenzierung der Antigen-stimulierten B-Zellen statt. Die T-Zone befindet sich in der Parakortikalzone des Lymphknoten. Sie liegt der B-Zone benachbart. Hier befinden sich interdigitierende dendritische Zellen, die den T-Zellen Antigene präsentieren und so zu deren Aktivierung führen. Die Parakortikalzone ist diejenige, die sich bei einer Lymphknotenschwellung vergrößert (Lüllmann-Rauch 2003).

\subsubsection{Halslymphknoten}

Am Hals findet sich eine vordere Lymphknotengruppe, die Nodi lymphatici cervicales anteriores, die sich wiederum in oberflächliche Lymphknoten (Lnn. superficiales) entlang der Vena jugularis anterior und in tiefe Lymphknoten (Lnn. profundi) unterteilen lässt. Die vorderen Lymphknoten fließen in ihrem Verlauf über die tiefen Halslymphknoten ab. Des Weiteren lassen sich Lnn. cervicales laterales am seitlichen Hals ausmachen. Diese werden ebenso in eine oberflächliche Gruppe (Lnn. superficiales) entlang der Vena jugularis externa und eine tiefe Gruppe unterteilt. In den Lymphknoten der oberflächlichen Gruppe sammelt sich die Lymphe aus dem Bereich der Ohrmuschel und dem unteren Teil der Ohrspeicheldrüse. Die Lymphknoten der tiefen seitlichen Gruppe lassen sich in Lnn. profundi superiores und Lnn. profundi inferiores aufteilen. Die Lnn. profundi superiores sammeln die Lymphe fast aller Kopflymphknoten, die Lnn. profundi inferiores die Lymphe fast aller Halslymphknoten. Die tiefen Halslymphknoten fließen über den jeweiligen Truncus jugularis ab. Man beachte, dass sich entlang des Gefäß-Nerven-Stranges des Halses die Hauptlymphknotenstraße befindet. Die erste Lymphknotenstation im Abflussgebiet der Arteria 
carotis interna, bzw. genauer der Carotisbifurkation, ist bisher nicht untersucht worden und lässt sich somit nicht genau lokalisieren. Aufgrund der räumlich nahen Beziehung zu den Lymphknoten der Vena jugularis interna ist allerdings von einem Abfluss in dieses Gebiet auszugehen (Fritsch und Kühnel 2003).

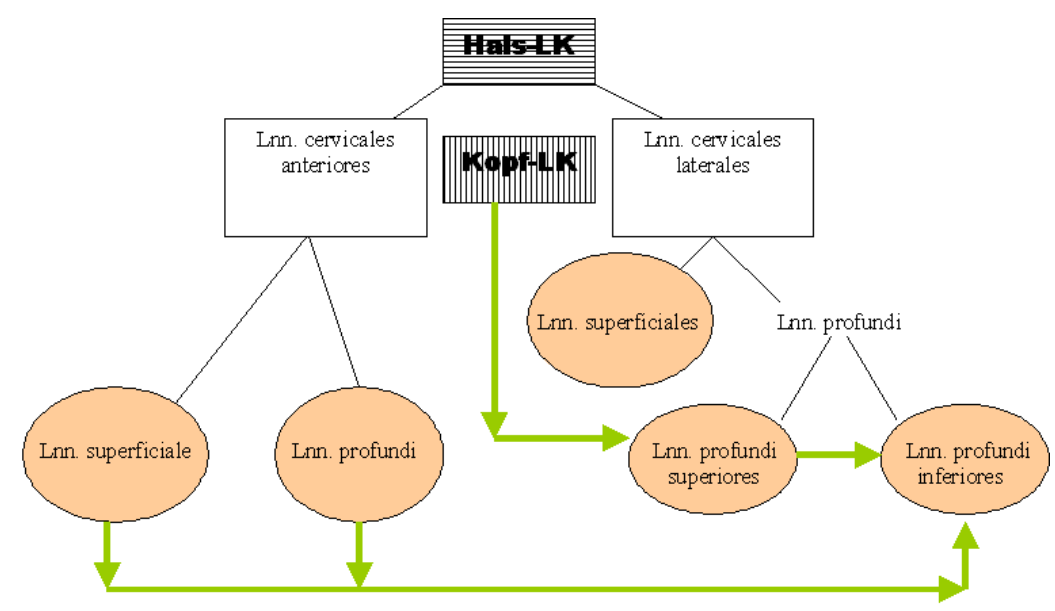

Abb. 2 Schematische Darstellung der Lymphknotenstationen des Kopfes und Halses 


\subsection{Problemstellung und Hypothese}

In fast allen Stadien der Entwicklung von Arteriosklerose lassen sich Entzündungszellen nachweisen. Des Weiteren tragen entzündliche Prozesse nicht nur zur Entstehung und Unterhaltung einer Plaque bei, sondern führen darüber hinaus unabhängig vom Stenosegrad zur Thrombusformation mit den Komplikationen eines akuten Gefäßverschlusses oder einer arterio-arteriellen Embolie. Bisher werden ACl-Stenosen in der Routinediagnostik allerdings hauptsächlich bezüglich ihres Stenosegrades evaluiert. Entzündungsprozesse in der Plaque als Hauptgrund und Hinweis für Instabilität können nicht bzw. nur schwierig beurteilt werden. Entsprechend orientieren sich auch die Empfehlungen zur Therapie hauptsächlich am Grad einer Stenose. Es wäre daher sinnvoll, eine Charakterisierung von ACI-Stenosen über den Stenosegrad hinaus mithilfe einfacher Mittel zur Verfügung zu haben, um gefährdete Patienten identifizieren zu können.

Aufgrund der Beteiligung von Lymphozyten und Monozyten bzw. Makrophagen an der Entstehung und Unterhaltung des Entzündungsgeschehens und der Tatsache, dass diese Zellen Lymphknotenschwellungen auslösen können, wäre es denkbar, dass die Entzündungsprozesse, die einer arteriosklerotischen Plaque der Arteria carotis interna innewohnen, in ihrer Folge zu einer Vergrößerung der am Hals befindlichen Lymphknoten führen könnten. Diese Lymphknotenschwellung wäre dann möglicherweise in der CTA des Halses sichtbar und könnte unabhängig vom Grad einer Stenose einen wichtigen Indikator für die Instabilität einer Plaque darstellen

Die vorliegende Arbeit wird also den möglichen Effekt einer arteriosklerotisch bedingten Entzündung auf die Größe und Anzahl lokoregionaler Lymphknoten auch unter Berücksichtigung von Symptomatik, Plaquemorphologie, Stenosegrad und Begleiterkrankungen der Patienten untersuchen. 


\section{Methoden}

\subsection{Material}

\begin{tabular}{|c|c|c|}
\hline \multirow[t]{3}{*}{ Datenquellen } & \multicolumn{2}{|c|}{ Digitale Datenbanken RIS (Radiologie Informations System) } \\
\hline & - $\quad$ Medos Web Client & Version 8.4.2, Medos AG, Langenselbold \\
\hline & - $\quad$ ixserv & Ixmid Software Technologie GmbH \\
\hline CT-Gerät & 16-Zeilen Multidetektoren CT & Aquilion TSX-101A, Toshiba, Tokyo, Japan \\
\hline \multirow[t]{2}{*}{ Kontrastmittelinjektion } & Kontrastmittel & $\begin{array}{l}\text { Immeron@ } 350 \text { (350mg Jod } / \mathrm{ml} \text {, Bracco } \\
\text { Diagnostics Inc., Princeton, New Jersey, } \\
\text { USA) }\end{array}$ \\
\hline & Gerät & $\begin{array}{l}\text { Nemoto@ Doppelkolbeninjektor (Nemoto \& } \\
\text { Co. Ltd., Tokyo, Japan) }\end{array}$ \\
\hline \multirow[t]{2}{*}{ Bildbearbeitung } & Hardware & Hewlett-Packard hp workstation xw 8200 \\
\hline & Software & $\begin{array}{l}\text { Vitrea@ Version } 3.8 \text { (Vital Images, Inc., } \\
\text { Nimmetonka, Minnesota, USA) }\end{array}$ \\
\hline
\end{tabular}

Tab. 2 Verwendete Materialien

\subsection{Datenerhebung}

Es erfolgte die retrospektive Analyse von CT-Angiographien (CTA) der Halsgefäße von Patienten der Universitätsmedizin Göttingen. Die Untersuchungen fanden jeweils zu diagnostischen Zwecken bei klinischer Indikation in der Abteilung Neuroradiologie statt. Im Rahmen dessen wurden die Aufnahmen zeitnah von einem ärztlichen Mitarbeiter der Abteilung befundet, so dass später etwaige entzündliche oder tumoröse Erkrankungen mit morphologischem Substrat in der CTA des Halses anhand des verfassten Berichtes ausgeschlossen werden konnten.

Zur Ermittlung der für die Lymphknoten-Analyse infrage kommenden Patienten wurden CTA-Befunde der Arteria carotis ab Dezember 2004 bis Januar 2008 für die weitere Prüfung ausgewählt. Sodann wurde für jeden Patienten das letzte vor der CTA-Untersuchung festgestellte Resultat des Urinstatus und der Messung des CRP-Wertes ermittelt. Außerdem wurden die Angaben durch Röntgen-Thorax-Befunde, die in den stationären Aufenthalt fielen, in dem die CTA-Untersuchung stattfand, vervollständigt. Nach Zusammenschau der Befunde (CRP, Urinstatus, Röntgen-Thorax) wurden erstmals alle Patienten ausgeschlossen, die nicht für die Lymphknoten-Analyse infrage kamen (Ausschlusskriterien s.u.). Die erhobenen Daten der übrigen Patienten wurden im Anschluss durch die jeweiligen Entlassungsbriefe der Stationen vervollständigt. Nach erneuter Zusammenschau der nun vollständig erhobenen Daten wurden ein zweites Mal nicht infrage kommende Patienten von der Analyse ausgeschlossen. 


\subsection{Erhobene Daten}

\subsubsection{C-reaktives Protein (CRP)}

Das C-reaktive Protein (CRP) wird in der Leber synthetisiert und dort als Akute-Phase-Protein freigesetzt. Ein Anstieg tritt bei Infektionen, nach größeren chirurgischen Eingriffen, metastasierenden Tumoren, schweren Traumata und immunologischen Erkrankungen (z.B. rheumatoide Arthritis) auf. Als Entzündungsparameter steigt es bei bakteriellen Entzündungen von allen Akute-Phase-Proteinen am schnellsten und stärksten an (innerhalb weniger Stunden auf das bis zu 2000fache) (Dörner 2003). Der Referenzwert für Erwachsene in der Abteilung Klinische Chemie der Universitätsmedizin Göttingen liegt bei bis zu $8 \mathrm{mg} / \mathrm{l}$.

\subsubsection{Urinstatus}

Ausgeschlossen wurden Patienten, bei denen es anhand des Urinstatus den Verdacht auf einen Harnwegsinfekt gab. Hinweise hierauf waren die folgenden Befunde in der Teststreifenuntersuchung (Dörner 2003):

- Stark alkalischer Urin $(\mathrm{pH}>7,5)$

- Proteinurie

- Hämaturie

- Leukozyturie (Granulozyturie)

- Nitrit.

\subsubsection{Röntgen-Thorax}

Nicht zur Analyse zugelassen wurden Patienten mit dem Röntgen-Thorax-Befund einer entzündlichen oder tumorösen Erkrankung der Lunge. So mussten raumfordernde maligne Prozesse ausgeschlossen sein. Auf entzündliche Erkrankungen, wie z.B. eine Pneumonie, wiesen die folgenden bildmorphologischen Kriterien hin:

- Verschattungen

- Infiltrate

- Ergüsse. 


\subsection{Patienten}

\subsubsection{Einschlusskriterien}

Zur Überprüfung der aufgestellten Hypothese wurden drei Gruppen von Patienten in die Studie einbezogen:

a) Patienten mit symptomatischer Carotisstenose

b) Patienten mit asymptomatischer Carotisstenose

c) Patienten ohne Carotisstenose (= "Gesunde“).

Des Weiteren mussten die Patienten zum Zeitpunkt der CTA-Untersuchung älter als 18 Jahre sein.

\subsubsection{Ausschlusskriterien}

Von der Analyse ausgeschlossen wurden diejenigen Patienten, bei denen anhand des Entlassungsbriefes ersichtlich war, dass sie in den 14 Tagen vor der CTA-Untersuchung operiert worden waren oder ein Trauma erlitten hatten. Außerdem durfte keine Neoplasie oder Operation am Hals in der Vorgeschichte bekannt sein. Zudem mussten sowohl ein Harnwegs- als auch ein pulmonaler Infekt oder andere systemische oder am Hals befindliche lokale entzündliche Erkrankungen während des stationären Aufenthaltes, v.a. aber zum Zeitpunkt der CTA-Untersuchung, ausgeschlossen werden können. Im Übrigen wurden Patienten mit einer Gefäßwanddissektion der Arteria carotis interna nicht in die Analyse aufgenommen. Ein erhöhter CRP-Wert allein war jedoch kein Ausschlusskriterium.

\subsection{CT-Angiographie (CTA)}

Für die CTA-Untersuchungen kam ein 16-Zeilen-Multidetektoren-CT (Aquilion TSX-101A, Toshiba, Tokyo, Japan) zum Einsatz. Den Patienten wurden $30 \mathrm{ml}$ eines Kontrastmittels (Immeron@ 350 (350mg Jod/ml, Bracco Diagnostics Inc., Princeton, New Jersey, USA)) über eine Cubitalvene appliziert. Die Flussrate betrug $4 \mathrm{ml} / \mathrm{s}$. Anhand eines Real Time Vorschaubildes in Echtzeit wurde der Scan zu dem Zeitpunkt gestartet, zu dem das Kontrastmittel in der Arteria carotis angeflutet war. Die Untersuchung des Patienten erfolgte sodann in kaudokranialer Richtung vom Aortenbogen bis zur Schädelkalotte ohne eine Kippung der Gantry. Hierbei wurde eine Schichtdicke von $1 \mathrm{~mm}$ bei einem Pitchfaktor von 1 und einem Rekonstruktionsintervall (Inkrement) von 0,79 mm gewählt. Der Röhrenstrom betrug $150 \mathrm{mAs}$ bei einer Röhrenspannung von $120 \mathrm{kV}$. 
Die Nachbearbeitung erfolgte an der Vitrea-Arbeitskonsole (Vitrea@ Version 3.8 (Vital Images, Inc., Nimmetonka, Minnesota, USA)).

\begin{tabular}{|l|l|l|}
\hline CT-Daten & Röhrenspannung & $120 \mathrm{kV}$ \\
\cline { 2 - 3 } & Röhrenstrom & $150 \mathrm{mAs}$ \\
\cline { 2 - 3 } & Kollimination & $1 \mathrm{~mm}$ \\
\cline { 2 - 3 } & Normaler Pitch & 1 \\
\cline { 2 - 3 } & Rekonstruierte Schichtdicke & $1 \mathrm{~mm}$ \\
\cline { 2 - 3 } & Rekonstruktionsintervall & $0,79 \mathrm{~mm}$ \\
\hline \multirow{5}{*}{ Kontrastmittel-Applikation } & Konzentration & $350 \mathrm{mg} \mathrm{Jod} / \mathrm{ml}$ \\
\cline { 2 - 3 } & Injektionsgeschwindigkeit & $4 \mathrm{ml} / \mathrm{s}$ \\
\cline { 2 - 3 } & NaCl & $30 \mathrm{ml}(4 \mathrm{ml} / \mathrm{s})$ \\
\cline { 2 - 3 } & Delay & Art. Bolusdetektion manuell \\
\cline { 2 - 3 } & Nadelkaliber & $20 \mathrm{G}$ \\
\hline
\end{tabular}

Tab. 3 Parameter der CT-Untersuchung

\subsection{Bildanalyse}

\subsection{1 Übersicht}

Ziel war es, die Anzahl, Größe und Lage der Lymphknoten der jeweils betrachteten CTA des Halses zu bestimmen. Hierzu wurden die gezählten Lymphknoten ausgemessen und zur Dokumentation ihrer Lage wurde der jeweilige Lymphknoten-Level nach Som et al. (2000) (s.u.) bestimmt. Außerdem von Interesse waren die drei größten Lymphknoten und die Lymphknoten, die sich in Beziehung zur Carotisgabel befanden. Abschließend wurde bei Patienten mit Carotisstenose der Stenosegrad der betroffenen Seite(n) nach NASCET, ECST und CC (s.u.) gemessen und die Morphologie der Plaque mit der Frage nach etwaigen Ulzerationen betrachtet. Alle gewonnenen Daten wurden in einem vorgefertigten „Formular zum Lymphknotenzählen" (s. Anhang S. 95) dokumentiert. Dem Untersucher wurden außer dem Namen, dem Geschlecht, dem Geburtsdatum und dem Datum der CTA-Aufnahme keine weiteren Informationen über die Patienten mitgeteilt. 


\subsubsection{Erkennungskriterien eines Lymphknotens}

Im CT stellen sich unterschiedlich dichte Gewebe in unterschiedlichen Graustufen dar, den so genannten „Hounsfield-Units“ (HU). Die Dichte von Wassers ist mit $0 \mathrm{HU}$, die Dichte von Luft mit $1000 \mathrm{HU}$ definiert. Jedem Gewebe sind so charakteristische Dichtewerte zugeordnet. Zur guten Differenzierung ist es sinnvoll, den mittleren Dichtewert im betrachteten Fenster nahe dem zu untersuchenden Gewebe zu wählen (Fensterweite). Über die Fensterbreite kann zusätzlich noch der Kontrast des Bildes gesteuert werden. Die meisten parenchymatösen Organe liegen in einem Bereich zwischen 10 und $90 \mathrm{HU}$. Die Dichte von Muskeln und Lymphknoten liegt mit 40 bis $60 \mathrm{HU}$ im gleichen Bereich. Die Differenzierung eines Lymphknotens von Gefäßen oder Muskeln im einzelnen Bild wird so durch die ähnlichen Dichtewerte der Strukturen erschwert. Daher ist es erforderlich, die nach kranial und kaudal angrenzenden Bildebenen vergleichend zu analysieren: Ein Lymphknoten taucht plötzlich für ein bis zwei Schichten auf und verschwindet wieder in den angrenzenden Schichten. Ein Muskel oder ein Gefäß dagegen lassen sich über mehrere Schichten kontinuierlich
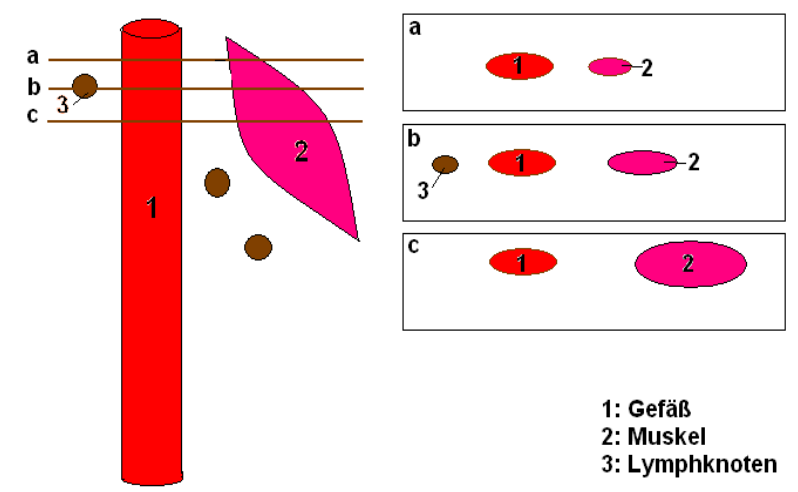

Abb. 3 Schematische Darstellung der vergleichenden Analyse mehrer Bildebenen zur Identifizierung eines Lymphknotens, modifiziert nach Hofer (2006), S. 15 verfolgen (Hofer 2006).

\subsubsection{Lymphknoten-Level nach Som et al. (2000)}

Zur Beschreibung der Lage der Lymphknoten am Hals wurde die Einteilung in Level nach Som et al. (2000) verwendet. Diese Klassifikation wurde zur Beurteilung metastatisch befallener Lymphknoten des Halses in der Schnittbildgebung entworfen. Es werden hiernach insgesamt 12 LymphknotenLevel unterschieden. Die Einteilung erfolgt in der axialen Bildebene. Jeder Level wird durch die folgenden anatomischen Strukturen des Halses begrenzt:

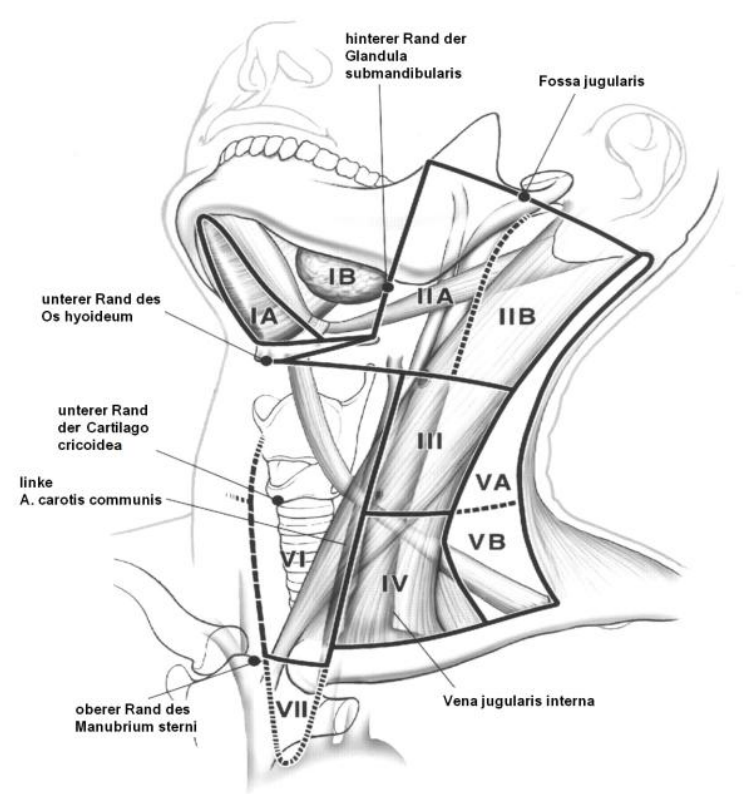

Abb. 4 Darstellung der Lymphknoten-Level des Halses, modifiziert nach Som et al. (2000), S. 838 
Level I:

- Kranial des Os hyoideum

- Unterhalb des M. mylohyoideus liegend

- Anterior des dorsalen Randes der Glandula submandibularis

Level IA:

- Zwischen den medialen Rändern der Ventres anteriores der Mm. digastrici

Level IB:

- Posterolateral der Level-IA-Lymphknoten

\section{Level II:}

- Von der Schädelbasis bis zum kaudalen Rand des Os hyoideum

- Posterior des dorsalen Randes der Glandula submandibularis

- $\quad$ Anterior des dorsalen Randes des M. sternocleidomastoideus

Level IIA:

- Anterior, lateral, medial und posterior der Vena jugularis interior

- Wenn posterior der Vena jugularis interior, dann direkt ihr anliegend

Level IIB:

- Posterior der Vena jugularis interna

- Von ihr durch Fett getrennt

Level III:

- Vom kaudalen Rand des Os hyoideum bis zum kaudalen Rand der Cartilago cricoidea

- Anterior des dorsalen Randes des M. sternocleidomastoideus

\section{Level IV:}

- Vom kaudalen Rand der Cartilago cricoidea bis zum kranialen Rand der Clavicula

- Anterior einer Verbindungslinie zwischen dem dorsalen Rand des M. sternocleidomastoideus und dem posterolateralen Rand des M. scalenus anterior

\section{Level V:}

- Von der Schädelbasis bis zum kaudalen Rand der Cartilago cricoidea

- Vom kaudalen Rand der Cartilago cricoidea bis zum kranialen Rand der Clavicula

- Posterior des dorsalen Randes des M. sternocleidomastoideus

Level VA:

- Von der Schädelbasis bis zum kaudalen Rand der Cartilago cricoidea

- Posterior des dorsalen Randes des M. sternocleidomastoideus 
Level VB:

- Vom kaudalen Rand der Cartilago cricoidea bis zum kranialen Rand der Clavicula

- Posterior einer Verbindungslinie zwischen dem dorsalen Rand des M. sternocleidomastoideus und dem posterolateralen Rand des M. scalenus anterior

\section{Level VI:}

- Zwischen den Arteriae carotides

- Vom kaudalen Rand des Os hyoideum bis zum kranialen Rand der Clavicula

\section{Level VII:}

- Zwischen den Arteriae carotides

- Unterhalb des Manubrium sterni

\section{Supraklavikulär:}

- $\quad$ Auf Höhe oder kaudal der Clavicula

- Lateral der Arteriae carotides

\section{Retropharyngeal:}

- $\quad$ Bis zu $2 \mathrm{~cm}$ unterhalb der Schädelbasis

- Zwischen den Arteriae carotides internae

In der vorliegenden Studie wurden nur Lymphknoten oberhalb des Manubrium sterni und der Clavicula berücksichtigt. Level VII und die supraklavikulären Lymphknoten waren so nicht von Interesse. Nachfolgend seien zur Verdeutlichung der verschiedenen Lymphknoten-Level BildBeispiele derselben in der CTA dargestellt:
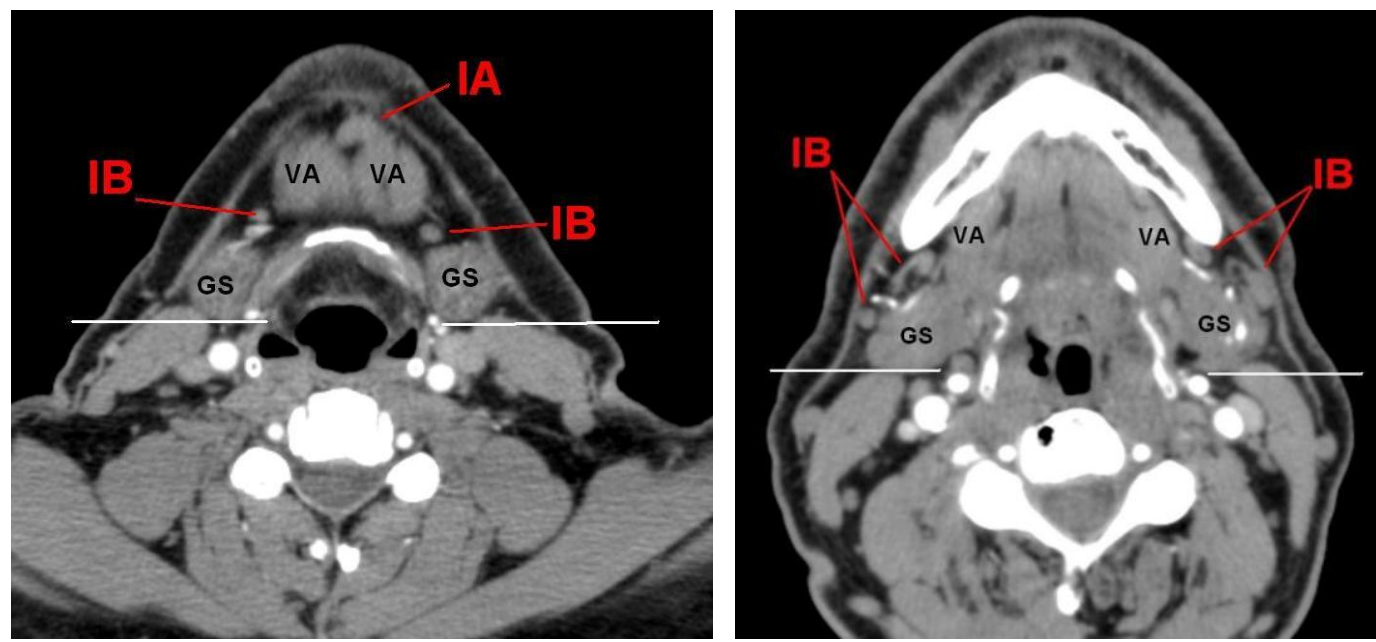

Abb. 5 Darstellung von Level IA- \& IB-Lymphknoten mit Markierung des dorsalen Randes der GS, $\underline{\mathrm{VA}}=$ Venter anterior des $\mathrm{M}$. digastricus, $\underline{\underline{G S}}=$ Glandula submandibularis 

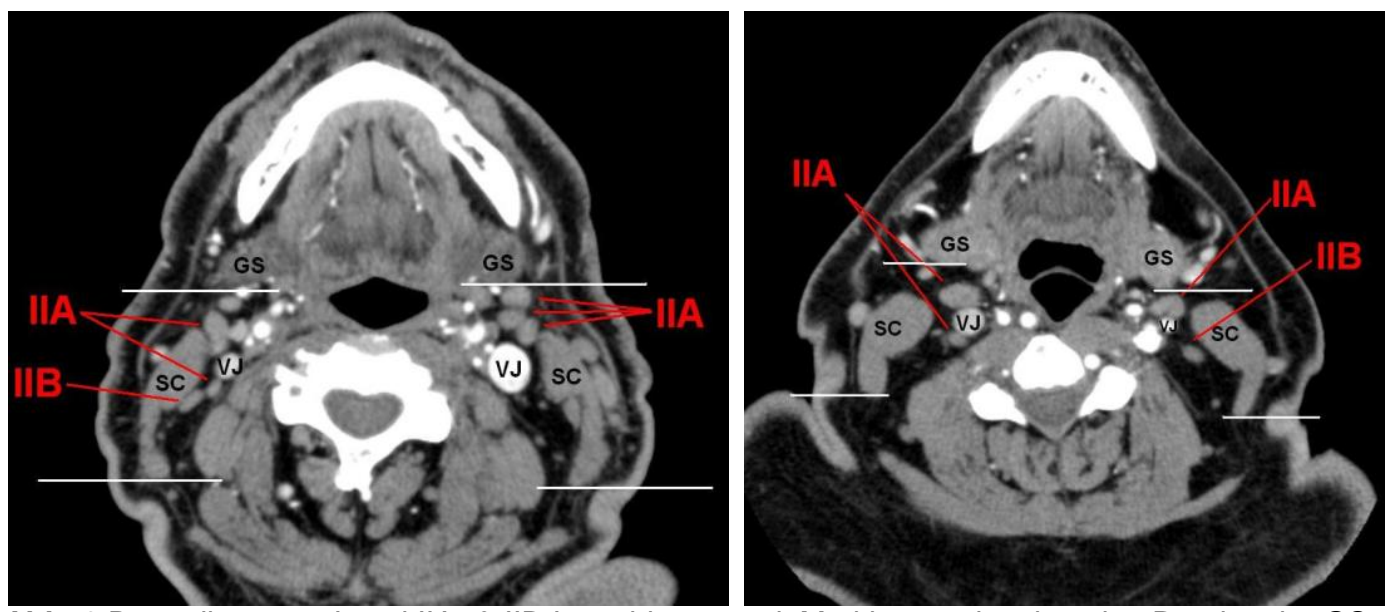

Abb. 6 Darstellung von Level IIA- \& IIB-Lymphknoten mit Markierung des dorsalen Randes der GS und des $\mathrm{SC}, \underline{\mathrm{GS}}=$ Glandula submandibularis, $\underline{\mathrm{VJ}}=$ Vena jugularis, $\underline{\mathrm{SC}}=\mathrm{M}$. sternocleidomastoideus
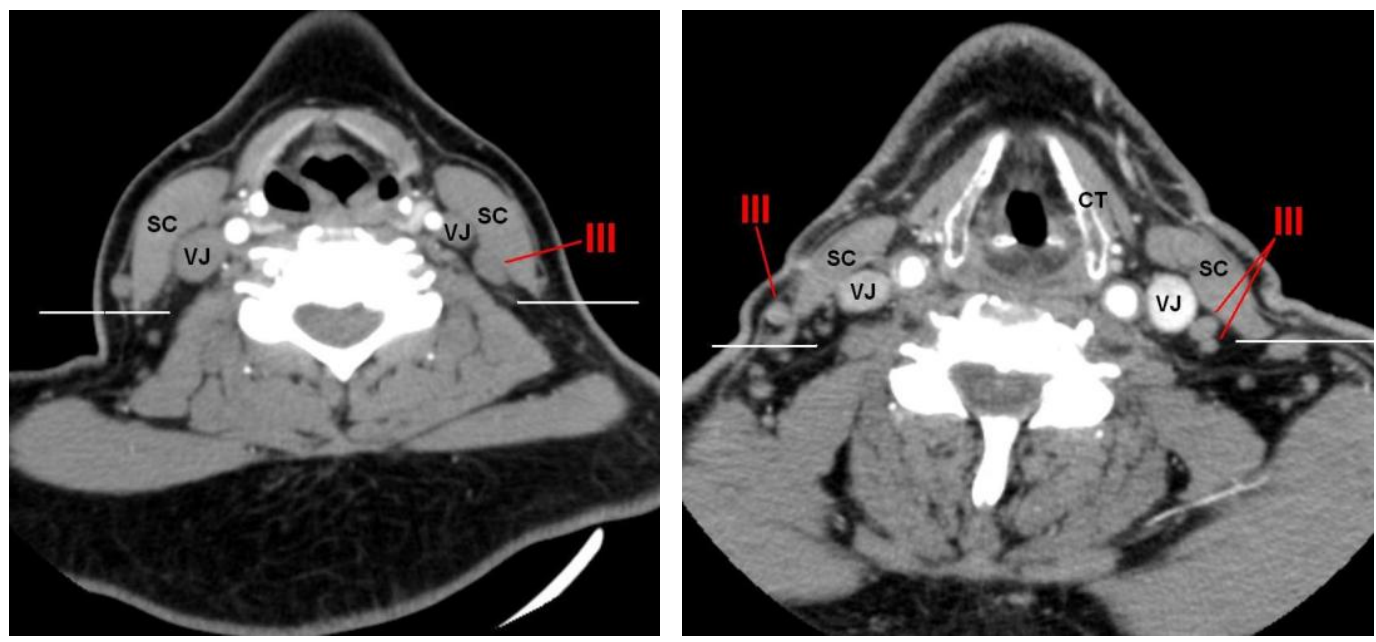

Abb. 7 Darstellung von Level III-Lymphknoten mit Markierung des dorsalen Randes des SC, $\underline{\mathrm{CT}}=$ Cartilago thyroidea, $\underline{\mathrm{SC}}=\mathrm{M}$. sternocleidomastoideus, $\underline{\mathrm{VJ}}=$ Vena jugularis
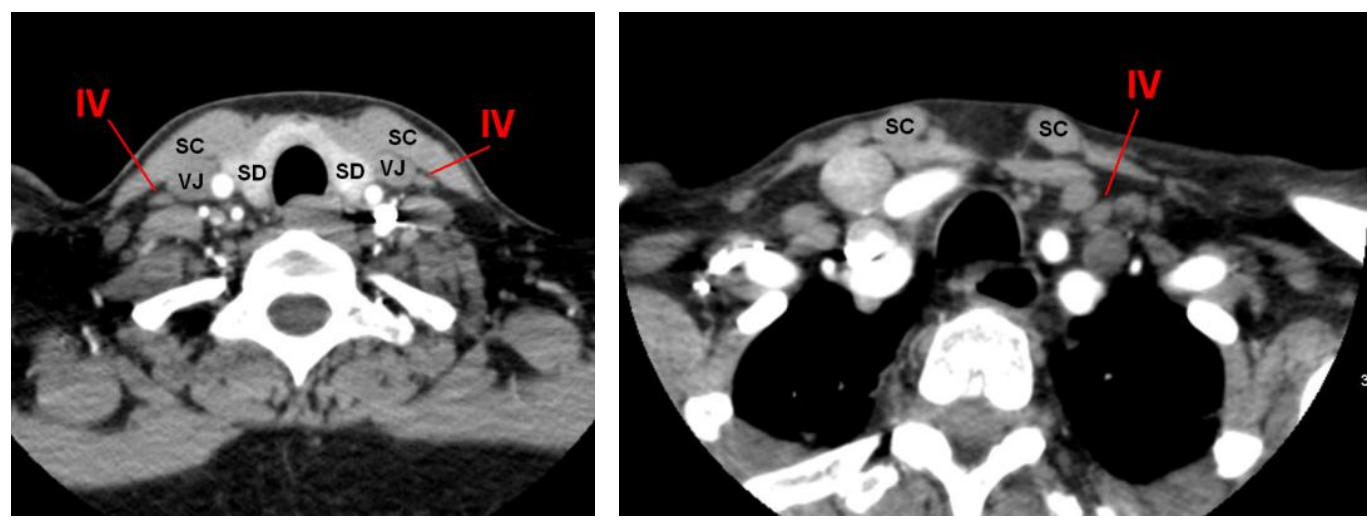

Abb. 8 Darstellung von Level IV-Lymphknoten, $\underline{\mathrm{SC}}=\mathrm{M}$. sternocleidomastoideus, $\underline{\mathrm{SD}}=$ Schilddrüse, $\underline{\mathrm{VJ}}=$ Vena jugularis 

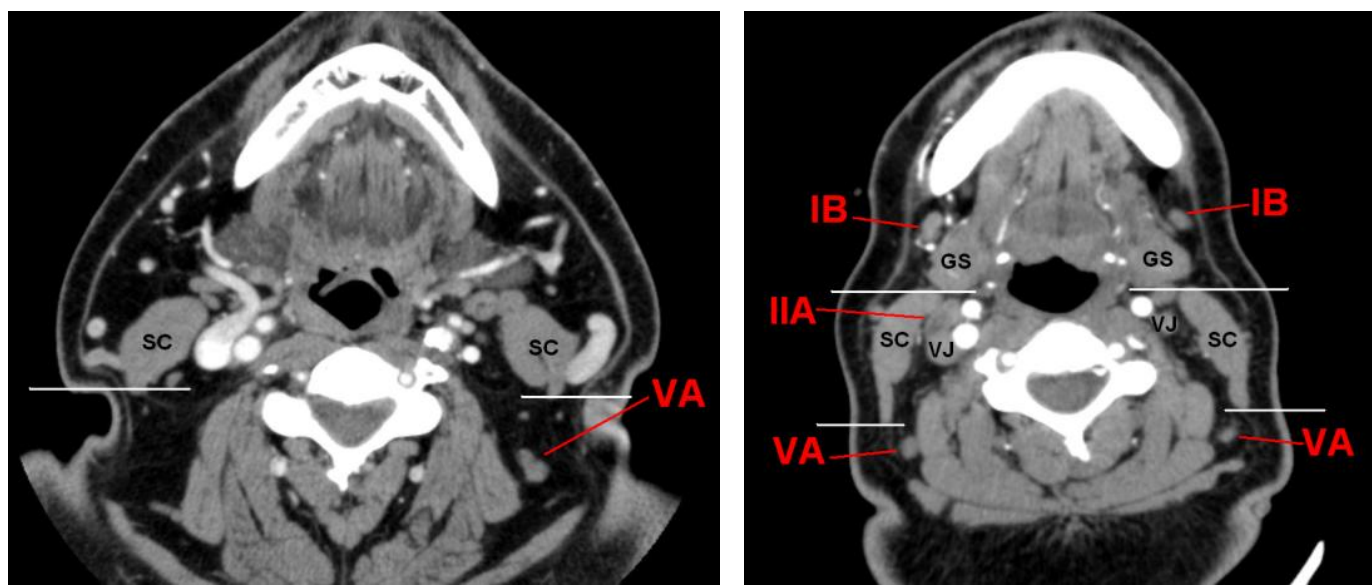

Abb. 9 Darstellung von Level VA-Lymphknoten, in der rechten Abb. zusätzlich von Level IB und IIA, inkl. Markierung des dorsalen Randes des SC und der GS (nur rechte Abb.), $\underline{\mathrm{SC}}=\mathrm{M}$. sternocleidomastoideus, $\underline{\mathrm{GS}}=$ Glandula submandibularis, $\underline{\mathrm{VJ}}=$ Vena jugularis
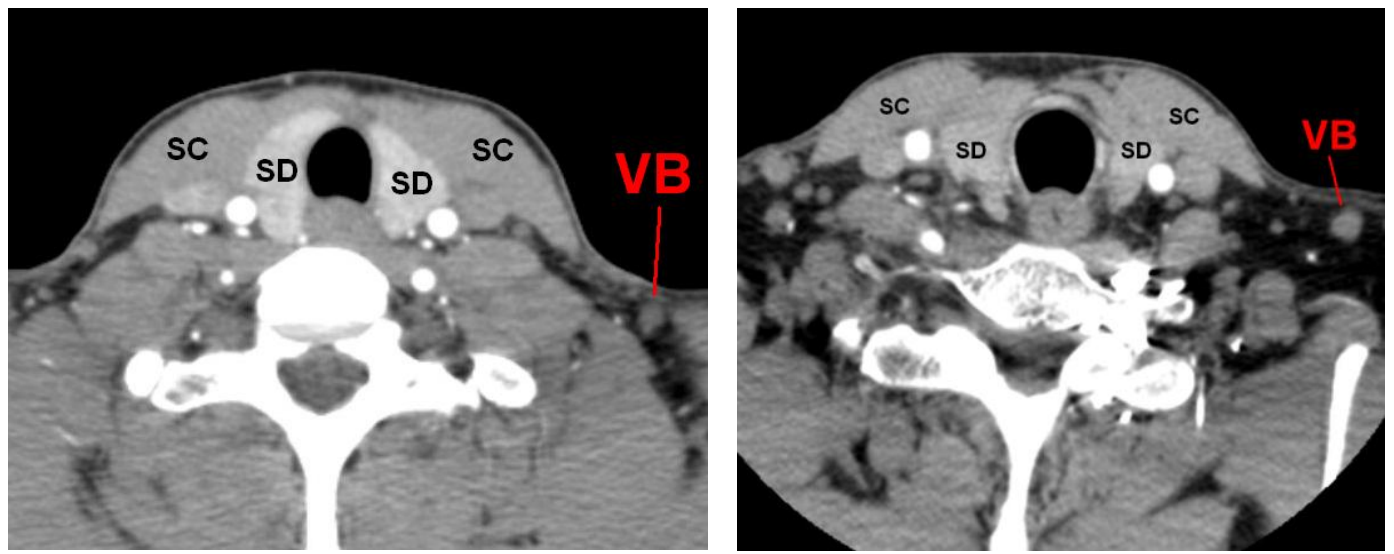

Abb. 10 Darstellung von Level VB-Lymphknoten, $\underline{\mathrm{SC}}=\mathrm{M}$. sternocleidomastoideus, $\underline{\mathrm{SD}}=$ Schilddrüse

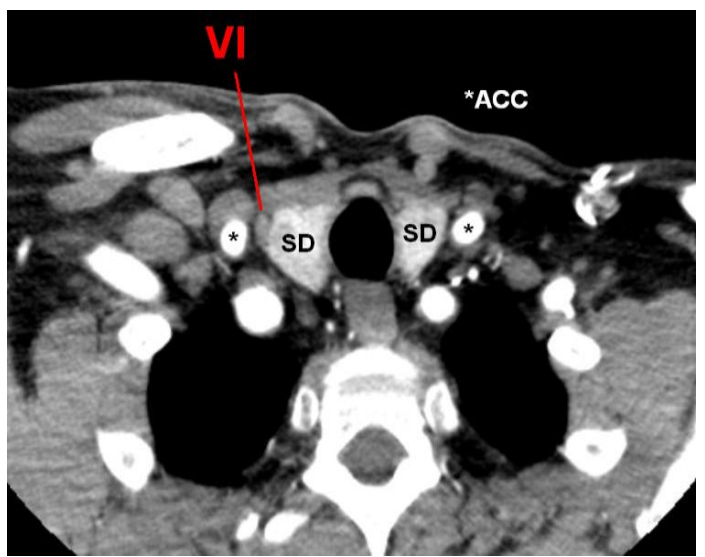

Abb. 11 Darstellung von Level VI-Lymphknoten, $\underline{\mathrm{ACC}}=\mathrm{A}$. carotis communis, $\underline{\mathrm{SD}}=$ Schilddrüse 


\subsubsection{Stenosegradbestimmung}

Zur Quantifizierung des Ausmaßes einer Carotisstenose wurden drei etablierte Verfahren benutzt. Bei diesen wird der Durchmesser des Restlumens der engsten Stelle der Stenose in Relation zu dem Durchmesser eines jeweils definierten Bezugspunktes im Verlauf des Gefäßes gesetzt. Der ermittelte Stenosegrad wird in Prozent (\%) angegeben. Die drei Methoden leiten sich ab von den folgenden Studien, die zur Ermittlung desjenigen Stenosegrades, bei dem eine Operation indiziert ist, durchgeführt wurden:

- North American Symptomatic Carotid Endarterectomy Trial (kurz: NASCET)

- European Carotid Surgery Trial (kurz: ECST)

- Common Carotid (kurz: CC) method.

Die Stenosen werden hiernach folgendermaßen eingeteilt (U-King-Im et al. 2004):

\begin{tabular}{|l|l|l|}
\hline Methode & Mäßige Stenose & Hochgradige Stenose \\
\hline NASCET & $50 \%-69 \%$ & $70 \%-99 \%$ \\
\hline ECST & $65 \%-81 \%$ & $82 \%-99 \%$ \\
\hline CC & $65 \%-81 \%$ & $82 \%-99 \%$ \\
\hline
\end{tabular}

Tab. 4 Einteilung der Stenosegrade je nach Methode

Die Bezugspunkte, zu denen der Durchmesser des Restlumens der engsten Stelle der Stenose (entspricht $D$ in Abb. 12) betrachtet wird, sind:

- Für NASCET: Der Durchmesser der normal weiten, distal der Stenose gelegenen Arteria carotis interna (entspricht $A$ in Abb. 12 )

- Für ECST: Der Durchmesser der gesamten Arteria carotis interna (d.h. nicht nur des Restlumens, sondern inkl. Plaque) an der Stelle der maximalen Einengung des Gefäßes (entspricht B in Abb. 12)

- Für CC: Der Durchmesser der proximal der Stenose gelegenen Arteria carotis communis (entspricht C in Abb. 12)

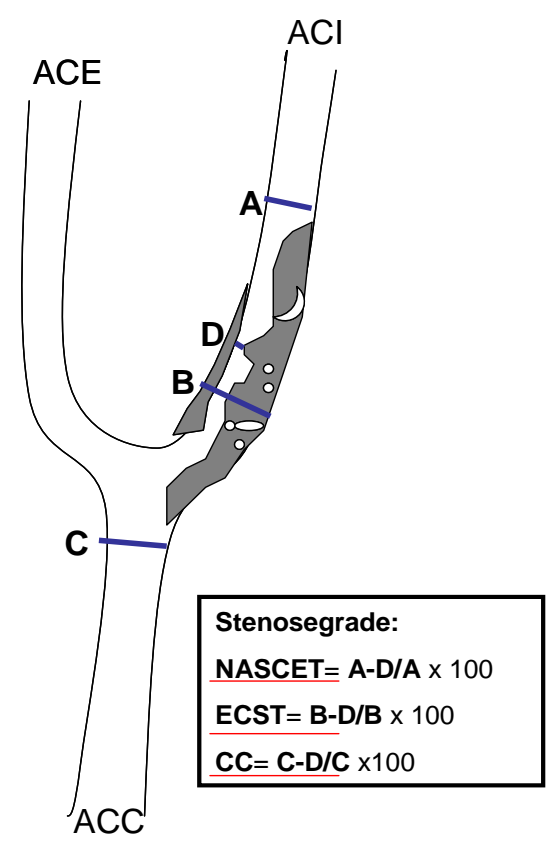

Abb. 12 Schematische Darstellung der Stenosegradbestimmung, Erläuterung

\subsubsection{Ulzerationen} siehe Text

Das Vorliegen einer Ulzeration innerhalb der arteriosklerotischen Carotisplaque wurde dokumentiert, wenn sich diese als unregelmäßig begrenzt und mit „Ausbuchtungen“ in der CTA präsentierte. 


\subsubsection{Bestimmung von Anzahl, Größe und Lage der Lymphknoten und Ermitteln der größten Lymphknoten}

Zunächst wurde die axiale Bildebene zur Darstellung der CTA-Aufnahmen des Halses ausgewählt. Dann erfolgte die Einstellung der Fensterweite und der Fensterbreite (s.o.) auf folgende Werte:

- Fensterweite (WW): 40

- Fensterbreite (WL): 340 .

Die jeweils dargestellten Schnitte wurden zur Verbesserung der Übersichtlichkeit gedanklich in je vier Quadranten unterteilt. Die Mitte dieser Quadranten befand sich wie im Folgenden dargestellt genau an der Vorderkante des in der jeweiligen Schicht befindlichen Wirbelkörpers:
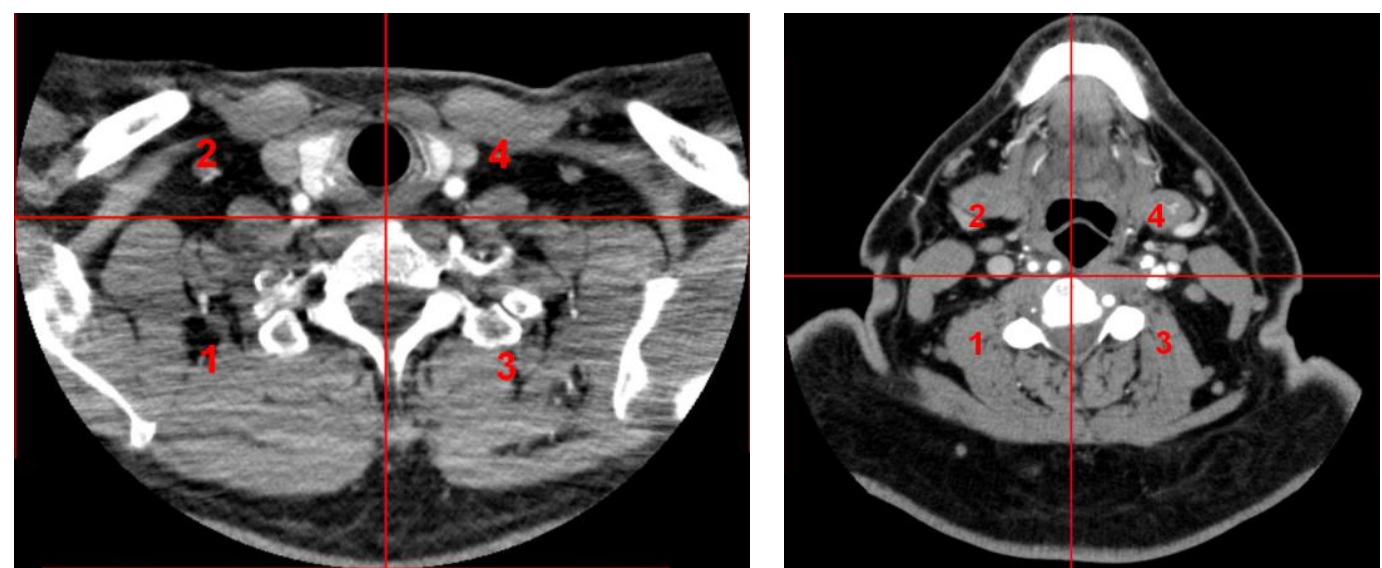

Abb. 13 Darstellung der vier Quadranten in zwei verschiedenen Bildebenen, inkl. Darstellung der bei der Betrachtung verwendeten Reihenfolge $(1 \rightarrow 2 \rightarrow 3 \rightarrow 4)$. Die Mitte des gedachten Kreuzes befindet sich jeweils mittig an der Vorderkante des gerade dargestellten Wirbelkörpers. Links: ca. auf Höhe der Schilddrüse, rechts: kranial des Os hyoideum

Die Betrachtung der CTA erfolgte für jeden Quadranten von der Oberkante des Sternums bis zur Unterkante des Mastoid-Knochens. In diesem Schritt der Analyse wurde jeder Lymphknoten einzeln betrachtet und genau ausgemessen. Hierzu wurde der Lymphknoten in der axialen Bildebene zunächst aufgesucht und mit dem 3D-Cursor markiert. Nun folgte die Betrachtung des Lymphknotens in allen drei Ebenen (axial, koronar, sagittal) gleichzeitig, um diejenige Ebene zu ermitteln, in der sich die äußere Form des Lymphknoten mit seiner typischen Taillierung, im Sinne einer "Nieren-" oder „Bohnenform“, am besten darstellte. Der Lymphknoten wurde nun in dieser Bildebene betrachtet. Hier wurde dann der kürzeste Durchmesser des Lymphknotens in Millimetern ausgemessen. Anschließend folgte die Benennung des Levels, in dem sich der Lymphknoten befand. Abschließend wurden die Informationen über Größe und Level des Lymphknotens anhand einer Strichliste in das „Formular zum Lymphknotenzählen“ (siehe Anhang) eingetragen. Hierbei wurden die Lymphknoten ihrer Größe nach den folgenden Gruppen zugeordnet:

- $3 \mathrm{~mm}$ bis $5 \mathrm{~mm}$

- Über $5 \mathrm{~mm}$ bis $7 \mathrm{~mm}$

- Über $7 \mathrm{~mm}$ bis $10 \mathrm{~mm}$

- Über $10 \mathrm{~mm}$. 
Zu erwähnen ist, dass der Durchmesser aller Lymphknoten, die sich größer als $5 \mathrm{~mm}$ darstellten, nicht allein durch eine Einteilung in die oben genannten Gruppen beschrieben, sondern zusätzlich genau vermerkt wurde. Aus diesen Angaben konnten nach Abschluss der Messung leicht die drei größten Lymphknoten ermittelt und in eine weitere Tabelle im „Formular zum Lymphknoten-Zählen“ (s. Anhang S. 95) mit Angaben des Levels, der Größe und der Nummer des Schnittes, auf dem sich der Lymphknoten darstellte, eingetragen werden. Lagen allerdings alle am Hals befindlichen Lymphknoten in einem Größenbereich zwischen $3 \mathrm{~mm}$ und $5 \mathrm{~mm}$, so wurden keine drei größten Lymphknoten ermittelt.
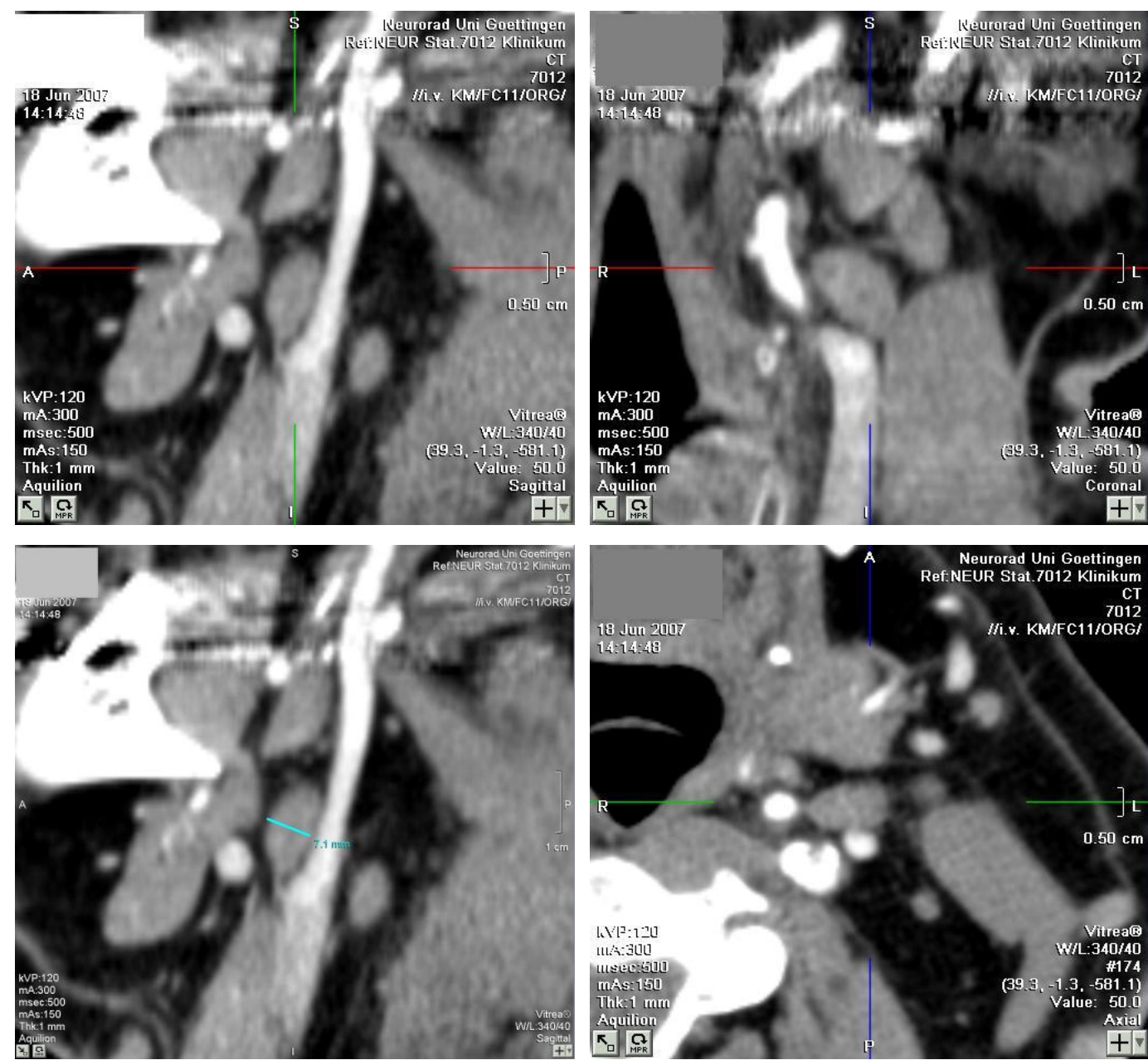

Abb. 14 Bsp. für die Darstellung eines Lymphknotens in allen drei Bildebenen (oben links: sagittal, oben rechts: koronar, unten rechts: axial) und Ausmessen des Lymphknotens in der Ebene, in der sich die typische Taillierung darstellt (unten links)

\subsubsection{Bestimmung der Lymphknoten mit Beziehung zur Carotisgabel}

Es wurden alle Einstellungen (Bildebene, Fenstereinstellung, Maßstab) wie oben beschrieben beibehalten. Zur Bestimmung der Lymphknoten mit räumlicher Beziehung zur Carotisgabel wurde zunächst für jede Seite des Halses diejenige Nummer des Schnittes bestimmt und dokumentiert, auf dem sich die Arteria carotis communis in die Arteria carotis externa und die Arteria carotis 
interna aufteilt. Nun wurden die Aufnahmen im Bereich der Carotiden jeweils von kaudal nach kranial ungefähr ab $2 \mathrm{~cm}$ unterhalb der Carotisgabel bis ungefähr $2 \mathrm{~cm}$ oberhalb der Carotisgabel (nachvollziehbar durch Angabe der Nummer des Schnittes) auf Lymphknoten durchgesehen. Hierbei wurden diejenigen Lymphknoten berücksichtigt, die sich in Level IIA und Level IIB, evtl. auch Level III (je nach Lage der Carotisbifurkation), befanden und mit dem Gefäß-Nerven-Bündel um die Arteria carotis in räumlicher Beziehung standen. Für jede Seite wurden die ermittelten Lymphknoten unter Angabe ihres Levels, ihrer Größe in Millimetern und der Nummer des Schnittes, auf dem sie sichtbar waren, dokumentiert.
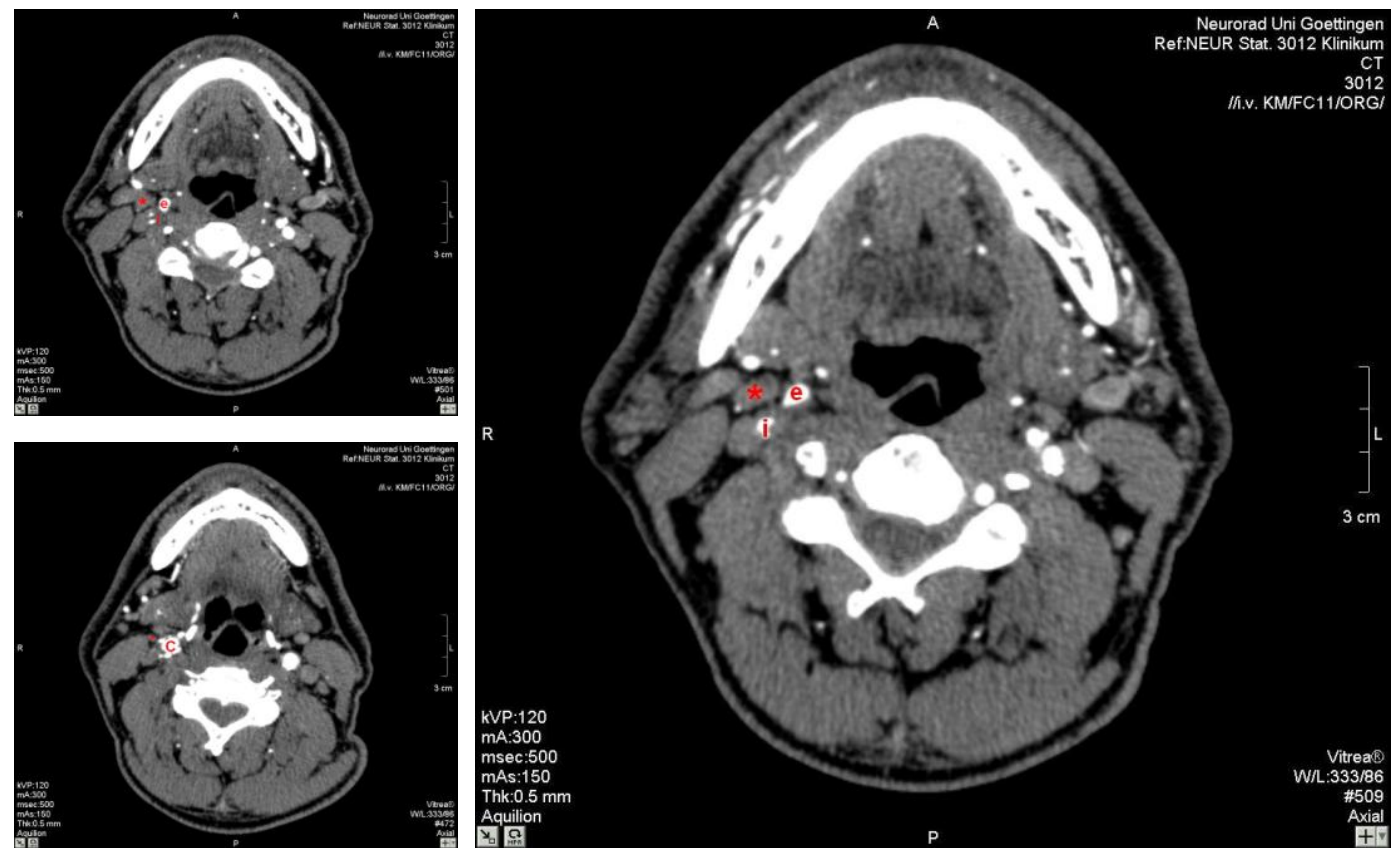

Abb. 15 Darstellung eines Lymphknotens $\left({ }_{-}^{*}\right)$ an der Carotisgabel in verschiedenen Bildebenen (unten links: kaudales Ende des LK, rechts: LK ungefähr mittig angeschnitten, oben links: kraniales Ende des LK), $\underline{i}=$ A. carotis interna, $\underline{e}=$ A. carotis externa, $\underline{\mathrm{C}}=\mathrm{A}$. carotis communis

\subsection{Datendokumentation}

Die Patientendaten wurden zunächst anonymisiert. Die Analyseergebnisse wurden handschriftlich im „Formular zum Lymphknoten-Zählen“ (s. Anhang S. 95) dokumentiert. Hiernach erfolgte die Übertragung und statistische Auswertung der gewonnenen Daten in Excel und SPSS.

\subsection{Statistische Auswertung}

Mittels des Kolmogorov-Smirnov-Testes wurde ermittelt, ob innerhalb der jeweils betrachteten Gruppen Normalverteilung vorlag. Im Folgenden wurden Mittelwert und Standardabweichung bestimmt. Bei Normalverteilung wurde mithilfe der Varianzanalyse ANOVA („Analysis Of Variance“) die Nullhypothese überprüft. 


\section{Ergebnisse}

\section{1 Übersicht zur Verteilung der Patienten}

\subsubsection{Verteilung von Stenose-Patienten und Nicht-Stenose-Patienten}

Nach Überprüfen der Kriterien und dem Ausschluss der für die Untersuchung ungeeigneten Patienten wurden insgesamt 66 Patienten in die Studie eingeschlossen. Diese verteilten sich wie folgt:

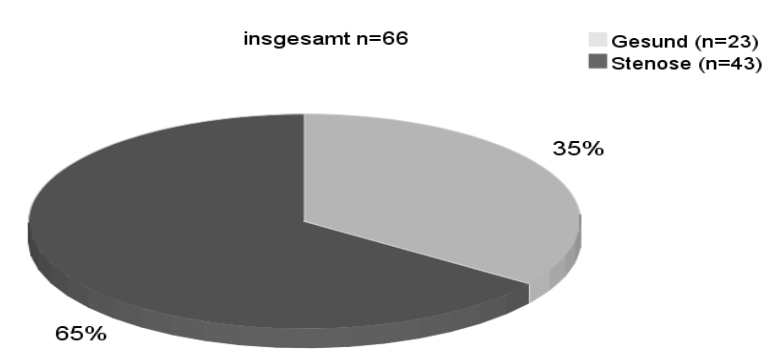

Von insgesamt 66 untersuchten Patienten wiesen 43 (65\%) eine Carotisstenose auf, bei den restlichen 23 (35\%) Patienten war keine Carotisstenose nachweisbar (siehe Abbildung 16). Letztere werden im Folgenden als „Gesunde“ bezeichnet.

Abb. 16 Erläuterung siehe Text

\subsubsection{Verteilung der Stenoseseite}

Von den 43 Patienten mit Carotisstenose befand sich die Stenose bei 35\% $(n=15)$ in der linken Arteria carotis interna, bei 30\% $(n=13)$ in der rechten Arteria carotis interna und bei weiteren 35\% $(n=15)$ lag eine beidseitige Stenose vor (siehe Abbildung 17).

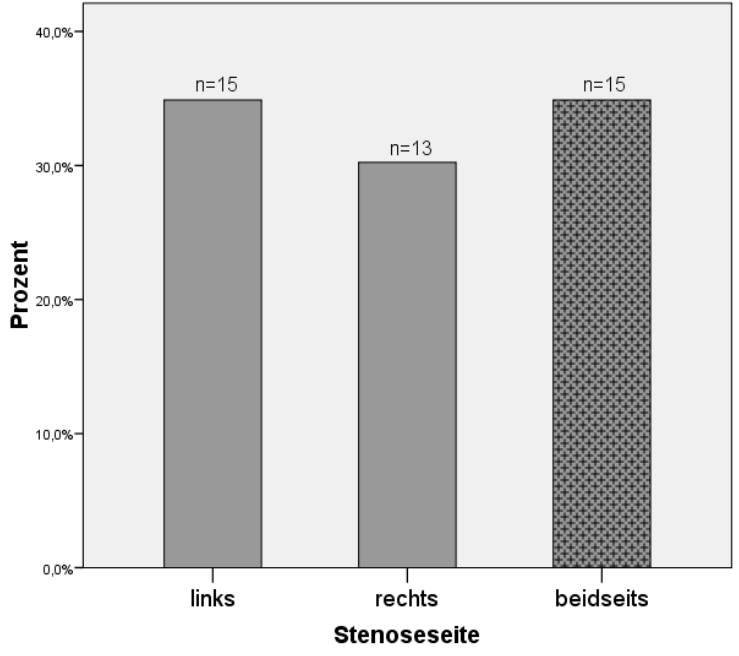

Abb. 17 Erläuterung siehe Text 


\section{2 Überprüfung der Hypothesen (3.2.1 - 3.2.5)}

Zur Überprüfung der Hypothesen wird jeweils die Verteilung der folgenden Lymphknoten für die unterschiedlichen Patientengruppen überprüft:

- Die Anzahl der Lymphknoten aller Level

- Die Anzahl der Lymphknoten der Level II, III und IV

- Die Größe der größten Lymphknoten

- Die Anzahl der Carotis-Lymphknoten

- Die Größe der Carotis-Lymphknoten.

Die Erläuterung zu den verschiedenen Lymphknoten-Gruppen erfolgte im Methodenteil. Sämtliche Tabellen zur Normalverteilung, deskriptiven Statistik und Signifikanzprüfung finden sich im Anhang.

\subsection{1 „Carotisstenosen haben mehr und/oder größere Lymphknoten (auf der Seite der Stenose).“}

\section{Alle Level und Level II bis IV, Anzahl, bezogen auf Patienten}

Es wird überprüft, ob bei Patienten mit einer Carotisstenose in allen zervikalen LymphknotenLeveln und/oder speziell in Level II, III und IV mehr Lymphknoten vorhanden sind als bei Patienten ohne Carotisstenose („Gesunde“). Es werden speziell Level II bis IV untersucht, da sich diese entlang der Arteria carotis befinden. Es besteht Normalverteilung.
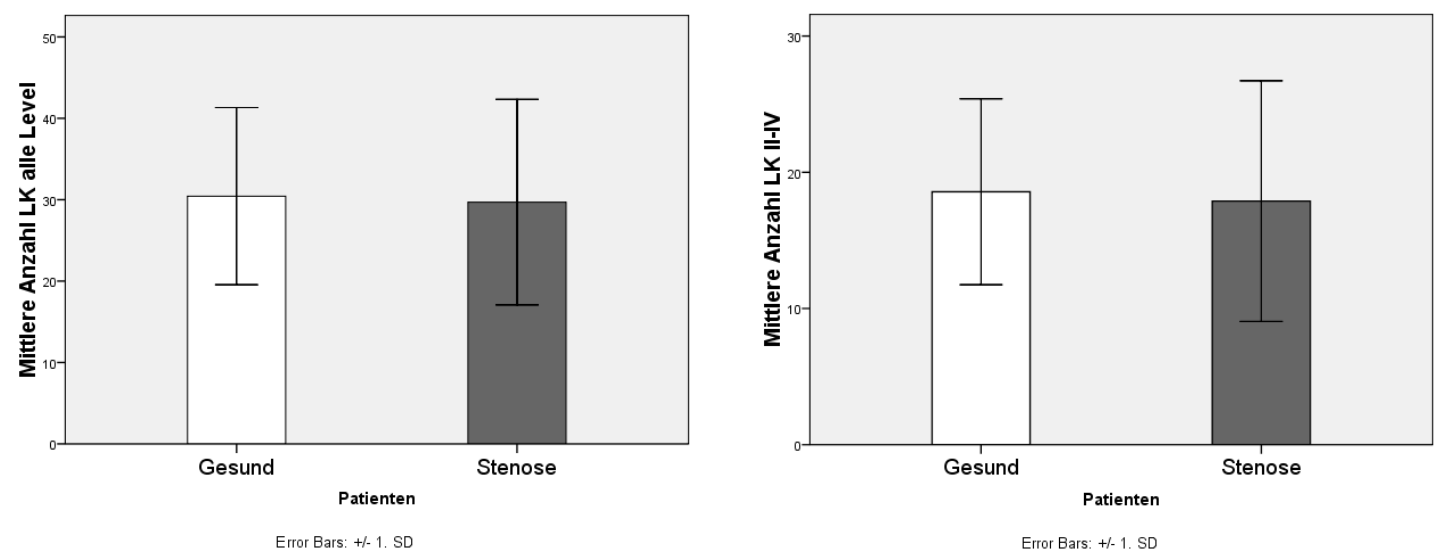

Abb. 18 a, b Erläuterung siehe Text

Patienten mit Carotisstenose haben weder in allen zervikalen Leveln, noch in Level II bis IV signifikant mehr Lymphknoten als gesunde Patienten. 


\section{Größte Lymphknoten, Größe, bezogen auf Patienten}

Es wird überprüft, ob bei Patienten mit einer Carotisstenose die größten Lymphknoten größer sind als bei Patienten ohne Carotisstenose („Gesunde“). Es besteht Normalverteilung.

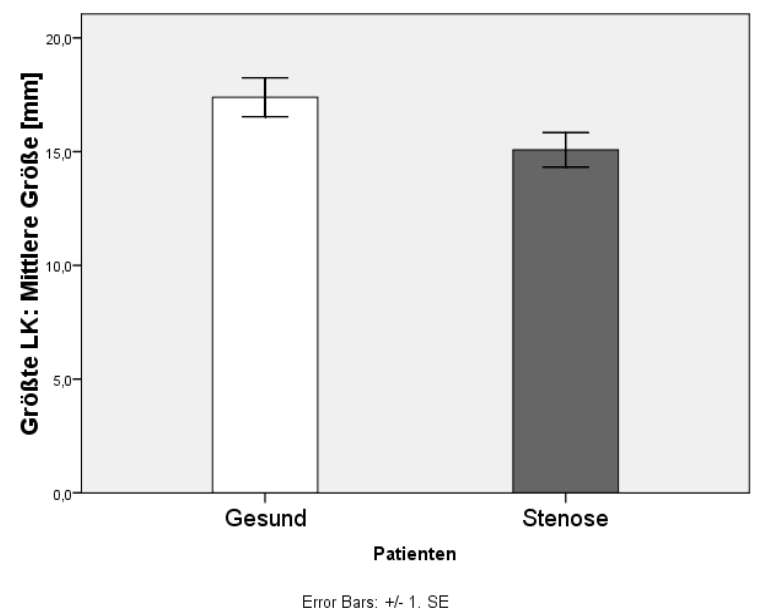

Abb. 19 Erläuterung siehe Text

Die größten Lymphknoten bei Patienten mit einer Carotisstenose sind nicht signifikant größer als die größten Lymphknoten gesunder Patienten.

\section{Carotis-Lymphknoten, Anzahl und Größe, bezogen auf Patienten}

Es wird überprüft, ob Patienten mit einer Carotisstenose mehr und/oder größere direkt an der Carotisbifurkation gelegene Lymphknoten aufweisen, als Patienten ohne Carotisstenose („Gesunde“). Es besteht Normalverteilung.
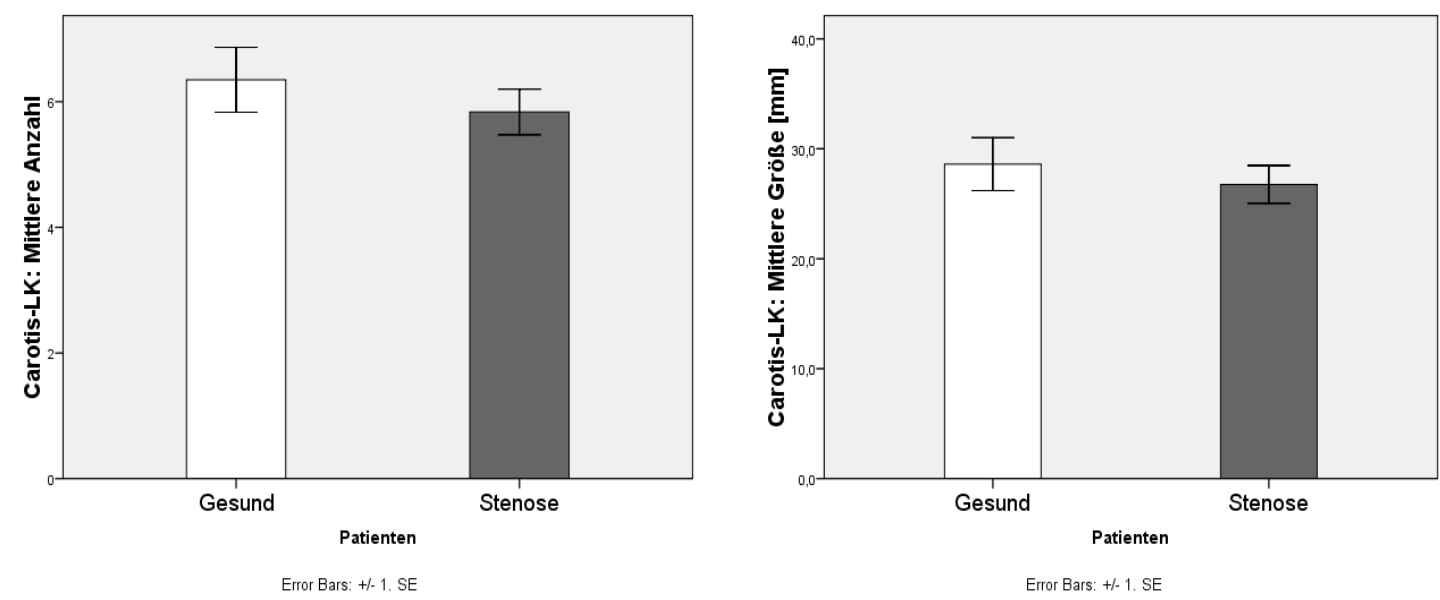

Abb. 20 a, b Erläuterung siehe Text

Patienten mit einer Carotisstenose weisen weder signifikant mehr, noch signifikant größere direkt an der Carotisbifurkation befindliche Lymphknoten auf als gesunde Patienten. 


\section{Alle Level und Level II bis IV, Anzahl, bezogen auf Carotiden}

Im Folgenden werden nicht mehr Patienten „als Ganzes“ betrachtet, sondern deren einzelne Carotiden (die Untersuchung bezieht sich also nicht mehr auf 66 Patienten, sondern auf 132 Carotiden). Es ergeben sich so drei Gruppen:

- Carotiden von Patienten ohne jegliche Carotisstenose („Gesund“)

- Carotiden, die zwar gesund sind, bei denen jedoch auf der Gegenseite eine Carotisstenose vorliegt („Gesund, aber mit Stenose auf der Gegenseite“, denn es wäre z.B. denkbar, dass sich eine Lymphknotenvermehrung bzw. -vergrößerung (auch) auf der gegenüberliegenden Seite einer Stenose zeigt)

- Stenosierte Carotiden („Stenose“).

Es wird überprüft, ob die Anzahl der Lymphknoten aller Level und/oder speziell der Level II, III, und IV auf der Seite der Stenose erhöht ist im Vergleich zu beidseits gesunden Carotiden und im Vergleich zu gesunden Carotiden, bei denen eine Carotisstenose auf der Gegenseite vorliegt.

Es besteht Normalverteilung.
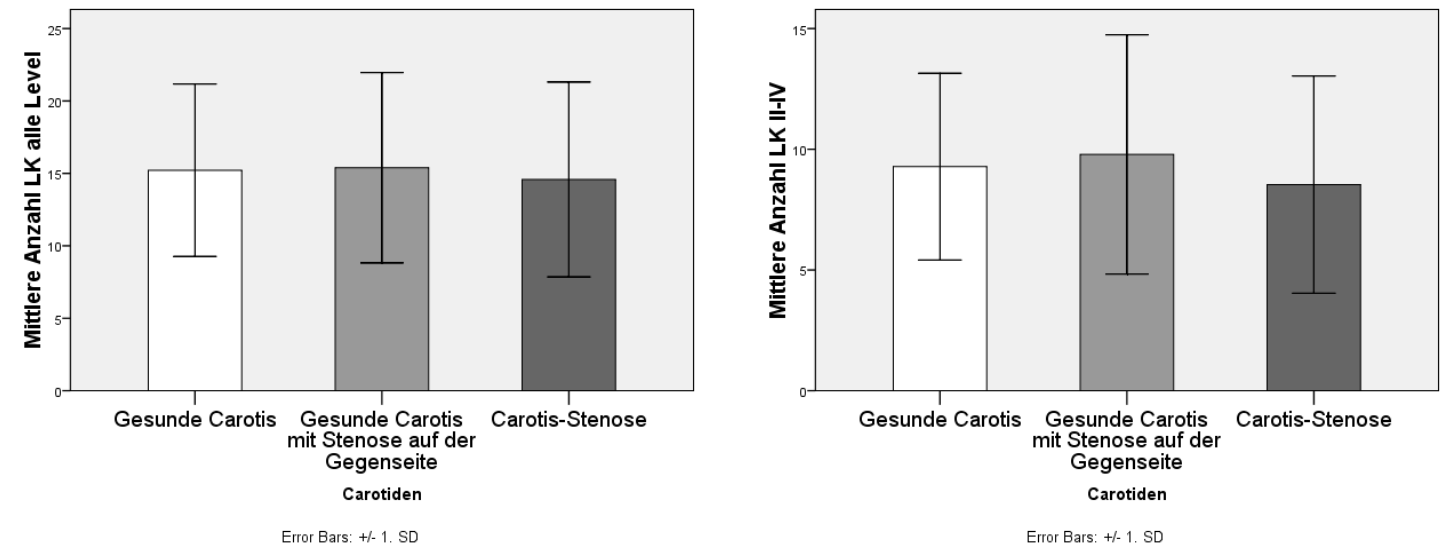

Abb. 21 a, b Erläuterung siehe Text

Bei keiner der Gruppen liegen in allen Lymphknoten-Leveln oder in Level II bis IV signifikant mehr Lymphknoten vor.

\section{Größte Lymphknoten, Größe, bezogen auf Carotiden}

Es wird überprüft, ob die Größe der größten Lymphknoten auf der Seite der Stenose erhöht ist im Vergleich zu beidseits gesunden Carotiden und im Vergleich zu gesunden Carotiden, bei denen eine Carotisstenose auf der Gegenseite vorliegt.

Es besteht Normalverteilung. 


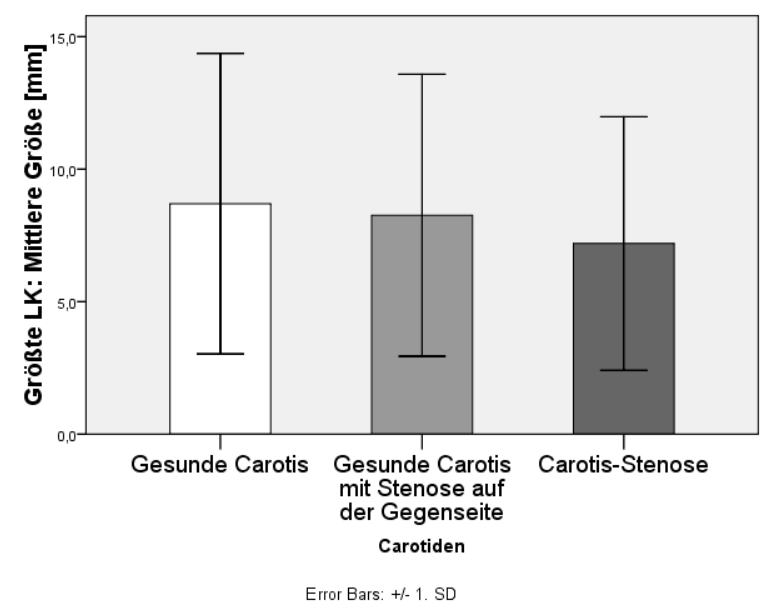

Abb. 22 Erläuterung siehe Text

Bei keiner der Gruppen liegen signifikant größere größte Lymphknoten vor.

\section{Carotis-Lymphknoten, Anzahl und Größe, bezogen auf Carotiden}

Es wird überprüft, ob die Anzahl und/oder Größe der direkt an der Carotisbifurkation gelegenen Lymphknoten auf der Seite der Stenose erhöht ist im Vergleich zu beidseits gesunden Carotiden und im Vergleich zu gesunden Carotiden, bei denen eine Carotisstenose auf der Gegenseite vorliegt.

Es besteht Normalverteilung.
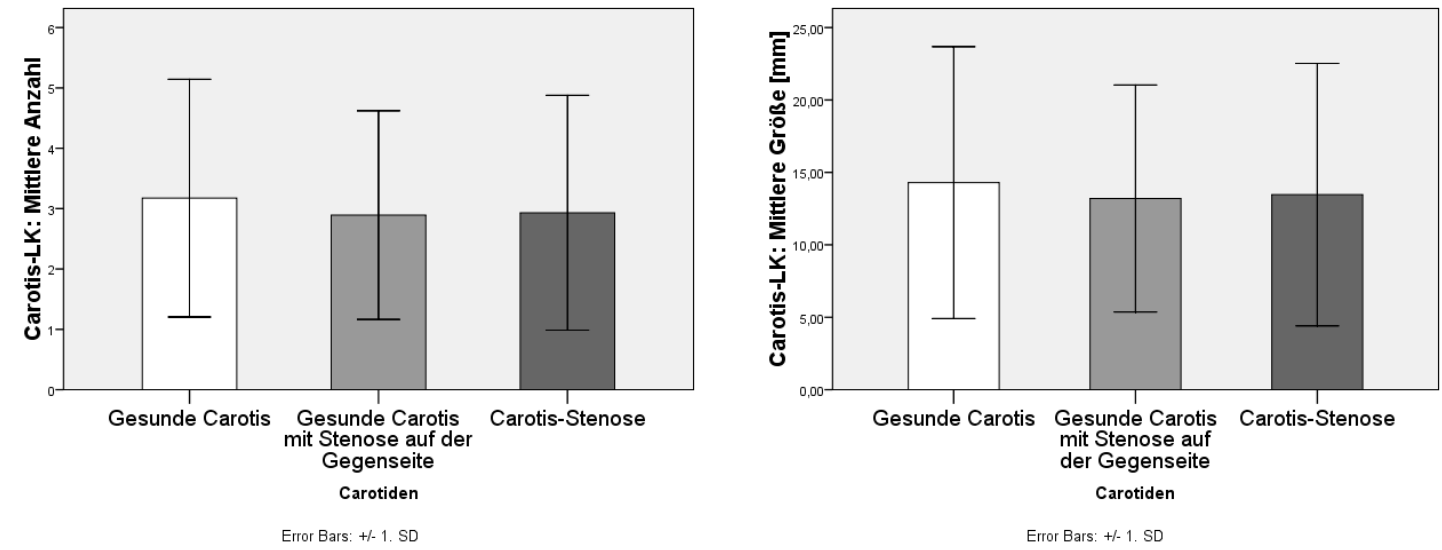

Abb. 23 a, b Erläuterung siehe Text

Bei keiner der Gruppen liegen signifikant mehr oder signifikant größere Carotis-Lymphknoten vor. 


\subsection{2 „Symptomatische Carotisstenosen haben mehr und/oder größere Lymphknoten (auf der Seite der Stenose).“}

\section{Verteilung der klinischen Symptomatik bei Stenose-Patienten}

Von den Patienten mit Arteria carotis interna-Stenose waren $28 \% \quad(n=12)$

klinisch asymptomatisch und $72 \%(n=31)$ klinisch symptomatisch (siehe Abbildung 24).

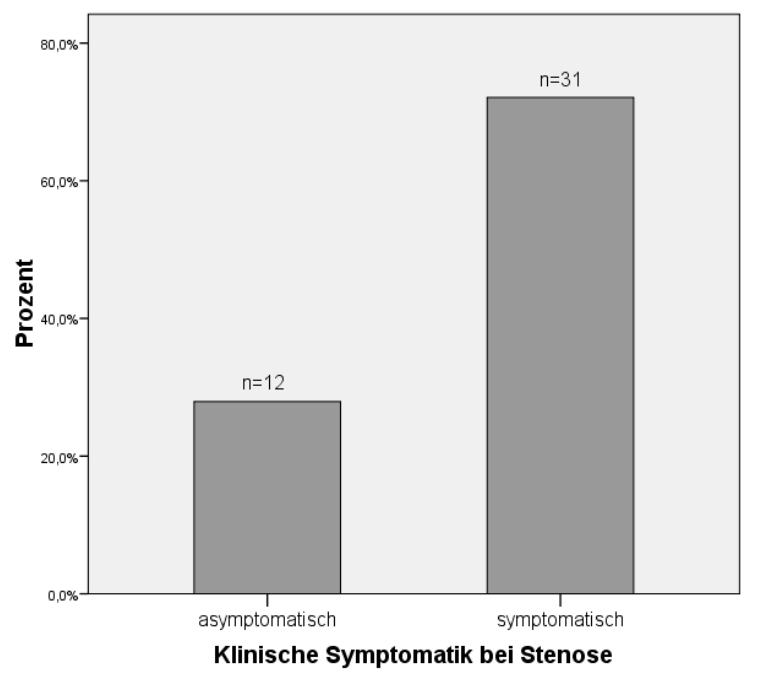

Abb. 24 Erläuterung siehe Text

Alle Level und Level II bis IV, Anzahl, bezogen auf Patienten

Es wird überprüft, ob Stenosepatienten je nach Symptomatik mehr Lymphknoten in allen zervikalen Lymphknoten-Leveln und/oder in Level II, III und IV vorweisen als gesunde Patienten. Es besteht Normalverteilung.
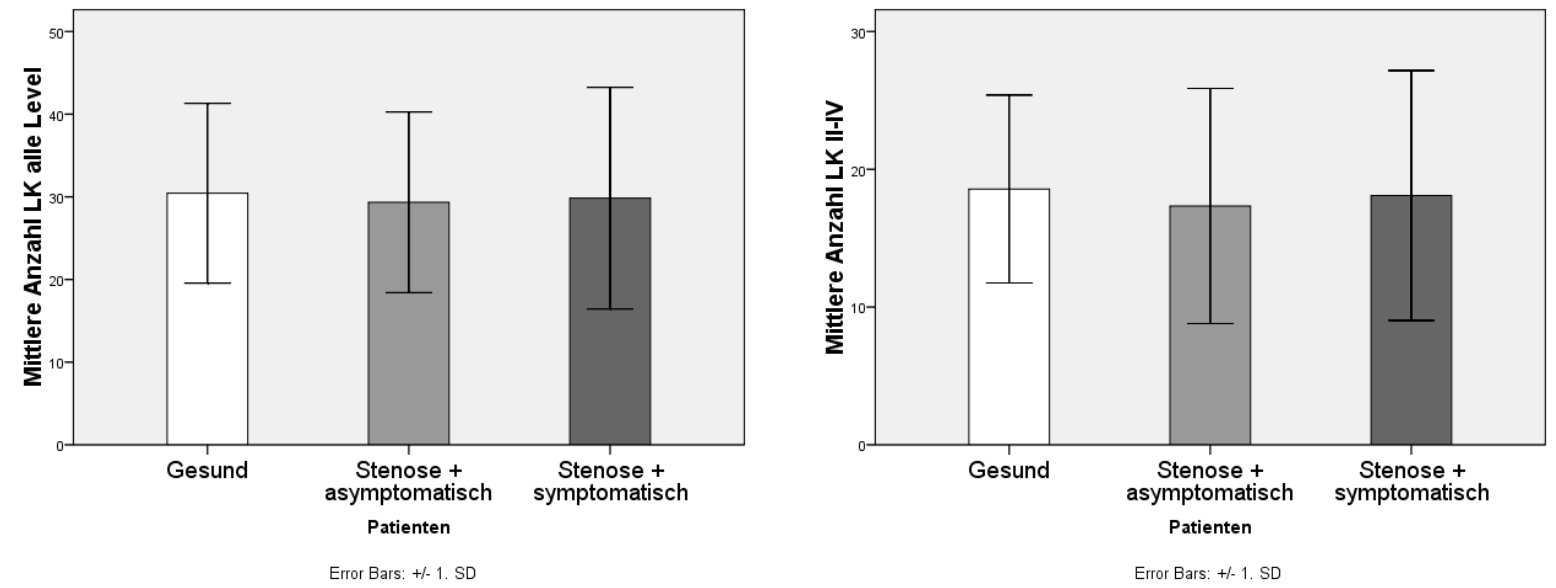

Abb. 25 a, b Erläuterung siehe Text

Symptomatische Patienten haben weder in allen Leveln noch in Level II bis IV signifikant mehr Lymphknoten als asymptomatische oder gesunde Patienten. 


\section{Größte Lymphknoten, Größe, bezogen auf Patienten}

Es wird überprüft, ob sich bei Stenosepatienten je nach Symptomatik größere Lymphknoten unter den größten Lymphknoten finden als bei gesunde Patienten. Es besteht Normalverteilung.

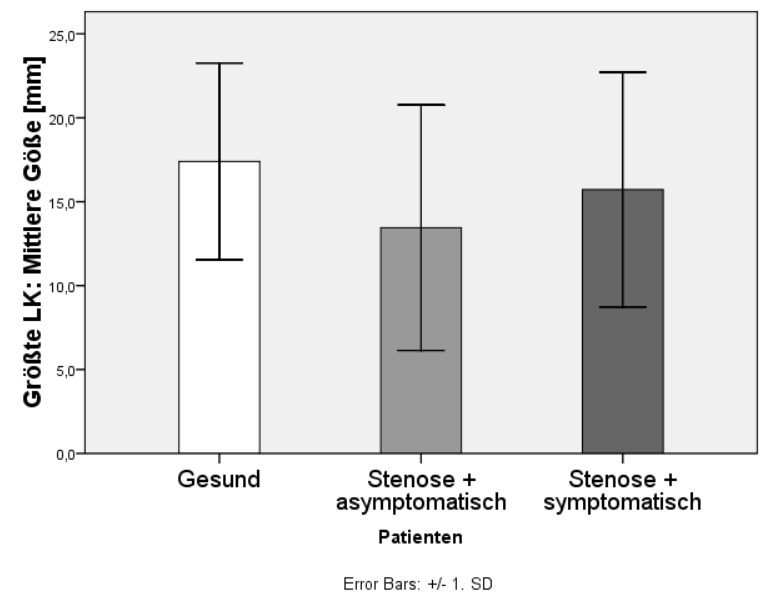

Abb. 26 Erläuterung siehe Text

Symptomatische Patienten haben nicht signifikant größere Lymphknoten unter den größten Lymphknoten als asymptomatische oder gesunde Patienten.

\section{Carotis-Lymphknoten, Anzahl und Größe, bezogen auf Patienten}

Es wird überprüft, ob sich bei Stenosepatienten je nach Symptomatik mehr und/oder größere direkt an der Carotisbifurkation befindliche Lymphknoten zeigen als bei gesunde Patienten. Es besteht Normalverteilung.

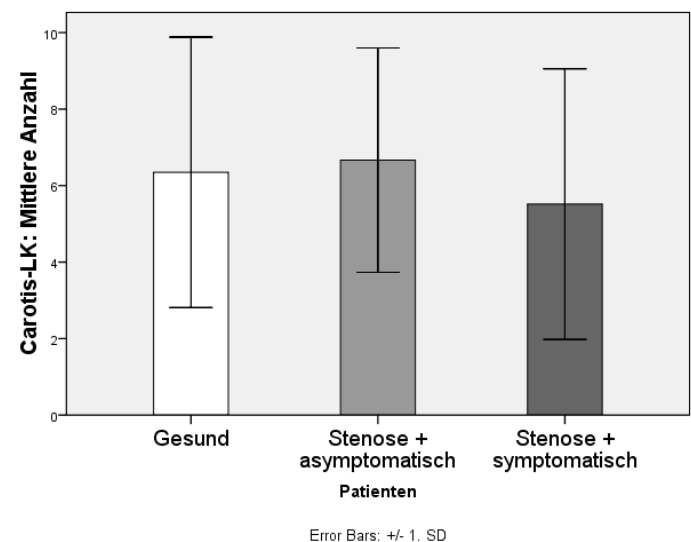

Abb. 27 a, b Erläuterung siehe Text

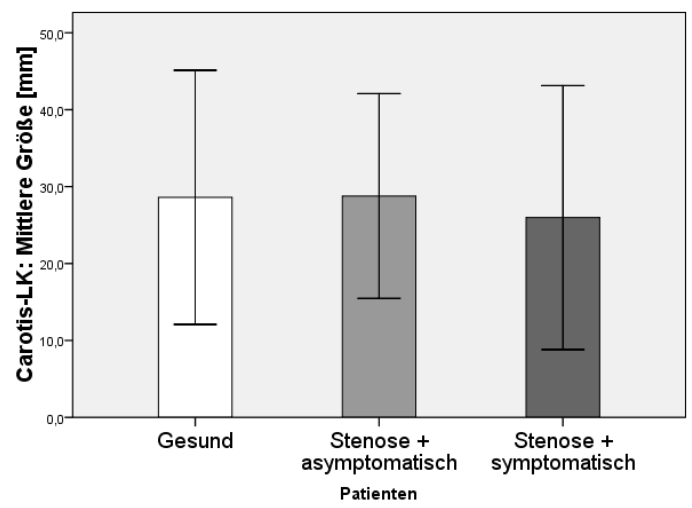

Error Bars: +1-1. SD 
Bei symptomatischen Patienten zeigen sich weder signifikant mehr noch signifikant größere direkt an der Carotisbifurkation gelegene Lymphknoten als bei asymptomatischen oder gesunden Patienten.

\section{Alle Level und Level II bis IV, Anzahl, bezogen auf Carotiden}

Im Folgenden wird die Überprüfung der Hypothese aufgeteilt nach Carotiden und nicht nach Patienten. Entsprechend den 66 untersuchten Patienten insgesamt, betrifft die folgende Analyse also nun 132 Carotiden.

Es ergeben sich die folgenden Gruppen:

- Patienten mit zwei gesunden Carotiden (Carotiden je "gesund“)

- Gesunde Carotiden mit einer stenosierten Carotis auf der Gegenseite („Gesund, aber mit Stenose auf der Gegenseite")

- Stenosierte Carotiden („Stenose“).

Es wird überprüft, ob symptomatische/asymptomatische stenosierte Carotiden oder gesunde Carotiden mit symptomatischen/asymptomatischen Stenosen auf der Gegenseite mehr Lymphknoten in allen zervikalen Leveln und/oder in Level II, III und IV aufweisen als die Carotiden beidseits gesunder Hälse.

Es besteht Normalverteilung.
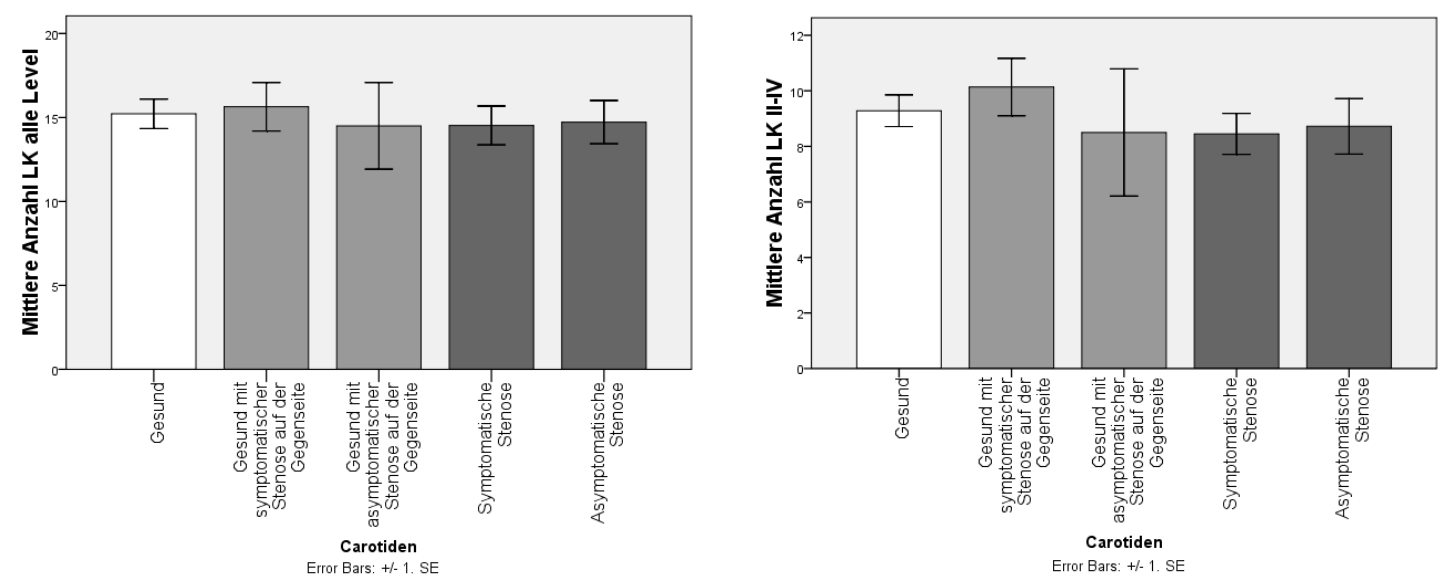

Abb. 28 a, b Erläuterung siehe Text

Betrachtet nach Carotis und Symptomatik weist keine Gruppe signifikant mehr Lymphknoten in allen Leveln oder in Level II bis IV auf als gesunde Carotiden. 


\section{Größte Lymphknoten, Größe, bezogen auf Carotiden}

Es wird überprüft, ob bei symptomatischen/asymptomatischen Carotiden oder gesunden Carotiden mit symptomatischen/asymptomatischen Stenosen auf der Gegenseite die größten Lymphknoten größer sind als bei Carotiden beidseits gesunder Hälse. Es besteht Normalverteilung.

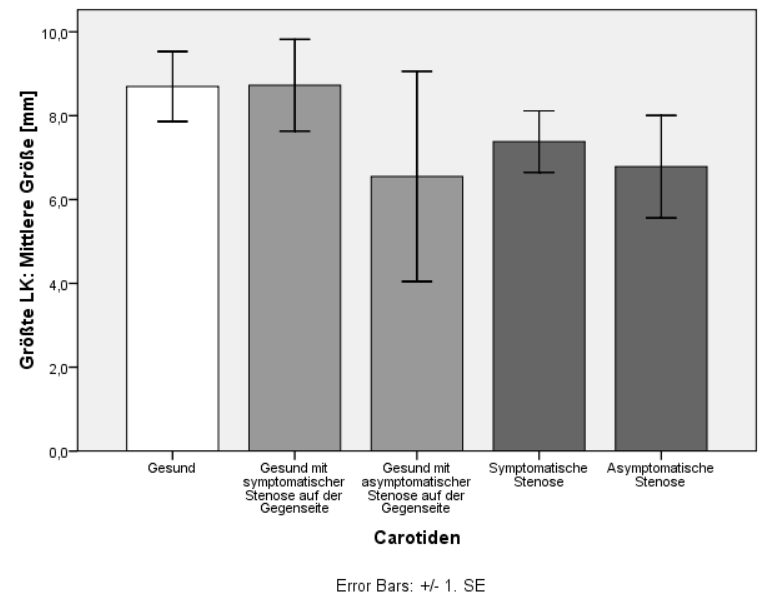

Abb. 29 Erläuterung siehe Text

Betrachtet nach Carotis und Symptomatik weist keine Gruppe signifikant größere größte Lymphknoten auf als gesunde Carotiden.

\section{Carotis-Lymphknoten, Anzahl und Größe, bezogen auf Carotiden}

Es wird überprüft, ob symptomatische/asymptomatische Carotiden oder gesunden Carotiden mit symptomatischen/asymptomatischen Stenosen auf der Gegenseite mehr und/oder größere direkt an der Carotisbifurkation gelegene Lymphknoten besitzen als Carotiden beidseits gesunder Hälse. Es besteht Normalverteilung.
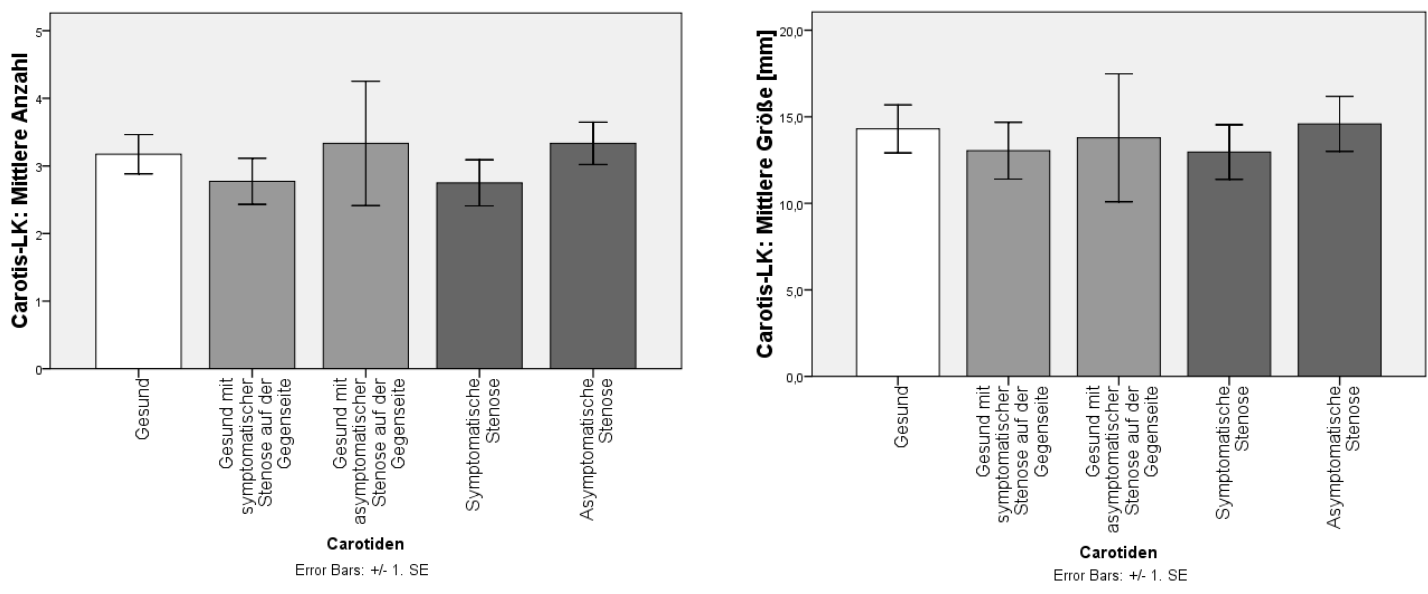

Abb. 30 a, b Erläuterung siehe Text 
Betrachtet nach Carotis und Symptomatik weist keine Gruppe signifikant mehr oder signifikant größere Carotis-Lymphknoten auf als gesunde Carotiden.

\subsection{3 „Ulzerierte Carotisplaques haben mehr und/oder größere Lymphknoten (auf der Seite des Ulkus).“}

\section{Verteilung von Ulzerationen}

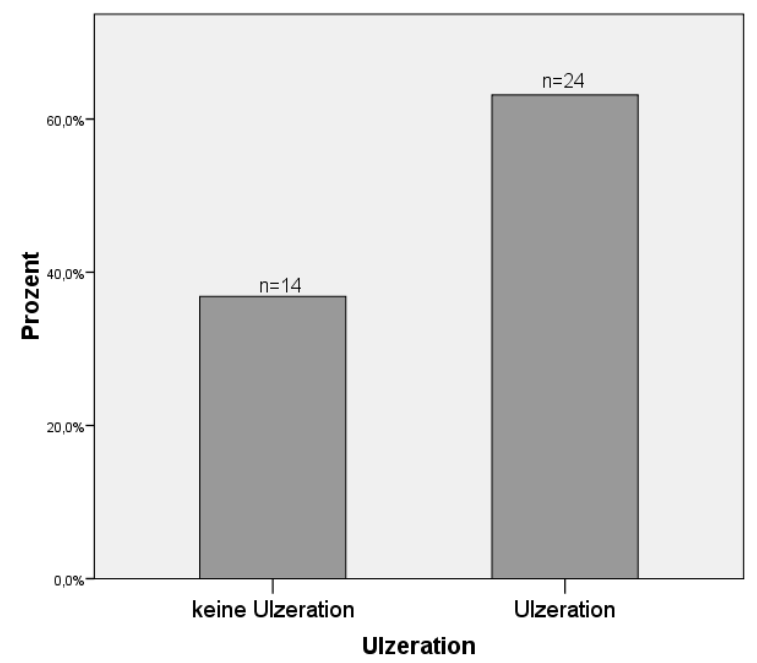

Bei 38 Stenosepatienten konnte das Vorliegen einer Ulzeration untersucht werden. Bei $37 \% \quad(n=14)$ konnte eine Ulzeration nachgewiesen werden, bei $63 \%$ $(n=24) \quad$ konnte keine Ulzeration nachgewiesen werden (siehe Abbildung 31).

Abb. 31 Erläuterung siehe Text

\section{Alle Level und Level II bis IV, Anzahl, bezogen auf Patienten}

Zunächst erfolgt die Betrachtung der "gesamten Patienten“. Es ergeben sich drei Patientengruppen:

- Patienten ohne Carotisstenose („Gesund“)

- Patienten mit nicht-ulzerierter Carotisstenose („Stenose ohne Ulkus“)

- Patienten mit ulzerierter Carotisstenose („Ulkus“).

Es wird überprüft, ob Patienten mit ulzerierten Carotisplaques mehr Lymphknoten in allen zervikalen Lymphknoten-Leveln und/oder in Level II, III und IV aufweisen als Patienten mit nichtulzerierten Plaques oder gesunde Patienten.

Es besteht Normalverteilung. 

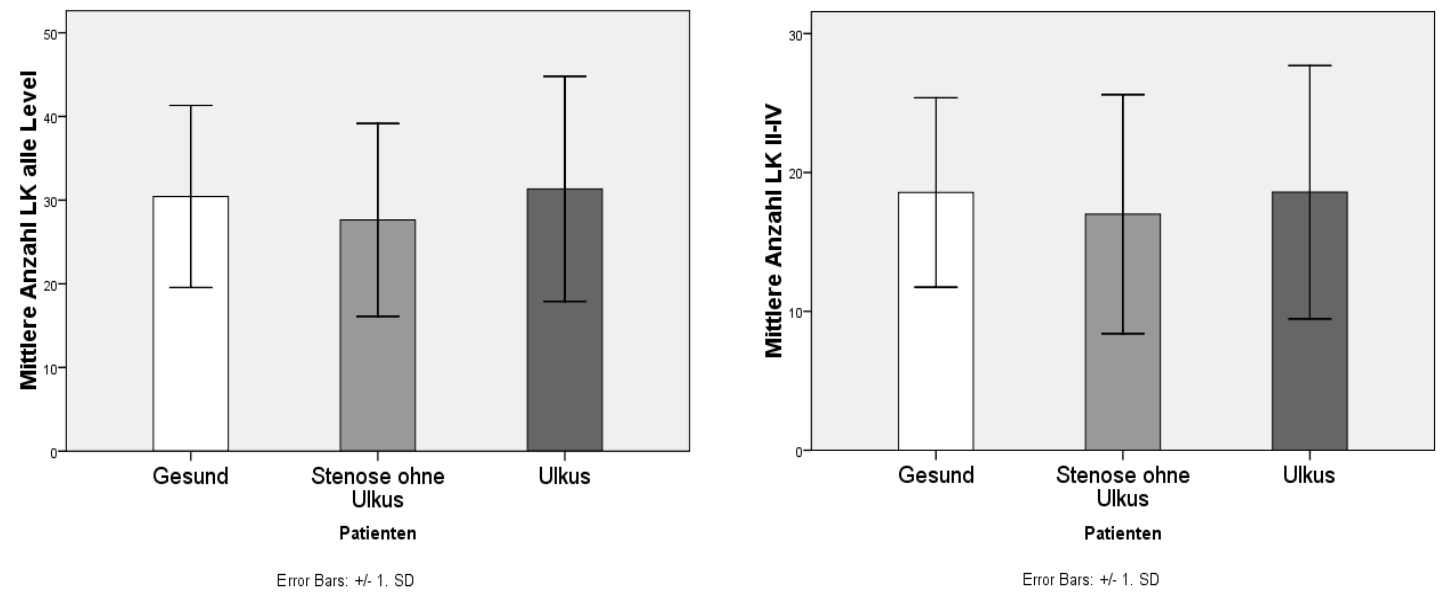

Abb. 32 a, b Erläuterung siehe Text

Patienten mit ulzerierten Carotisplaques weisen weder in allen Lymphknoten-Leveln, noch in Level II bis IV signifikant mehr Lymphknoten auf als Patienten mit nicht-ulzerierten Plaques oder gesunde Patienten.

\section{Größte Lymphknoten, Größe, bezogen auf Patienten}

Es wird überprüft, ob die größten Lymphknoten bei Patienten mit ulzerierten Carotisplaques größer sind als bei Patienten mit nicht-ulzerierten Plaques oder gesunden Patienten.

Es besteht Normalverteilung.

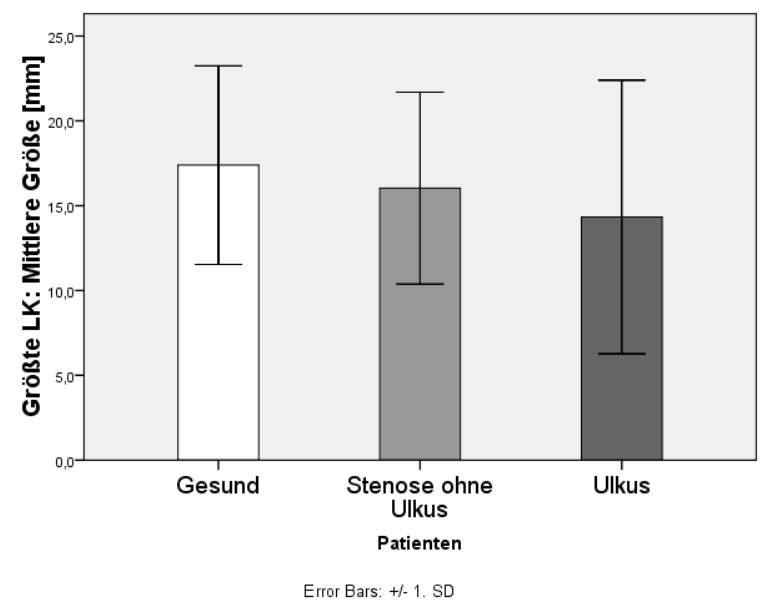

Abb. 33 Erläuterung siehe Text

Die größten Lymphknoten bei Patienten mit ulzerierten Plaques sind nicht signifikant größer als bei Patienten mit nicht-ulzerierten Plaques oder gesunden Patienten. 


\section{Carotis-Lymphknoten, Anzahl \& Größe, bezogen auf Patienten}

Es wird überprüft, ob Patienten mit ulzerierten Carotisplaques mehr und/oder größere direkt an der Carotisbifurkation liegende Lymphknoten aufweisen als Patienten mit nicht-ulzerierten Plaques oder gesunde Patienten.

Es besteht Normalverteilung.
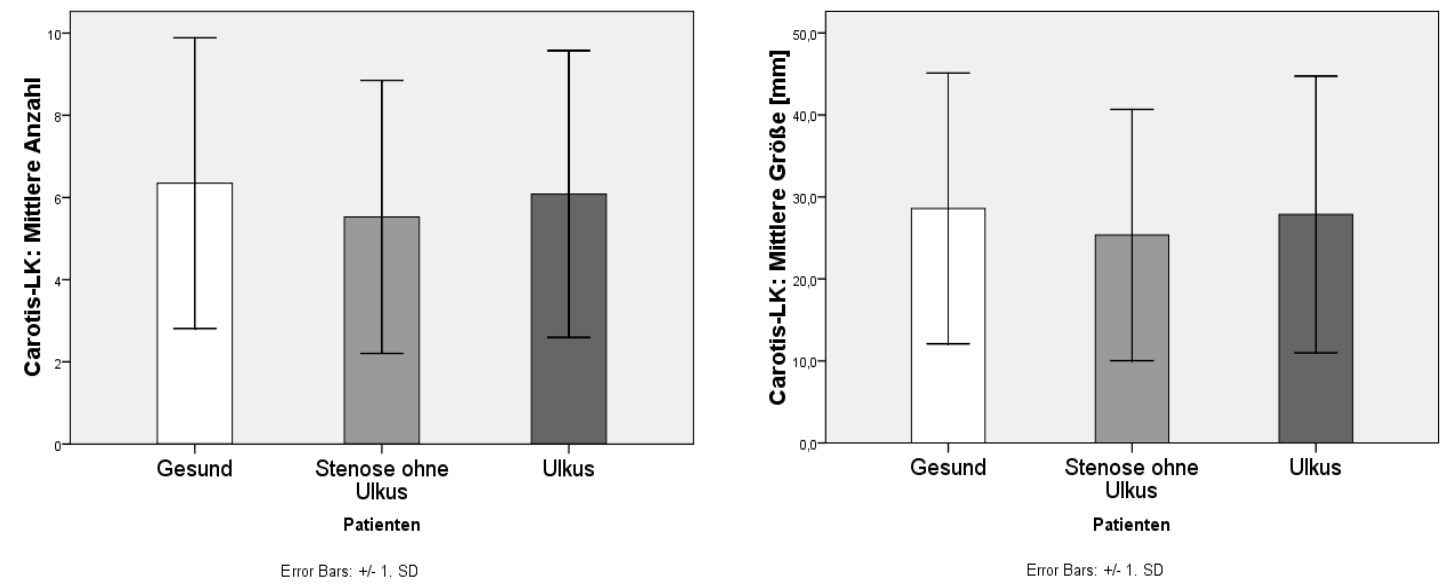

Abb. 34 a, b Erläuterung siehe Text

Patienten mit ulzerierten Carotisplaques weisen nicht signifikant mehr oder signifikant größere direkt an der Carotisbifurkation gelegene Lymphknoten auf als Patienten mit nicht-ulzerierten Plaques oder gesunde Patienten.

\section{Alle Level und Level II bis IV, Anzahl, bezogen auf Carotiden}

Im Folgenden wird die Hypothese bezogen auf die einzelnen Carotiden überprüft. Es werden jeweils die Lymphknoten der zur Carotis zugehörigen Seite betrachtet. Es ergeben sich die folgenden Gruppen:

- Gesunde Carotis

- Stenosierte Carotis ohne Ulkus

- Stenosierte Carotis mit Ulkus.

Es wird überprüft, ob sich bei stenosierten Carotiden mit Ulkus mehr Lymphknoten in allen Leveln und/oder in Level II, III und IV finden als bei stenosierten Carotiden ohne Ulkus und gesunden Carotiden.

Es besteht Normalverteilung. 

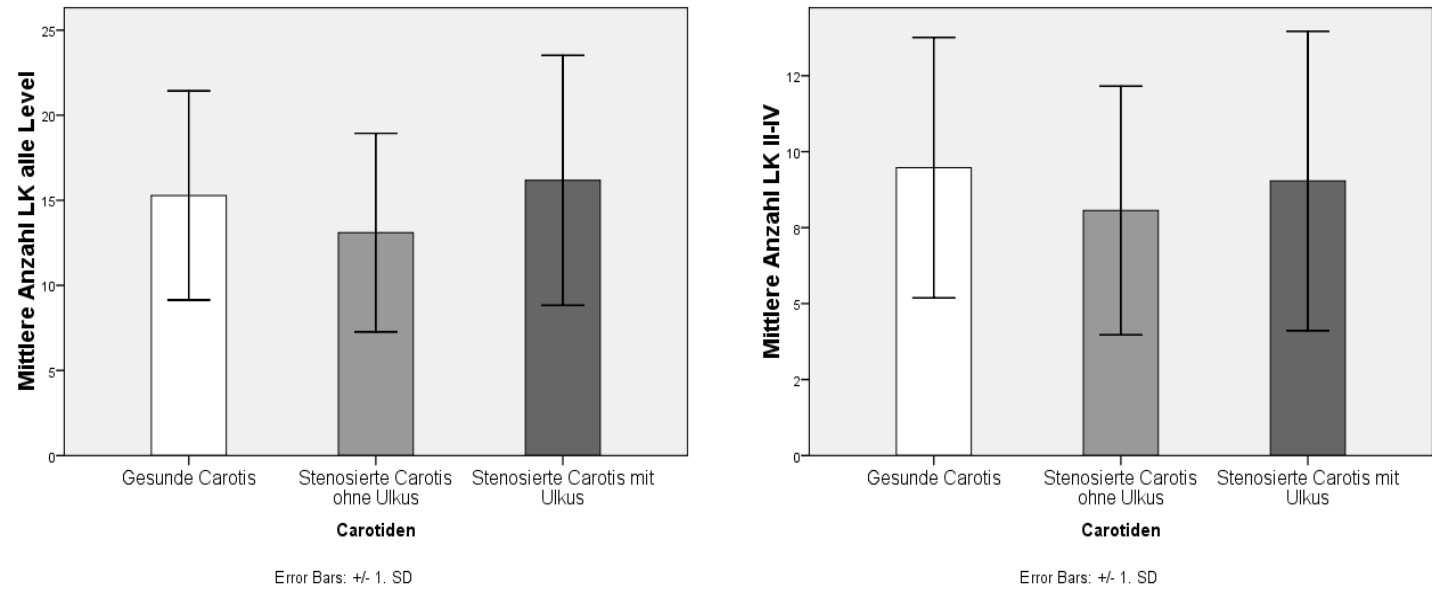

Abb. 35 a, b Erläuterung siehe Text

Bei ulzerierten Carotiden lassen sich weder in allen Lymphknoten-Leveln noch in Level II bis IV signifikant mehr Lymphknoten nachweisen als bei nicht-ulzerierten oder gesunden Carotiden.

\section{Größte Lymphknoten, Größe, bezogen auf Carotiden}

Es wird überprüft, ob sich bei stenosierten Carotiden mit Ulkus größere Lymphknoten unter den größten Lymphknoten finden als bei stenosierten Carotiden ohne Ulkus und gesunden Carotiden. Es besteht Normalverteilung.

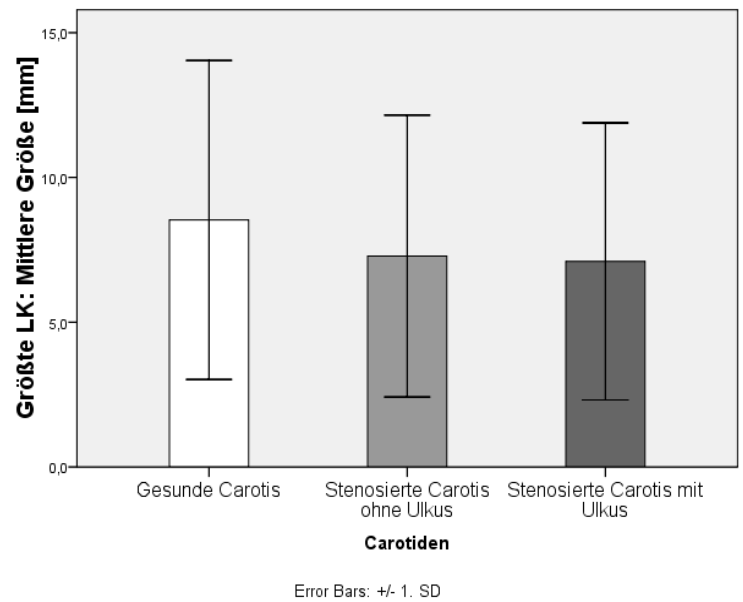

Abb. 36 Erläuterung siehe Text

Ulzerierte Carotiden weisen nicht signifikant größere Lymphknoten unter den größten Lymphknoten auf als nicht-ulzerierte oder gesunde Plaques. 


\section{Carotis-Lymphknoten, Anzahl und Größe, bezogen auf Carotiden}

Es wird überprüft, ob sich bei stenosierten Carotiden mit Ulkus mehr und/oder größere Lymphknoten bei den direkt an der Carotisbifurkation gelegenen Lymphknoten finden als bei stenosierten Carotiden ohne Ulkus und gesunden Carotiden. Es besteht Normalverteilung.
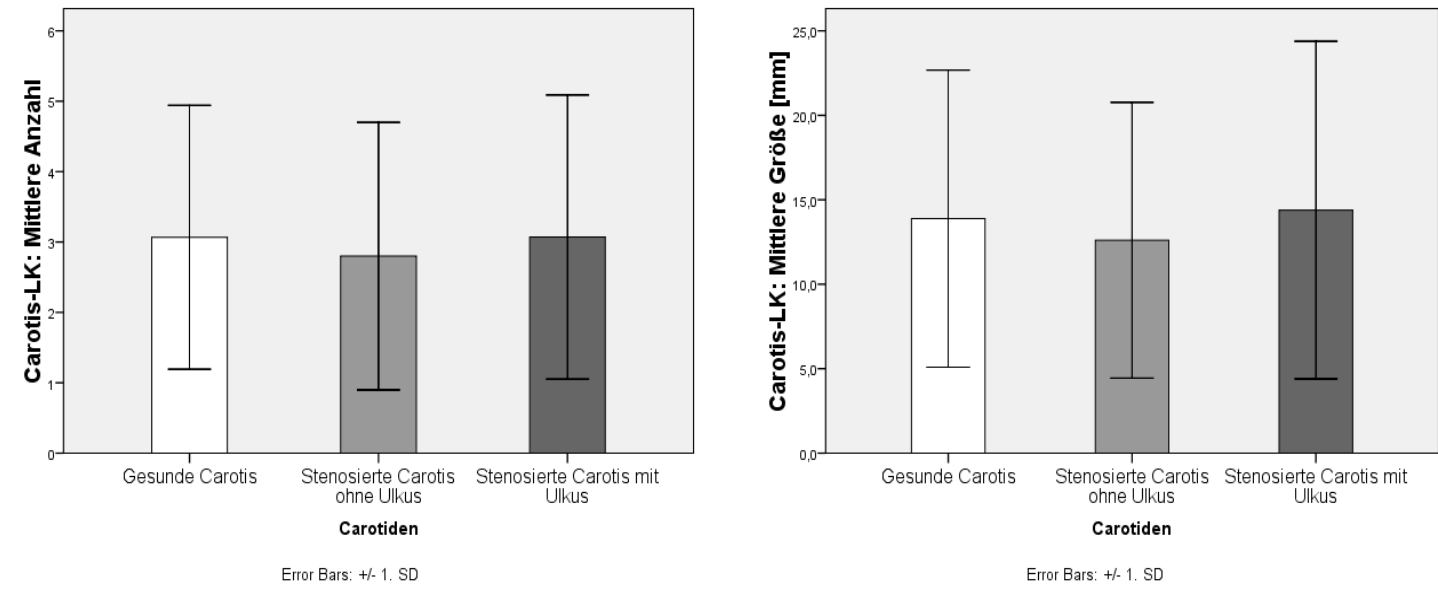

Abb. 37 a, b Erläuterung siehe Text

Ulzerierte Carotiden weisen nicht signifikant mehr oder signifikant größere Lymphknoten bei den Lymphknoten auf, die direkt um die Carotisbifurkation liegen, als nicht-ulzerierte oder gesunde Plaques.

\subsection{4 „Es besteht ein Zusammenhang zwischen dem Grad einer Carotisstenose und der Anzahl bzw. Größe der zervikalen Lymphknoten.“}

Die Überprüfung der genannten Hypothese erfolgt in allen Analysen nach Carotiden (nicht 66 Patienten, sondern 132 Carotiden), so dass sich folgende Gruppen ergeben:

- Gesunde Carotis

- Gesunde Carotis mit Stenose auf der Gegenseite

- Stenosierte Carotis mit ECST $65-81 \%$ (mäßige Stenose)

- Stenosierte Carotis mit ECST 82-99\% (hochgradige Stenose)

- Verschlossene Carotis, entspricht ECST $100 \%$.

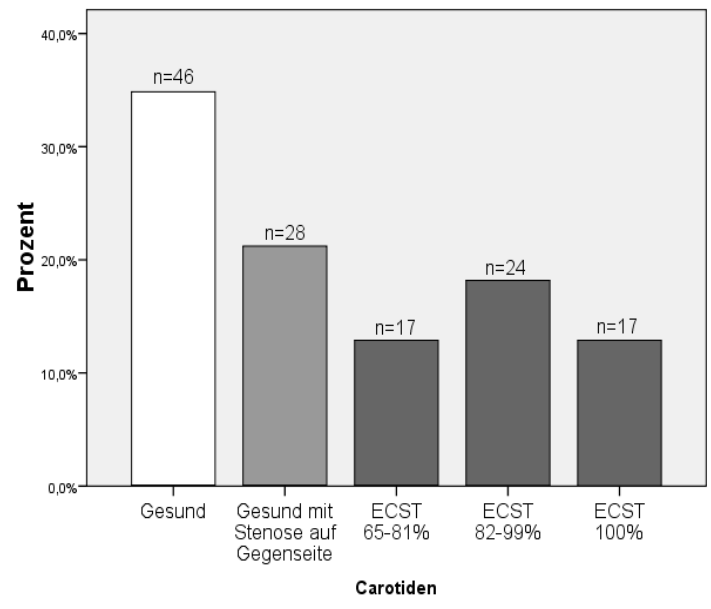

Abb. 38 Erläuterung siehe Text 


\section{Alle Level und Level II bis IV, Anzahl, bezogen auf Carotiden}

Es wird überprüft, ob sich bei Patienten mit Carotisstenose mit steigendem Stenosegrad mehr Lymphknoten in allen Lymphknoten-Leveln und/oder in Level II, III und IV finden lassen.

Es besteht Normalverteilung.
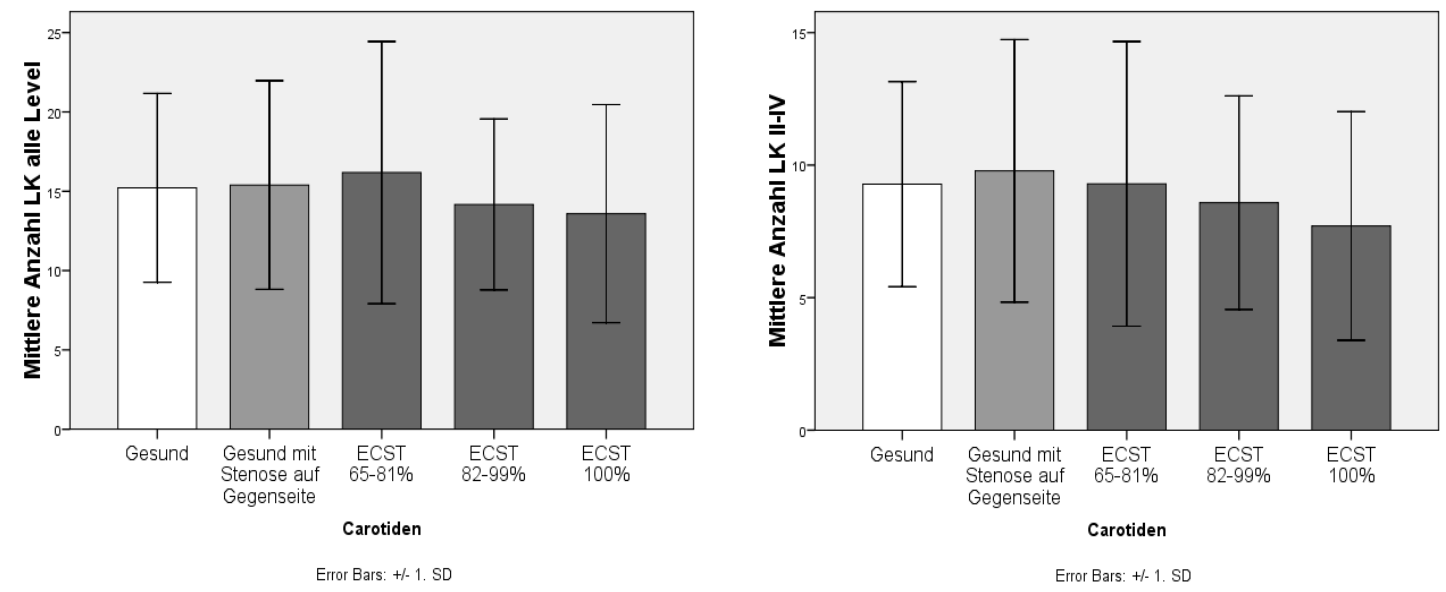

Abb. 39 a, b Erläuterung siehe Text

Höhergradige Stenosen besitzen nicht signifikant mehr Lymphknoten in allen Lymphknoten-Leveln und in Level II bis IV als geringgradiger stenosierte oder gesunde Carotiden.

\section{Größte Lymphknoten, Größe, bezogen auf Carotiden}

Es wird überprüft, ob sich bei Patienten mit Carotisstenose mit steigendem Stenosegrad größere Lymphknoten unter den größten Lymphknoten finden lassen.

Es besteht Normalverteilung.

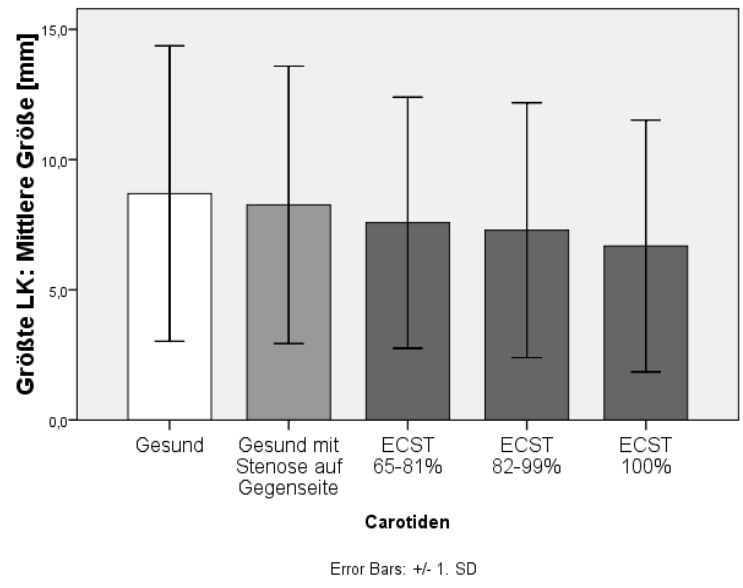

Abb. 40 Erläuterung siehe Text

Höhergradige Stenosen besitzen nicht signifikant größere Lymphknoten unter den größten Lymphknoten als geringgradiger stenosierte oder gesunde Carotiden. 


\section{Carotis-Lymphknoten, Anzahl und Größe, bezogen auf Carotiden}

Es wird überprüft, ob sich bei Patienten mit Carotisstenose mit steigendem Stenosegrad mehr und/oder größere direkt an der Carotisbifurkation gelegene Lymphknoten finden.

Es besteht Normalverteilung.
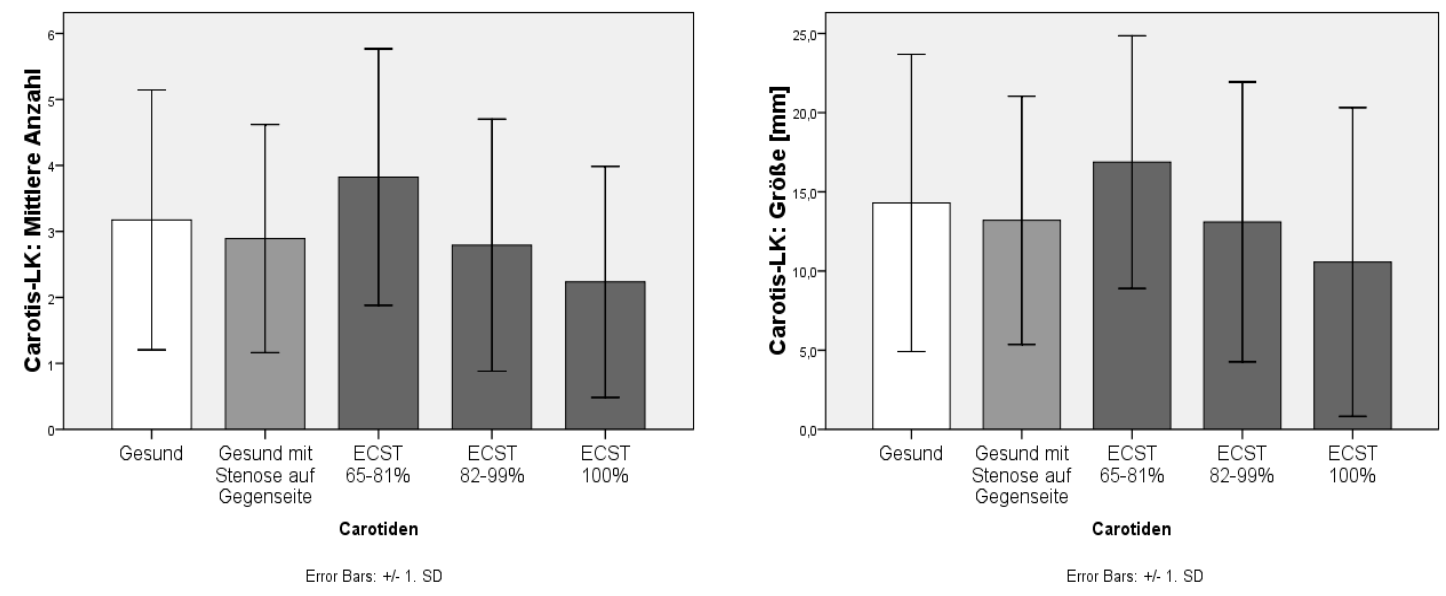

Abb. 41 a, b Erläuterung siehe Text

Bei höhergradigen Stenosen finden sich weder signifikant mehr, noch signifikant größere Lymphknoten in der Nähe der Carotisbifurkation als bei geringgradiger stenosierten oder gesunden Carotiden.

\subsection{5 „Es besteht ein Zusammenhang zwischen den Begleiterkrankungen eines Stenosepatienten und der Anzahl bzw. Größe seiner zervikalen Lymphknoten.“}

Es erfolgte die Betrachtung der Lymphknotenanzahl bzw. -größe in Bezug zu den Begleiterkrankungen eines Patienten. Die folgenden Begleiterkrankungen, bei denen es sich zugleich um Risikofaktoren für die Entstehung kardiovaskulärer Erkrankungen handelt, wurden berücksichtigt:

- Arterieller Hypertonus

- Diabetes mellitus

- Hypercholesterinämie

- $\mathrm{CRP}>5 \mathrm{mg} / \mathrm{l}$

- Nikotinabusus.

Es ergeben sich jeweils die folgenden Patientengruppen:

- Gesund ohne Begleiterkrankung

- Gesund mit Begleiterkrankung 
- Stenosepatient ohne Begleiterkrankung

- Stenosepatient mit Begleiterkrankung.

Es wurden jeweils alle „Lymphknoten-Eigenschaften“ (alle Level, Level II bis IV, größte Lymphknoten, Carotis-Lymphknoten) wie in den vorangegangenen Kapiteln untersucht. Bezüglich arterieller Hypertonus, Hypercholesterinämie, CRP $>5 \mathrm{mg} / \mathrm{l}$ und Nikotinabusus ließen sich in keiner Kategorie signifikant mehr oder signifikant größere Lymphknoten nachweisen.

Einzig Stenosepatienten mit einem Diabetes mellitus besitzen signifikant mehr Lymphknoten in allen Lymphknoten-Leveln als gesunde Patienten mit einem Diabetes mellitus $(p=0,021)$. Bezüglich aller anderen Lymphknoten-Eigenschaften (Level II bis IV, größte Lymphknoten, CarotisLymphknoten) lassen sich aber auch hier keine signifikanten Ergebnisse finden.

Im Folgenden sei für jede Begleiterkrankung exemplarisch die Verteilung der Lymphknoten aller Lymphknoten-Level graphisch dargestellt.

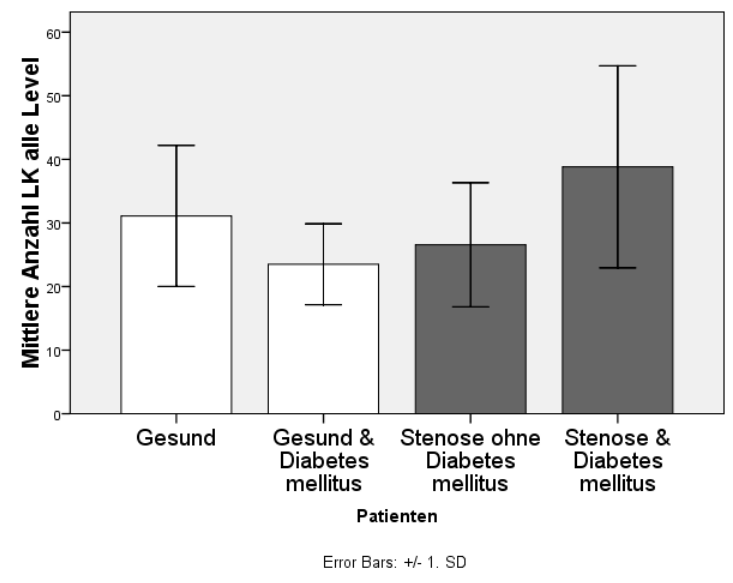

Abb. 42 Erläuterung siehe Text
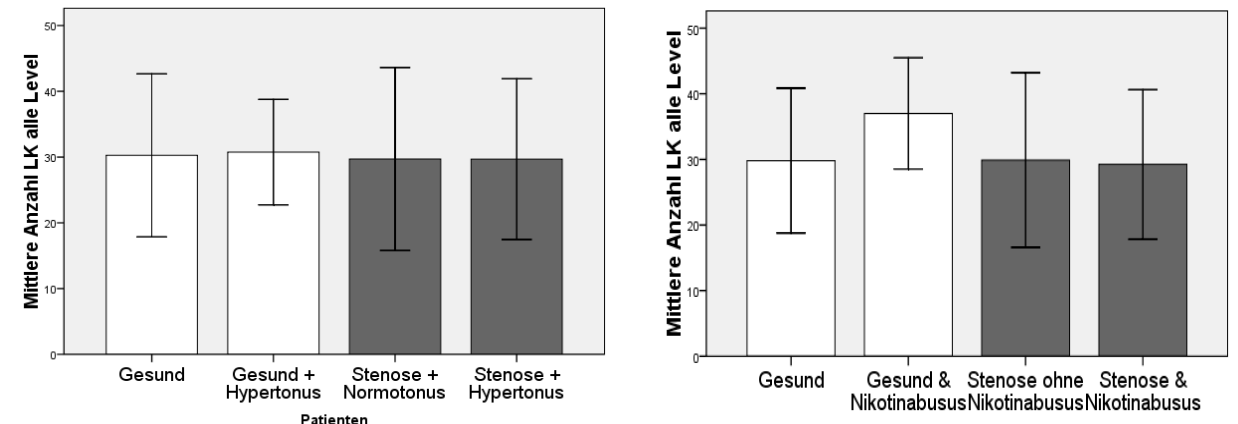

Error Bars +1-1. SD
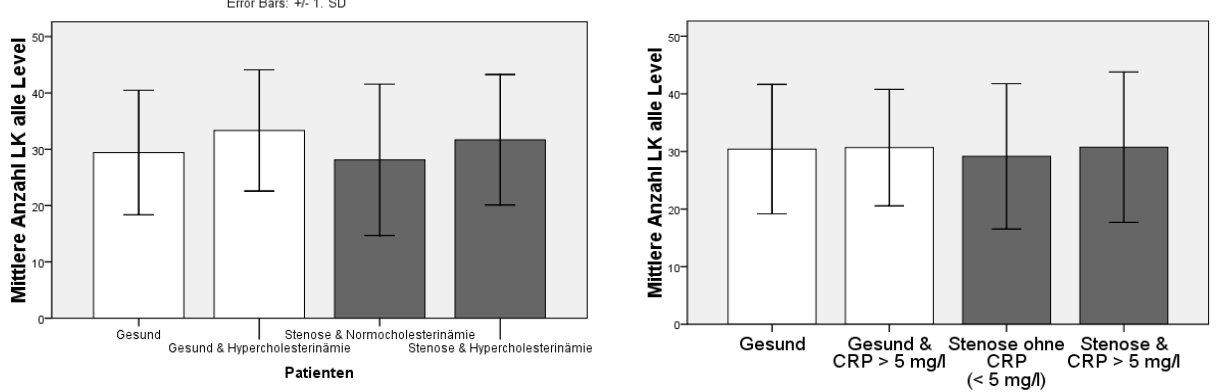

Patiente

Abb. 43 a, b, c, d Erläuterung siehe Text 


\section{Diskussion}

\subsection{Einleitung}

Das Ziel der vorliegenden Arbeit war es, den möglichen Effekt einer arteriosklerotisch bedingten Entzündung der Arteria carotis interna auf die Größe und Anzahl lokoregionaler Lymphknoten des Halses unter Berücksichtigung von Symptomatik, Plaquemorphologie, Stenosegrad und Begleiterkrankungen der Patienten zu untersuchen. Aufgrund der Ergebnisse lässt sich in der vorliegenden Studie kein Zusammenhang zwischen Stenosen der Arteria carotis interna und Lymphknotenvergrößerungen oder -vermehrungen in der CTA nachweisen.

Schlaganfälle sind die dritthäufigste Todesursache und die führende Ursache dauernder Invalidität (Poeck und Hacke 2006). Die Arteriosklerose der Arteria carotis interna ist für ungefähr ein Drittel aller ischämischen Schlaganfälle verantwortlich (Denzel et al. 2005). Es ist von großem Interesse, das Risiko einer arteriosklerotischen Plaque vor dem ischämischen Ereignis einschätzen zu können.

Im Folgenden seien alternative Identifizierungsmöglichkeiten einer vulnerablen arteriosklerotischen Plaque und mögliche Erklärungen und Diskussionen für das negative Ergebnis der vorliegenden Arbeit dargestellt.

\subsection{Alternative Identifizierungsmöglichkeiten einer vulnerablen Plaque}

\subsubsection{Bildgebung der Arteria carotis interna}

\section{Duplexsonographie}

Mithilfe der farbkodierten Duplexsonographie kommt eine Darstellung des Gefäßes aufgrund von Flussgeschwindigkeiten des Blutes (funktionelle Darstellung) und aufgrund von Grauskalen (B-Mode, anatomische Darstellung) zustande, so dass sich also kein echtes anatomisches Bild des Gefäßlumens ergibt (Wardlaw 2008). Die Bestimmung des Grades einer Stenose erfolgt über die Zuordnung bestimmter Flussgeschwindigkeit zu bestimmten Stenosegraden (Wardlaw 2008). Die Sensitivität und Spezifität der Duplexsonographie für das Erkennen 70-99\%iger Stenosen liegen bei $86 \%$ und $87 \%$, für das Aufspüren von Gefäßverschlüssen bei $96 \%$ und $100 \%$ (Nederkoorn et 
al. 2003). Allerdings ist die Darstellung einer 50-69\%igen Stenose wenig akkurat mit einer schlechten Sensitivität von 63\% (Wardlaw et al. 2006, Anderson et al. 2000).

Über den Stenosegrad hinaus können insbesondere Nekrosen und Hämorrhagien und die Dicke der fibrösen Kappe mittels Ultraschall als Hinweise auf eine vulnerable Plaque betrachtet werden. Die Abbildung von Ulzerationen, Oberflächenthromben und der Oberflächenkontur ist dahingegen unzuverlässig (Lammie et al. 2000, Gronholdt 1999). Die Sensitivität für das Erkennen von Ulzerationen liegt so nur bei 37\% und ist abhängig vom Grad der vorliegenden Stenose (Saba et al. 2007, Gronholdt 1999).

Als weiteres Merkmal für die Vulnerabilität einer Plaque gilt in der Ultraschalldiagnostik die fehlende Echogenität desselben. Patienten mit derartigen Plaques haben ein sehr viel höheres Risiko für das Auftreten von Schlaganfällen und cerebrovaskulären Ereignissen als Patienten mit Plaques, die sich im Ultraschall als echogen darstellen (Geroulakos et al. 1993, Gronholdt 1999). Als echolos erscheinen im Ultraschall Lipide, Thromben und Hämorrhagien - allesamt assoziiert mit vulnerablen Plaques (Mathiesen et al. 2001). Echoreiche Plaques sind meistens fibrös (Nighoghossian et al. 2005).

Als weiteres Mittel zur Einordnung der Vulnerabilität einer Carotisplaque wurde die Technik der Mikroembolie-Detektion untersucht. Hierbei werden mittels transkraniellem Doppler zirkulierende Embolien distal einer Carotisstenose dokumentiert. Es konnte für die Symptomatik des Patienten und den Grad der Stenose ein positiver Zusammenhang zum Vorhandensein und der Anzahl von Mikoremboliesignalen gezeigt werden. Es bestand jedoch kein signifikanter Unterschied in dem Vorhandensein oder der Anzahl von Mikroembolien bei verschiedener Echogenität einer Plaque (Droste et al. 1999). Insbesondere bei asymptomatischen Carotisstenosen kann das Vorhandensein von Mikroemboliesignalen ein erhöhtes Risiko für einen ipsilateralen Schlaganfall oder eine TIA anzeigen. Umgekehrt können bei fehlendem Mikroemboliesignal diejenigen Patienten mit asymptomatischer Stenose identifiziert werden, die ein geringes Risiko für cerebrovaskuläre Ereignisse auf dem Boden ihrer Carotisplaque haben (Markus et al. 2010).

Des Weiteren ist mittels Duplexsonographie die Einschätzung des allgemeinen kardiovaskulären Risikos eines Patienten durch die Messung der Intima-Media-Dicke in der Arteria carotis möglich. Für jeden Zuwachs an Dicke von 0,1 mm steigt so das Risiko eines akuten Myokardinfarktes um $11 \%$ an (Sidhu und Allan 1997).

Nachteile der Duplexsonographie sind die zweidimensionale Betrachtung, Abschattungsartefakte durch Kalzifikationen und die grobe Mittelung der Grauwerte über dem gesamten arteriosklerotischen Areal (Denzel et al. 2005). Außerdem besteht eine erhebliche Abhängigkeit der Ergebnisse vom Untersucher (Wardlaw 2008). Von Vorteil sind die gute Verfügbarkeit von Ultraschallgeräten, die geringen Kosten einer Untersuchung und die einfache Handhabung (Wardlaw 2008). 


\section{Computertomographie}

Die Einführung mehrzeiliger Spiral-CT-Scanner macht die CT-Angiographie (CTA), d.h. die selektive Darstellung arterieller Gefäße mithilfe von jodhaltigem Kontrastmittel möglich. Die Scanzeit konnte reduziert und so der kurzen arteriovenösen Transitzeit angepasst werden. Auf diese Weise kann die Phase der arteriellen Füllung ohne venöse Überlagerungen dargestellt werden. Für die Untersuchung der gesamten Arteria carotis vom Aortenbogen bis zum Circulus arteriosus Willisii benötigt ein 16-Zeilen-CT-Scanner so nur wenige Sekunden (Lell et al. 2006). Durch diese kontrastmittelgestützte Darstellung des Gefäßlumens der Arteria carotis interna ermöglicht die CTA auf dieselbe Weise wie die DSA die Evaluation einer Carotisstenose bezüglich ihres Stenosegrades mithilfe der Methoden nach NASCET, ECST und CC (siehe Methodenteil). In vielen Studien wurde die Vergleichbarkeit zwischen den Messergebnissen der CTA und dem Goldstandard DSA untersucht. In ihrer prospektiven Studie dokumentieren Randoux et al. (2001) eine signifikante Korrelation zwischen dem gemessenen Stenosegrad in der CTA und demjenigen in der DSA. Zu einem ähnlich guten Ergebnis kommen Silvennoinen et al. (2007), allerdings beschreiben sie eine Unterschätzung moderater und hochgradiger Stenosen in der CTA im Vergleich zur DSA. In weiteren Quellen wird diese Beobachtung ebenfalls postuliert (Wardlaw 2008, Berg et al. 2005). Dahingegen können auf beiden Seiten des Lumens hochgradig kalzifizierte Plaques der Arterie zu einer Überschätzung der Stenose im CT führen (Lell et al. 2007).

Die Sensitivität und Spezifität der CTA in der Literatur liegen zwischen 65\% und 100\% und 63\% und 100\% (Silvennoinen et al. 2007). Die Beschreibung einer moderaten, 50-69\%igen Stenose hat eine relativ geringe Sensitivität von $88 \%$ und eine Spezifität von $82 \%$ (Silvennoinen et al. 2007). Für das Erkennen einer hochgradigen, 70-99\%igen Stenose beträgt die Sensitivität 85\% und die Spezifität 93\%. Für die Darstellung eines Verschlusses werden übereinstimmend eine Sensitivität und Spezifität von je 100\% dokumentiert (Koelemay et al. 2004). Trotz dieser guten Ergebnisse gelingt es der CTA nicht, zuverlässig zwischen moderaten und hochgradigen Carotisstenosen zu differenzieren (Anderson et al. 2000). Dies ist jedoch für die nachfolgende therapeutische Entscheidung von großem Interesse (North American Symptomatic Carotid Endarterectomy Trial Collaborators 1991). Von Relevanz ist außerdem die richtige Einschätzung eines beinahen Verschlusses der Arteria carotis interna, da dieser mit einem geringeren Schlaganfallrisiko assoziiert ist als eine hochgradige Stenose und so andere therapeutische Konsequenzen nach sich zieht. Für diese spezielle Form der Stenose wurde eine verlässliche Sensitivität und Spezifität beschrieben (92\% und 96\%) (Bartlett et al. 2006). Darüber hinaus ist die Übereinstimmung zwischen verschiedenen Untersuchern für die CTA exzellent (Randoux et al. 2001, Lell et al. 2006).

Mithilfe der CTA lässt sich jedoch nicht nur das Gefäßlumen, sondern auch das umgebende Gewebe inklusive der betroffenen Gefäßwand darstellen (Berg et al. 2005). Diese Möglichkeit kann zu einer Einschätzung der Vulnerabilität einer Plaque über den Stenosegrad hinaus beitragen (Oliver et al. 1999). Mehrere Aspekte einer arteriosklerotischen Plaque der Arteria carotis interna 
wurden diesbezüglich bereits auf ihre Aussagekraft hin untersucht. In ihrer prospektiven Studie beschreiben Oliver et al. (1999), dass die einzelnen Plaquebestandteile in der CTA unterschiedlich zur Darstellung kommen. Im Vergleich zum Muskel bilden sich so Kalzifikationen hyperdens, Fibrose isodens und Lipide und Hämorrhagien hypodens ab (siehe Tabelle 5). Ulzerationen einer Plaque lassen sich anhand eines irregulär begrenzten Gefäßlumens erkennen.

\begin{tabular}{|l|c|c|}
\hline & Hounsfield-Units & Dichte zum Muskel \\
\hline Thrombus & 20 & hypodens \\
\hline Lipide & 50 & hypodens \\
\hline Fibrose & 100 & isodens \\
\hline Calcium & $>300$ & hyperdens \\
\hline
\end{tabular}

Tab. 5 Darstellung der verschiedenen Plaquebestandteile im CT, nach Oliver et al. (1999) und Fuster et al. (2005b)

Im Vergleich zur Histopathologie gewonnener Endarteriektomiepräparate fanden die Autoren eine gute Sensitivität und Spezifität für die Beurteilung von Fibrose ( $86 \%$ und $94 \%$ ) und Lipid bzw. Hämorrhagien (94\% und $86 \%$ ) innerhalb einer Plaque. Für das Erkennen von Ulzerationen besitzt die CTA laut der Studie eine schlechte Sensitivität (50\%). Allerdings wird die Beurteilbarkeit von Ulzerationen als Hinweis auf Plaqueinstabilität in der CTA unterschiedlich eingeschätzt. So schreiben Randoux et al. (2001) der CTA eine größere Genauigkeit beim Erkennen von Wandirregularitäten im Sinne von Ulzerationen zu als der DSA, begründet durch die begrenzte Anzahl der Blickwinkel auf die Carotisstenose in derselben. Saba et al. (2007) unterstützen diese Einschätzung und geben eine hohe Sensitivität (94\%) und Spezifität für das Erkennen von Ulzerationen in der CTA an. In einer weiteren Studie zur Vergleichbarkeit der Bildgebung in der CTA und der Histopathologie wurden die verschiedenen Hounsfield-Units der Plaquebestandteile auf ihre Aussagekraft hin untersucht (Walker et al. 2002). So können verschiedene Dichtewerte verschiedenen Plaquebestandteilen zugeordnet werden (Fuster et al. 2005b) (siehe Tabelle 5). Die Autoren fanden zwar signifikante Unterschiede in den Dichtewerten je nach Lipidmenge oder Ulzerationen einer Plaque, kamen jedoch aufgrund des insgesamt relativ homogenen Erscheinungsbildes einer arteriosklerotischen Läsion in der CTA im Vergleich zur Histopathologie zu dem Schluss, dass die CTA zur Differenzierung zwischen fettigen und fibrösen Plaques ungeeignet sei. Hämorrhagien und inflammatorische Infiltrate konnten des Weiteren nur unzureichend dargestellt werden. Des Weiteren konnten in der Studie von Oliver et al. (1999) die Dicke der fibrösen Kappe und die Entzündung innerhalb der Plaque als Marker für eine instabile Läsion mittels CTA nicht eingeschätzt werden.

Die alleinige Betrachtung des Calciums innerhalb einer arteriosklerotischen Plaque kann jedoch bereits wichtige Informationen über dessen Eigenschaften liefern. So fanden McKinney et al. (2005), dass es eine starke Korrelation zwischen dem in der CTA gemessenen Calciumvolumen der Carotisbifurkation und dem Grad der nach NASCET gemessenen Arteria carotis internaStenose gibt. Die Autoren dokumentieren eine Sensitivität zwischen $88 \%$ und $94 \%$, eine Spezifität 
zwischen $76 \%$ und $87 \%$ und einen hohen negativ prädiktiven Wert für das Aufspüren einer Stenose über 40\% mittels der Bestimmung des Calciumvolumens in der CTA. Auch Nandalur et al. (2006) fanden in ihrer Studie zum Zusammenhang zwischen Calciumlast und Symptomen eines Patienten signifikant mehr Calcium in den ACls von Patienten mit höhergradigen (>60\%) Stenosen. Des Weiteren zeigte sich in dieser retrospektiven Studie bei symptomatischen Patienten im Gegensatz zu asymptomatischen eine signifikant höhere Calciumlast des extrakraniellen Anteils der Arteria carotis interna. Diese Calciumlast könnte so unabhängig helfen, das Risiko für das Auftreten einer TIA oder eines Apoplexes einzuschätzen. Dabei spiegelt sie allerdings wahrscheinlich weniger die Instabilität der Plaque an sich, sondern eher dessen Aktivität wider (Nandalur et al. 2006). Denn wie in der Einleitung bereits erwähnt, führen mehrere Zyklen bestehend aus Plaqueruptur und Heilung zum Auftreten kalzifizierter Plaques (Virmani et al. 2000). Diese Einschätzung wird durch eine radiologische und eine histologische Studie unterstützt, die beide zeigen, dass kalzifizierte Plaques der Arteria carotis interna weniger oft cerebrale Symptome verursachen als nicht-kalzifizierte Plaques (Hunt et al. 2002, Nandalur et al. 2005). Somit kann Calcium innerhalb einer arteriosklerotischen Plaque der Arteria carotis interna als Stabilität verleihender Bestandteil, aber auch als Indikator für die Aktivität und Ausprägung der Plaque angesehen werden. Trotz des Einsatzes von Kontrastmittel wird die Darstellbarkeit und Beurteilbarkeit arteriosklerotischen Calciums in der CTA durchweg als sehr gut beschrieben (Nandalur et al. 2005, Denzel et al. 2005, McKinney et al. 2005).

Zusammenfassend ist mittels der CTA eine zuverlässige Einschätzung des Grades einer Carotisstenose möglich, allerdings sollte vor allem die Differenzierung moderater und hochgradiger Stenosen sorgfältig erfolgen. Auch zur Zusammensetzung einer Carotisplaque ist in der CTA eine mit der Histopathologie vergleichbare Aussage möglich. Von besonderem Interesse ist in diesem Zusammenhang die Evaluation des gegebenenfalls enthaltenen Calciums, das einen Hinweis auf Aktivität und Ausprägung des arteriosklerotischen Geschehens liefern kann. Nicht möglich ist die Darstellung des entzündlichen Geschehens innerhalb einer arteriosklerotischen Läsion mittels CTA. Von praktischem Vorteil sind die flächendeckende Verfügbarkeit des CTs, die vergleichsweise geringen Kosten und die fehlende Invasivität.

\section{Magnetresonanztomographie}

Die Angiographie mittels MRT (MRA) gelingt durch verschiedene Verfahren. So ist eine Darstellung der Arterien mit Hilfe von Kontrastmittel wie bei der CTA, aber auch eine Darstellung ohne die Gabe von Kontrastmittel möglich. Verfahren, die ohne Kontrastmittel auskommen, sind die Time-of-flight-Angiographie (TOF) und die Phasenkontrastangiographie. Bei beiden Formen handelt es sich um funktionelle Methoden, die Flussphänomene darstellen. Gefäßmorphologie oder -anatomie wird nicht abgebildet. Des Weiteren steht die Kontrastmittelangiographie mit Hilfe von gadoliniumhaltigen Kontrastmitteln zur Verfügung (contrast-enhanced MRA, kurz CE-MRA). Sie ist vom Prinzip her mit der CTA vergleichbar (Poeck und Hacke 2006, Wardlaw 2008). Auch 
die MRA ermöglicht wie die DSA die Evaluation einer Carotisstenose bezüglich ihres Stenosegrades mithilfe der Methoden nach NASCET, ECST und CC (siehe Methodenteil). Genau wie für die CTA wurde auch für die MRA diesbezüglich die Vergleichbarkeit zum Goldstandard DSA untersucht.

In ihrer prospektiven Studie geben Randoux et al. (2001) für die CE-MRA eine Sensitivität und Spezifität von $93 \%$ und 100\% für die Darstellung einer Arteria carotis interna-Stenose von über $70 \%$ an, beurteilen die Methode insgesamt aber etwas schlechter als die CTA (je 100\%). In ihrem Review kommt Wardlaw (2008) hingegen zu dem Schluss, dass die CE-MRA die höchste Sensitivität und Spezifität für die Erfassung von über 70\%igen Stenosen vor dem Doppler, der MRA und der CTA aufweist. Für die Differenzierung zwischen einer unter 70\%igen und einer 70-99\%igen Stenose findet man in der Literatur Angaben zur Sensitivität und Spezifität von 95\% und $90 \%$ für die MRA, die damit besser abschneidet als die Doppler-Sonographie. Für die Darstellung eines Verschlusses wird der MRA eine ähnlich gute Sensitivität und Spezifität wie dem Doppler-Ultraschall zugeschrieben (Nederkoorn et al. 2003). In ihrer Meta-Analyse ermittelten Wardlaw et al. (2006) bezüglich der Bildgebung aller Grade einer Carotisstenose (70-99\%, 50-69\%, 0-49\%, Verschluss) die höchste Sensitivität für die CE-MRA vor CTA, MRA und Ultraschall. Bei der Darstellung von Gefäßstenosen ist bei der MRA grundsätzlich der Aspekt des „flow void“ zu beachten. Fließt das Blut z.B. nach einer hochgradigen Stenose (>70\%) zu schnell für den MR-Scanner, so kommt es zu einem fehlenden Signal. Dieses Phänomen kann auch bereits bei geringgradigeren Stenosen auftreten und es besteht so eher die Gefahr, die Stenose zu überschätzen oder sogar als Gefäßverschluss zu interpretieren (Wardlaw 2008).

Ebenso wie die CTA ermöglicht auch die MRA durch die zusätzliche Darstellung der Gefäßwand die Beurteilung einer Carotisstenose über den Stenosegrad hinaus. Mithilfe der MRA lassen sich so viele Eigenschaften einer vulnerablen Plaque identifizieren (aktive Entzündung, dünne fibröse Kappe, ein großer nekrotischen Kern, endotheliale Denudation, oberflächliche Plättchenaggregation, eine eingerissene Plaque, eine über 90\%ige Stenose) (Saam et al. 2007). Verschiedene Plaquekomponenten kommen in den unterschiedlichen MR-Sequenzen unterschiedlich zur Darstellung. Aufgrund der verschiedenen Kombinationen von Signalintensitäten in den verschiedenen Wichtungen ist so eine Differenzierung möglich (siehe Tabelle 6).

\begin{tabular}{|l|l|l|l|l|}
\hline & T1W & PDW & T2W & TOF \\
\hline Thrombus & Hyper- bis isointens & Hypo- bis isointens & Hypo- bis isointens & Hyperintens \\
\hline Lipide & Hyperintens & Hyperintens & Hypointens & Isointens \\
\hline Fibrose & Isointens & Hyperintens & Iso bis hyperintens & Iso- bis hyperintens \\
\hline Calcium & Hypointens & Hypointens & Hypointens & Hypointens \\
\hline
\end{tabular}

Tab. 6 Darstellung der verschiedenen Plaquebestandteile je nach Wichtung im MRT, nach Fuster et al. (2005b) 
Ein nekrotischer Kern lässt sich mittels MRT mit einer Sensitivität und Spezifität von 85\% und $92 \%$ darstellen (Saam et al. 2007). Des Weiteren besteht eine gute Übereinstimmung der Messungen des Verhältnisses von fibröser Kappe zu nekrotischem Kern im MRT und an histologischen Schnitten von Endarteriektomiepräparaten. Mit dieser Messung lässt sich gut das Risiko einer Plaque, Komplikationen hervorzurufen, einschätzen. Denn je größer der nekrotische Kern und je dünner die fibröse Kappe ist, desto höher ist die Gefahr einer Plaqueruptur mit den entsprechenden Konsequenzen (Trivedi et al. 2004).

Auch für die MRT-Darstellung der Integrität der fibrösen Kappe (intakt und dick/intakt und dünn/rupturiert) fand sich eine gute Korrelation zur Histologie (Hatsukami et al. 2000). Die Sensitivität und Spezifität für die Identifikation einer dünnen oder rupturierten fibrösen Kappe liegen bei $81 \%$ und $90 \%$ (Saam et al. 2007).

Bezüglich eines oberflächlich an einer arteriosklerotischen Läsion gelegenen Thrombus lässt sich im MRT entsprechend der ablaufenden Organisation des Thrombus das Alter desselben über Veränderungen in der Signalintensität bestimmen (Saam et al. 2007).

Dass mittels der Identifizierung gefährdeter Plaques durch das MRT nicht nur eine Verbindung zur Histologie, sondern auch zur Klinik eines Patienten hergestellt werden kann, ließ sich bereits nachweisen. So konnte in retro- und prospektiven Studien gezeigt werden, dass die Plaques symptomatischer Patienten öfter größere hämorrhagische Areale, dünne oder sogar rupturierte fibröse Kappen und frische Thromben im MRT aufweisen als die Plaques asymptomatischer Kontrollgruppen (Takaya et al. 2006, U-King-Im et al. 2008, Saam et al. 2006). Das MRT ist somit zuverlässig in der Lage, anhand der Beschreibung einer arteriosklerotischen Läsion eine gewisse Prognose über die Symptomatik eines Patienten abzugeben.

Zur Darstellung aktiver Entzündung innerhalb einer Plaque im MRT als Grundlage des arteriosklerotischen Geschehens gibt es unterschiedliche Ansätze. Von besonderem Interesse ist diesbezüglich die Aktivität der Makrophagen. Eine Infiltration der Gefäßwand mit Makrophagen im Sinne einer ablaufenden Entzündung konnte bereits als Kontrastmittelanreicherung in derselben dargestellt werden (Kerwin et al. 2006) Von Nutzen zur Bildgebung der Makrophagen sind außerdem sogenannte UPSIOs (ultrasmall supraparamagnetic iron oxide). Diese Substanz wird nach der intravenösen Gabe von aktivierten Makrophagen aufgenommen und führt nach einigen Stunden zu einem Suszeptibilitätseffekt im MRT. Der Vergleich von symptomatischen und asymptomatischen Carotisplaques desselben Patienten mittels UPSIO zeigte, dass symptomatische Plaques signifikant mehr Entzündungsaktivität aufweisen als asymptomatische (Tang et al. 2006). Des Weiteren wurden einige Plaques identifiziert, die morphologisch nach den oben aufgeführten Kriterien als stabil eingeschätzt wurden, aber trotzdem große inflammatorische Aktivität beherbergten und so doch als "gefährlich" angesehen werden mussten. Außerdem ließ sich nachweisen, dass die symptomatischen Plaques zwar mehr UPSIO-Uptake zeigten, in den asymptomatischen kontralateralen Plaques derselben Patienten aber durchaus ebenfalls Entzündungsaktivität dargestellt werden konnte (Tang et al. 2006). Dank UPSIO kann also die morphologische Beschreibung der arteriosklerotischen Läsion um eine funktionelle Beschreibung 
erweitert werden. Diese Möglichkeiten der Darstellung unterstützen nicht nur die „Entzündungshypothese“, sondern auch das MRT als diesbezügliches bildgebendes Verfahren. Zusammenfassend ist mittels MRT die Bestimmung des Grades einer Stenose der Arteria carotis interna möglich, darüber hinaus bietet es durch seine gute Weichteildarstellung und der Möglichkeit des Einsatzes spezifischer Substanzen wie UPSIO eine sehr gute Darstellbarkeit des morphologischen und funktionellen Plaquegeschehens.

\section{Digitale Subtraktionsangiographie}

Bei der digitalen Subtraktionsangiographie (DSA) handelt es sich um eine dynamische Durchleuchtung mit der Hilfe von Röntgenstrahlen und der Applikation von Kontrastmittel. Die Arterien werden mittels der intraarteriellen Injektion eines jodhaltigen Kontrastmittels sichtbar gemacht. Das Kontrastmittel wird mit Hilfe eines Katheters, der über die Arteria femoralis eingebracht wird, selektiv in die darzustellenden Gefäße, wie die Arteria carotis, injiziert. Es handelt sich also um ein invasives Verfahren (Poeck und Hacke 2006). Im Anschluss wird das Bild vor der Kontrastmittelinjektion von dem Bild nach der Kontrastmittelinjektion elektronisch subtrahiert. Auf diese Weise bleibt nur das gewünschte Gefäß dargestellt und man erhält ein Bild, das die anatomischen Verhältnisse wiedergibt (Wardlaw 2008). Bei der DSA wird die Arteria carotis in definierte Ebenen dargestellt.

In den Endarteriektomie-Studien NASCET, ECST und CC (siehe Methodenteil) wurde die DSA zur Quantifizierung von Carotisstenosen benutzt und die gewonnenen Stenosegrade wurden mit dem nachfolgenden Risiko für das Auftreten ischämischer Komplikationen korreliert. Mit Hilfe der Daten wurden Empfehlungen für die Durchführung einer Carotis-TEA abgegeben (European Carotid Surgery Trialists' Collaborative Group 1998, Barnett et al. 1998). Aufgrund dessen wird die DSA gemeinhin als Goldstandard für die Darstellung von Gefäßstenosen der Arteria carotis und vor allem für deren Evaluation bezüglich des Stenosegrades und des Ischämierisikos angesehen (Wardlaw 2008). Es konnte gezeigt werden, dass das Risiko für das Auftreten eines cerebralen Ereignisses mit dem Grad der Carotisstenose ansteigt (Rothwell et al. 2000).

Über den Stenosegrad hinaus ließ sich außerdem ein Zusammenhang zwischen der Morphologie einer Carotisplaque in der DSA und ihrem Erscheinungsbild in der Histologie zeigen (Lovett et al. 2004). Je nachdem, ob sich eine Plaque in der DSA als glatt, irregulär begrenzt oder ulzeriert darstellt, setzt er sich aus unterschiedlichen histologischen Bestandteilen zusammen. So liegen bei in der DSA irregulär begrenzten und ulzerierten Läsionen in der histologischen Aufarbeitung eher eine Ruptur der fibrösen Kappe, Hämorrhagien, ein größerer lipidhaltiger Kern und weniger fibröses Gewebe vor. Sich in der DSA irregulär begrenzt oder ulzeriert darstellende Plaques gehören somit eher in die Gruppe der instabilen Läsionen als glatt begrenzte Plaques (Lovett et al. 2004). Es konnte außerdem eine Relation zwischen der Morphologie einer Plaque in der DSA und der Klinik eines Patienten gezeigt werden. So haben Stenosepatienten mit 
Oberflächenunregelmäßigkeiten in der DSA ein erhöhtes Risiko für das Auftreten eines ipsilateralen ischämischen Schlaganfalls (Rothwell et al. 2000).

Obwohl die DSA der Goldstandard zur Quantifizierung von Carotisstenosen ist, birgt sie aufgrund ihres invasiven Charakters Komplikationsrisiken. Mechanismen, die zu neurologischen Komplikationen als Folge der Durchführung einer DSA führen können, sind zum einen Thromboembolien, entweder ausgehend von dem benutzten Angiographie-Katheter selbst oder ausgelöst durch die Verletzung der arteriosklerotischen Plaque durch Manipulation mit dem Katheter. Zum anderen besteht die Gefahr von Dissektionen von Gefäßwänden, von Thrombozytenaktivierung, von Veränderungen der Gerinnungsfaktoren und von einer Neurotoxizität des Kontrastmittels (Willinsky et al. 2003).

Die Komplikationsrate der Angiographie liegt insgesamt bei 1,6\%. Für transiente und reversible neurologische Komplikationen besteht ein Risiko zwischen 0,4\% und 2,3\% und für das Auftreten bleibender neurologischer Komplikationen liegt das Risiko zwischen 0,1\% und 0,5\% (Willinsky et al. 2003). Die Komplikationsrate steigt mit dem Patientenalter, mit dem Vorliegen eines ischämischen Schlaganfalls oder einer Carotisstenose, mit einer längeren Durchleuchtungszeit und mit einer geringeren Erfahrung des Untersuchers an. Neben neurologischen Komplikationen kann es des Weiteren zu allergischen Hautreaktionen, Hämatomen an der Punktionsstelle und Nierenversagen kommen (Willinsky et al. 2003).

\section{Zusammenfassung und Vergleich der verschiedenen bildgebenden Verfahren}

Die Duplexsonographie ist weit verbreitet, günstig, einfach durchführbar und schnell erlernbar. Ein wichtiger Punkt ist außerdem die fehlende Strahlenbelastung für den Patienten und die mögliche Durchführung am Patientenbett. Die Sonographie stellt sowohl die Morphologie einer Plaque, als auch das Gefäßlumen dar. Der Stenosegrad wird über indirekte Zeichen, wie die Flussgeschwindigkeit innerhalb des Gefäßes abgeleitet. Es ergibt sich also eine funktionelle Einschätzung einer Carotisstenose. Mittels der Duplexsonographie ist nicht nur eine Beurteilung der Vulnerabilität einer Plaque über dessen Echogenität, sondern auch eine Einschätzung des kardiovaskulären Risikos durch die Messung der Intima-Media-Dicke möglich. Die Duplexsonographie ist jedoch sehr untersucherabhängig und kann durch Kalkplaques in ihren Möglichkeiten eingeschränkt werden. Sie kann vor allem zur ersten Evaluation eines stenoseverdächtigen Patienten benutzt werden.

In der CTA ist eine zuverlässige Einschätzung des Stenosegrades möglich. Darüber hinaus können Plaquebestandteile evaluiert werden, unter besonderer Berücksichtigung des in der CTA im Gegensatz zur MRA gut darstellbaren Calciums. Nicht möglich ist eine Beschreibung des inflammatorischen Geschehens innerhalb einer arteriosklerotischen Läsion. Die CTA ist in der genauen Einschätzung der Plaquezusammensetzung zwar der MRA unterlegen, bietet aber den 
Vorteil der weiten Verbreitung, selbst in peripheren Kliniken, und der kurzen Untersuchungszeit. Allerdings besteht eine Strahlenbelastung für den Patienten.

Auch mittels MRT besteht die Möglichkeit der Einschätzung des Stenosegrades. Ferner bietet diese Technik die relativ genaue Bildgebung der Bestandteile einer arteriosklerotischen Läsion und ist diesbezüglich aufgrund der besseren Weichteildarstellung in ihrer Genauigkeit dem CT überlegen. Im Gegensatz zum CT kann die MRT ferner eine funktionelle Darstellung des inflammatorischen Geschehens innerhalb einer arteriosklerotischen Plaque liefern (z.B. mittels UPSIO). In praktischer Hinsicht sind MRT-Geräte jedoch nicht so weit verbreitet wie CT-Geräte und brauchen lange Untersuchungszeiten. Das MRT ist daher vor allem in der Akutphase wenig geeignet. Von Vorteil ist die fehlende Strahlenbelastung.

Bei der DSA handelt es sich um den Goldstandard zur Darstellung und Einschätzung einer Carotisstenose. Über den Stenosegrad hinaus ist auch eine gewisse Einschätzung der Vulnerabilität einer Läsion durch gegebenenfalls vorhandene Irregularitäten der Plaque möglich. Allerdings bietet die DSA keine Darstellung der arteriosklerotischen Plaque an sich. Des Weiteren ist sie als invasives Verfahren mit gewissen Risiken für den Patienten verbunden.

\subsubsection{Inflammatorische Marker, unter besonderer Berücksichtigung des C-reaktiven Proteins}

Wie in der Einleitung dieser Arbeit dargestellt, ist das inflammatorische Geschehen innerhalb einer vulnerablen arteriosklerotischen Plaque komplex. Es wird durch die verschiedensten Zellen, Rezeptoren, Liganden, Stoffwechselprodukte und Botenstoffe initiert und aufrechterhalten. Aufgrund dessen gibt es neben der Bildgebung einer arteriosklerotischen Läsion den Ansatz, die Plasmalevel der beteiligten inflammatorischen Mediatoren als Marker für die Entzündungsaktivität der Plaque und somit für dessen Vulnerabilität zu benutzen.

Für eine Reihe von Markern wurde bereits der prognostische Wert für das Auftreten kardiovaskulärer Ereignisse gezeigt: P-Selektin, CAMs (cell adhesion molecules), IL-6 (Interleukin 6), TNF a (Tumor-Nekrose-Faktor a), CD40, Serum Amyloid A und Plasma Protein A (PAPP-A) (Blake und Ridker 2001, Spagnoli et al. 2007, Naghavi et al. 2003, Schillinger et al. 2005).

Von besonderem Interesse und am besten untersucht ist allerdings die Rolle des C-reaktiven Proteins (CRP), einem Akute-Phase-Protein (Blake und Ridker 2001). CRP wird hauptsächlich in der Leber synthetisiert. Es konnte jedoch gezeigt werden, dass Endothelien selbst in der Lage sind, CRP zu bilden. Niedrige Plasmalevel können so Ausdruck einer Produktion des CRP außerhalb der Leber sein (Blake und Ridker 2001).

In Studien wurde bereits der Stellenwert des CRP als stärkster Marker zur Einschätzung des kardiovaskulären Risikos für einen Myokardinfarkt, einen Schlaganfall, Tod aufgrund eines kardiovaskulären Ereignisses und eine periphere arterielle Verschlusskrankheit hervorgehoben 
(Blake und Ridker 2001, Spagnoli et al. 2007, Ridker 2005). Zum Beispiel konnte bei Patienten nach plötzlichem Herztod im Vergleich zu Patienten, die aus anderen als kardiovaskulären Gründen starben, ein erhöhter mittlerer CRP-Wert nachgewiesen werden. Auch für Patienten mit einer Carotisstenose ließ sich ein höheres CRP zeigen als für Patienten ohne eine solche. Dieser Zusammenhang konnte vor allem für Frauen ermittelt werden (Wang et al. 2002). Darüber hinaus lässt sich eine Beziehung zwischen den gemessenen CRP-Werten eines Patienten und seiner Intima-Media-Dicke im Ultraschall nachweisen (Wang et al. 2002, Van der Meer et al. 2002, Thakore et al. 2007). Ferner korreliert die Höhe des CRP-Wertes mit Veränderungen der Flussmessung des Gefäßes im Ultraschall über einen bestimmten Zeitraum. Im Verlauf kann ein steigendes CRP des Weiteren auf eine Zunahme der Stenose hindeuten (Schillinger et al. 2005). Bezüglich der Vulnerabilität einer Plaque ist zu erwähnen, dass bei Patienten mit höheren CRP-Werten öfter Läsionen mit einer dünnen fibrösen Kappe vorliegen als bei Patienten mit niedrigeren Werten (Virmani et al. 2006, Alvarez Garcia et al. 2003). Es konnte zusätzlich ein direkter Zusammenhang zwischen der Vulnerabilität einer Plaque und deren endogener CRP-Synthese hergestellt werden. So exprimieren ulzerierte vulnerable Plaques mehr CRP als nicht ulzerierte Plaques (Krupinski et al. 2006).

Außerdem ist das CRP bei Patienten mit einer symptomatischen Carotisstenose signifikant höher als dasjenige bei Patienten mit einer asymptomatischen Stenose (Rerkasem et al. 2002, Alvarez Garcia et al. 2003).

Von Nutzen ist die Erhebung des CRP-Wertes ferner bei der Planung interventioneller Maßnahmen. So sind vor einem Stenting der Arteria carotis interna erhöhte CRP-Werte mit einem erhöhten Schlaganfall- und Todesrisiko des Patienten nach der Prozedur assoziiert (Gröschel et al. 2007).

Fraglich ist letztendlich jedoch, ob das CRP selbst das arteriosklerotische Geschehen verursachen kann oder nur in dessen Folge ansteigt. Zur Klärung dieser Frage wurden Patienten mit genetisch bedingt erhöhten CRP-Werten auf ihr Herzinfarkt- und Schlaganfallrisiko hin untersucht. In der Studie waren erhöhte CRP-Werte aller Patienten zwar wiederum ein Marker für das Vorliegen kardiovaskulärer Erkrankungen, allerdings wurde kein erhöhtes Risiko für die Patientengruppe mit den genetisch determinierten, dauerhaft erhöhten CRP-Werten gefunden. Somit scheint das CRP als Marker für arteriosklerotische Läsionen von Nutzen zu sein, ist allerdings nicht kausal mit solchen verknüpft (Zacho et al. 2008).

\subsection{Bildgebung zervikaler Lymphknoten}

Die Bildgebung von Halslymphknoten erfolgt fast ausschließlich im Rahmen des Stagings von Kopf- und Halstumoren bzw. Lymphomen in dieser Lokalisation. Die onkologische Diagnostik umfasst den Ultraschall, das CT, das MRT und das FDG-PET-CT (Fluoro-Desoxy-GlucosePositronen-Emissions-Tomographie-CT) (Yoon et al. 2009). Die Charakterisierung der 
Lymphknoten zur Identifizierung solcher, die metastatisch befallen sind, geschieht über die gleichzeitige Einschätzung von Größe, intranodaler Architektur (Nekrosen, Zysten, Kalzifizierungen), Gruppierung zu anderen Lymphknoten und Begrenzung derselben (Van den Brekel et al. 1990, Gor et al. 2006). Die Studien zur Sensitivität und Spezifität der verschiedenen bildgebenden Verfahren beziehen sich so auf das Erkennen metastatisch befallener Lymphknoten und nicht auf die korrekte Einschätzung ihrer Größe, wie es für diese Arbeit relevant wäre. Die nachfolgenden Aussagen sind also in diesem Zusammenhang zu werten, lassen aber trotzdem Schlussfolgerungen für die vorliegende Arbeit zu.

Für die Einschätzung zervikaler Lymphknoten im CT liegen die Sensitivität und Spezifität bei 77\% und $99 \%$, im MRT bei $77 \%$ und $99 \%$ und im Ultraschall bei $78 \%$ und $98,5 \%$, also für alle drei Modalitäten in ähnlichen Bereichen (Yoon et al. 2009).

Im Ultraschall sind nicht alle Lymphknoten-Level darstellbar, insbesondere nicht Level IIB (Hohlweg-Majert et al. 2009). Des Weiteren kann der Ultraschall zu einem großen Anteil durch die Bestimmung der intranodalen Veränderungen eines Lymphknotens zur Diagnosefindung beitragen, wohingegen im CT mehr die Größe des Lymphknoten an Bedeutung gewinnt (Sumi et al. 2001). Bezüglich der Messung eines Lymphknotens ist der minimale axiale Durchmesser der zuverlässigste Wert zur Einschätzung beim Staging (Van den Brekel et al. 1990). Hieraus lässt sich ableiten, dass Lymphknotenvergrößerungen in erster Linie in dieser Ebene aufzutreten scheinen, so dass die in der vorliegenden Arbeit benutzte Messung dieses Durchmessers vermutlich am besten etwaige Größenveränderungen registriert hat.

CT und MRT sind zur Evaluation bei onkologischen Fragestellungen aufgrund ihrer guten anatomischen Auflösung, d.h. also auch zum Ausmessen von Lymphknoten, Methoden der Wahl. Im Ultraschall steht vor allen Dingen die Einschätzung der intranodalen Architektur im Vordergrund. Es handelt sich ferner um kein geeignetes Verfahren zur Beurteilung tiefer zervikaler Lymphknoten (Yoon et al. 2009). Somit erfüllt das CT am besten die geforderten Voraussetzungen zur Verwendung in der vorliegenden Studie.

\subsection{Grenzen der vorliegenden Arbeit}

\subsubsection{Statine (HMG-CoA-Reduktase-Inhibitoren)}

Statine senken über eine Hemmung der HMG-CoA-Reduktase (3-Hydroxy-3-MethylglutarylCoenzym-A-Reduktase) die Cholesterinbiosynthese und damit unter anderem die Synthese des LDL, welches eine große Rolle bei der Entstehung einer arteriosklerotischen Plaque spielt. Neben einer Abnahme der Lipide werden den Statinen zusätzliche antiinflammatorische Effekte zugeschrieben. So machte man die Beobachtung, dass Statine auf der einen Seite zu einer nur geringen Minderung des Grades einer arteriosklerotischen Stenose führen, auf der anderen Seite 
aber eine große Reduktion der Häufigkeit koronarer Ereignisse bewirken (Libby und Sasiela 2006). Weitere Ergebnisse zeigen, dass eine intensive Statin-Therapie bereits zu früh zu einer Reduktion kardiovaskulärer Ereignisse führt, als dass dies durch die alleinige Senkung des LDL-Spiegels zu erklären wäre (Cannon et al. 2004). Es muss also über die LDL-Senkung hinausgehende Effekte der Statine geben.

Diesbezüglich konnte eine weitere Studie zeigen, dass Patienten mit niedrigem LDL- und niedrigem CRP-Spiegel ein niedriges kardiovaskuläres Risiko besitzen und nicht von einer Therapie mit Statinen profitieren. Dahingegen haben Patienten mit einem erhöhten LDL-Spiegel ein erhöhtes kardiovaskuläres Risiko und profitieren von einer lipidsenkenden Therapie. Darüber hinaus konnte aber außerdem gezeigt werden, dass Patienten mit einem niedrigen LDL-Spiegel, aber einem erhöhten CRP-Spiegel ebenfalls ein erhöhtes kardiovaskuläres Risiko aufweisen und ähnlich wie die Patienten mit Hyperlipidämie von einer Statin-Therapie profitieren. Des Weiteren sind Statine unabhängig von den vorliegenden Lipid-Werten in der Lage, das CRP zu senken (Ridker et al. 2001). Das beste klinische Outcome zeigen solche Patienten, bei denen LDL und CRP gleichermaßen gesenkt werden können (Ridker 2005). Neben dem CRP sind Statine ferner in der Lage, weitere inflammatorische Marker wie IL-6, Serum-Amyloid A, ICAM-1 oder P-Selektin zu senken (Schönbeck und Libby 2004).

Statine beeinflussen eine arteriosklerotische Plaque auf fast allen Ebenen ihrer Entstehung. So hemmen sie über verschiedene Mechanismen die Adhäsion und Migration der Entzündungszellen durch das Endothel. Des Weiteren behindern Statine die Expression und Funktion verschiedener proinflammatorischer, in die Plaqueentstehung involvierter Zytokine und Chemokine. Ferner wird Statinen die Fähigkeit zugeschrieben, Apoptose zu induzieren. Bezüglich der Mechanismen, die zu der Ruptur einer Plaque führen, sind Statine in der Lage, Matrix-Metalloproteinasen zu hemmen und im Folgenden noch den Tissue Factor und die Thrombozyten antikoagulatorisch zu beeinflussen. Letztendlich sollen Statine auch die endotheliale Vasodilatation, die Blutviskosität und die Oxidierung des LDL beeinflussen (Schönbeck und Libby 2004).

Wie dargelegt, sind Statine in der Lage, arteriosklerotische Plaques zu stabilisieren und ihre Entzündungsaktivität zu hemmen. Deshalb ist es denkbar, dass die Ergebnisse der vorliegenden Studie durch Patienten, deren Medikation zum Zeitpunkt der CT-Untersuchung Statine beinhaltete, wie es bei vielen Gefäßpatienten der Fall ist, verfälscht worden sind. Leider ließ sich retrospektiv anhand der Entlassungsbriefe eine etwaige Statintherapie nicht mit Sicherheit ausschließen.

\subsubsection{Auswahl der Patienten}

Ein Bias der Studie war sicher die Tatsache, dass die Patienten ohne Carotisstenose zwar diesbezüglich gesund waren, jedoch in den meisten Fällen ebenfalls aus anderen Gründen hospitalisiert waren. Trotz der sehr strengen Ausschlusskriterien handelte es sich so um in irgendeiner Weise erkrankte Patienten. Es ist somit denkbar, dass andere Faktoren und 
Erkrankungen zu einer Lymphknotenvergrößerung und -vermehrung beigetragen haben könnten und die Unterschiede bezüglich der Carotisstenosen so verdeckt wurden. Andererseits spiegelt dieses Patientengut die alltägliche Situation in der radiologischen Praxis wider. Damit hätte der Einsatz „Vollkommen gesunder" Patienten als Kontrollgruppe die Nutzbarkeit der Lymphknoten in der CTA als prognostischer Marker verfälscht. 


\section{Zusammenfassung}

Der Schlaganfall ist die dritthäufigste Todesursache und die führende Ursache andauernder Invalidität (Poeck und Hacke 2006). Das frühzeitige Erkennen gefährdeter Patienten spielt eine entscheidende Rolle. Für arteriosklerotisch bedingte Carotisstenosen, die 10-20\% der Schlaganfälle bedingen (Kastrup et al. 2008), orientieren sich die Empfehlungen zur Therapie hauptsächlich am Grad der Stenose (Schellinger et al. 2008). Mechanismen, die zu Komplikationen einer Stenose führen, sind jedoch nicht nur die stetige Größenzunahme einer Plaque und der daraus resultierende eingeschränkte Blutfluss im Gefäß, sondern auch die durch entzündliche Prozesse hervorgerufene Instabilität und folgende Ruptur oder Erosion einer arteriosklerotischen Läsion, die nachfolgend zur Thrombusformation führen kann (Libby 2008). Die gebildeten Thromben verschließen das Gefäß entweder „an Ort und Stelle“ oder verursachen distale, cerebrale Embolien. An den unabhängig vom Stenosegrad ablaufenden Entzündungsvorgängen sind Lymphozyten, Makrophagen und Mastzellen beteiligt (Libby 2002), welche wiederum Lymphknotenschwellungen auslösen können. Lymphknotenvergrößerungen als Marker der Entzündungsaktivität innerhalb einer arteriosklerotischen Plaque, welche deren Vulnerabilität widerspiegelt, wären ein einfaches Mittel zur Stratifizierung des Risikos eines Patienten. Die vorliegende Arbeit hat den Effekt einer arteriosklerotisch bedingten Entzündung der Arteria carotis interna auf die Größe und Anzahl lokoregionaler Lymphknoten in der CTA, auch unter Berücksichtigung von Symptomatik, Plaquemorphologie, Stenosegrad und Begleiterkrankungen der Patienten, untersucht.

Zur Überprüfung der Hypothese wurde in den CTA-Bildern von 66 Patienten mit und ohne Carotisstenose retrospektiv die Anzahl und Größe aller Halslymphknoten ermittelt. Ferner wurden der Stenosegrad, das Vorliegen von Ulzerationen, die Symptomatik und die Vorerkrankungen der Patienten dokumentiert. Von der Analyse ausgeschlossen wurden nach Zusammentragen verschiedener laborchemischer und Verlaufsinformationen Patienten mit Hinweisen auf ein entzündliches oder tumoröses Geschehen oder ein kurz zuvor stattgehabtes Trauma oder eine Operation.

Die nachfolgende statistische Auswertung brachte weder für die unterschiedlichen Patientengruppen noch für die betrachteten unterschiedlichen Lymphknoten-Gruppen signifikante Ergebnisse. Es ließ sich kein Zusammenhang zwischen dem Vorliegen einer Carotisstenose und Lymphknotenvermehrungen oder -vergrößerungen in der CTA des Halses nachweisen.

Mögliche Gründe für das negative Ergebnis dieser Arbeit sind die Auswahl anderweitig erkrankter Patienten als Kontrollgruppe und die mögliche, nicht sicher auszuschließende Einnahme von Statinen der Patienten, da Statinen eine entzündungshemmende, plaquestabilisierende Wirkung nachgesagt wird (Schönbeck und Libby 2004).

Die Beurteilung von Lymphknoten in der CTA des Halses bietet also keine Möglichkeit, das Risiko eines Patienten mit Carotisstenose für einen Schlaganfall zu evaluieren. In der Literatur wird jedoch bereits von verschiedenen bildgebenden Verfahren (morphologisch/funktionell) als auch 
von Serummarkern (z.B. CRP) berichtet, die zur Einschätzung einer Carotisstenose bezüglich ihrer Vulnerabilität herangezogen werden (Lammie et al. 2000, Oliver et al. 1999, Saam et al. 2007, Tang et al. 2006, Blake und Ridker 2001). 


\section{Anhang}

\subsection{Tabellen}

Es folgen sämtliche zum Ergebnisteil gehörenden Tabellen zur Normalverteilung, deskriptiven Statistik und Signifikanztestung. Die Reihenfolge entspricht derjenigen des Ergebnisteils.

\section{„Carotisstenosen haben mehr LK auf der Seite der Stenose.“}

\section{Für alle Level, Level II-IV, Größe größte LK, Anzahl \& Größe Carotis-LK}

\begin{tabular}{|c|c|c|c|c|c|c|c|}
\hline \multicolumn{8}{|c|}{ Ein-Stichproben Kolmogorov-Smirnov Test } \\
\hline \multicolumn{3}{|l|}{ Stenose } & $\begin{array}{c}\text { Anzahl LK alle } \\
\text { Level }\end{array}$ & $\begin{array}{l}\text { Anzahl } \\
\text { LK II-IV }\end{array}$ & $\begin{array}{l}\text { größte LK: } \\
\text { Größe [mm] }\end{array}$ & $\begin{array}{c}\text { Carotis-LK: } \\
\text { Anzahl }\end{array}$ & $\begin{array}{l}\text { Carotis-LK: } \\
\text { Größe [mm] }\end{array}$ \\
\hline \multirow{8}{*}{ Gesund } & $\mathrm{N}$ & & 46 & 46 & 46 & 46 & 46 \\
\hline & Normalparameter ${ }^{\mathrm{a}}$ & Mittelwert & 30,43 & 18,57 & 17,391 & 6,35 & 28,600 \\
\hline & & Std.-Abweichung & 10,757 & 6,745 & 5,7900 & 3,497 & 16,3328 \\
\hline & Größte Differenzen & Absolut & 0,103 & 0,119 & 0,187 & 0,144 & 0,113 \\
\hline & & Positiv & 0,103 & 0,100 & 0,127 & 0,144 & 0,113 \\
\hline & & Negativ & $-0,063$ & $-0,119$ & $-0,187$ & $-0,096$ & $-0,097$ \\
\hline & Kolmogorov-Smirnov Z & & 0,699 & 0,808 & 1,270 & 0,979 & 0,767 \\
\hline & $\mathrm{p}$-Wert & & 0,713 & 0,530 & 0,080 & 0,293 & 0,598 \\
\hline \multirow[t]{8}{*}{ Stenose } & $\mathrm{N}$ & & 86 & 86 & 86 & 86 & 86 \\
\hline & Normalparameter $^{\mathrm{a}}$ & Mittelwert & 29,70 & 17,88 & 15,084 & 5,84 & 26,758 \\
\hline & & Standardabweichung & 12,557 & 8,778 & 7,0345 & 3,367 & 15,9798 \\
\hline & Größte Differenzen & Absolut & 0,111 & 0,166 & 0,182 & 0,180 & 0,161 \\
\hline & & Positiv & 0,111 & 0,166 & 0,142 & 0,180 & 0,161 \\
\hline & & Negativ & $-0,092$ & $-0,107$ & $-0,182$ & $-0,104$ & $-0,084$ \\
\hline & Kolmogorov-Smirnov Z & & 1,029 & 1,543 & 1,686 & 1,665 & 1,492 \\
\hline & $\mathrm{p}$-Wert & & 0,240 & 0,017 & 0,007 & 0,008 & 0,023 \\
\hline
\end{tabular}

a. Es besteht Normalverteilung.

Tab. 7 Prüfung der Normalverteilung zur Hypothese „Carotisstenosen haben mehr Lymphknoten auf der Seite der Stenose“ für alle Level, Level II-IV, Größe größte Lymphknoten, Anzahl und Größe CarotisLymphknoten

Beschreibende Statistik

\begin{tabular}{|c|c|c|c|c|c|c|}
\hline & Stenose & $\mathrm{N}$ & Minimum & Maximum & Mittelwert & Std.-Abweichung \\
\hline \multirow[t]{2}{*}{ Anzahl LK alle Level } & Gesund & 46 & 11 & 56 & 30,43 & 10,757 \\
\hline & Stenose & 86 & 13 & 70 & 29,70 & 12,557 \\
\hline \multirow[t]{2}{*}{ Anzahl LK II-IV } & Gesund & 46 & 7 & 36 & 18,57 & 6,745 \\
\hline & Stenose & 86 & 7 & 42 & 17,88 & 8,778 \\
\hline \multirow[t]{2}{*}{ größte LK: Größe [mm] } & Gesund & 46 & 0,0 & 24,0 & 17,391 & 5,7900 \\
\hline & Stenose & 86 & 0,0 & 24,7 & 15,084 & 7,0345 \\
\hline \multirow[t]{2}{*}{ Carotis-LK: Anzahl } & Gesund & 46 & 0 & 14 & 6,35 & 3,497 \\
\hline & Stenose & 86 & 0 & 13 & 5,84 & 3,367 \\
\hline \multirow[t]{2}{*}{ Carotis-LK: Größe [mm] } & Gesund & 46 & 0,0 & 60,6 & 28,600 & 16,3328 \\
\hline & Stenose & 86 & 0,0 & 63,4 & 26,758 & 15,9798 \\
\hline \multirow[t]{2}{*}{ Stichprobenumfang } & Gesund & 46 & & & & \\
\hline & Stenose & 86 & & & & \\
\hline
\end{tabular}

Tab. 8 Beschreibende Statistik zur Hypothese „Carotisstenosen haben mehr Lymphknoten auf der Seite der Stenose" für alle Level, Level II-IV, Größe größte Lymphknoten, Anzahl und Größe Carotis-Lymphknoten 


\begin{tabular}{|c|c|c|c|c|c|c|}
\hline \multicolumn{7}{|c|}{ ANOVA } \\
\hline & & Quadratsumme & Freiheitsgrad & $\begin{array}{c}\text { Mittlere } \\
\text { Quadratsumme }\end{array}$ & $\mathrm{F}$ & $\mathrm{p}$-Wert \\
\hline \multirow[t]{3}{*}{ Anzahl LK alle Level } & Zwischen den Gruppen & 16,283 & 1 & 16,283 & 0,114 & 0,736 \\
\hline & Innerhalb der Gruppen & 18609,444 & 130 & 143,150 & & \\
\hline & Total & 18625,727 & 131 & & & \\
\hline \multirow[t]{3}{*}{ Anzahl LK II-IV } & Zwischen den Gruppen & 13,919 & 1 & 13,919 & 0,210 & 0,647 \\
\hline & Innerhalb der Gruppen & 8596,142 & 130 & 66,124 & & \\
\hline & Total & 8610,061 & 131 & & & \\
\hline \multirow[t]{3}{*}{ größte LK: Größe [mm] } & Zwischen den Gruppen & 159,587 & 1 & 159,587 & 3,630 & 0,059 \\
\hline & Innerhalb der Gruppen & 5714,754 & 130 & 43,960 & & \\
\hline & Total & 5874,341 & 131 & & & \\
\hline \multirow[t]{3}{*}{ Carotis-LK: Anzahl } & Zwischen den Gruppen & 7,814 & 1 & 7,814 & 0,671 & 0,414 \\
\hline & Innerhalb der Gruppen & 1514,156 & 130 & 11,647 & & \\
\hline & Total & 1521,970 & 131 & & & \\
\hline \multirow[t]{3}{*}{ Carotis-LK: Größe [mm] } & Zwischen den Gruppen & 101,671 & 1 & 101,671 & 0,392 & 0,532 \\
\hline & Innerhalb der Gruppen & 33709,369 & 130 & 259,303 & & \\
\hline & Total & 33811,040 & 131 & & & \\
\hline
\end{tabular}

Tab. 9 Varianzanalyse zur Hypothese „Carotisstenosen haben mehr Lymphknoten auf der Seite der Stenose“ für alle Level, Level II-IV, Größe größte Lymphknoten, Anzahl und Größe Carotis-Lymphknoten

Für alle Level, Level II-IV, Größe größte LK, Anzahl \& Größe Carotis-LK, auf die Stenoseseite bezogen

\begin{tabular}{|c|c|c|c|c|c|c|c|}
\hline \multicolumn{8}{|c|}{ Ein-Stichproben Kolmogorov-Smirnov Test } \\
\hline \multicolumn{3}{|c|}{ Carotis Stenose / Gesund / Gesund mit Stenose } & \begin{tabular}{|c|} 
Anzahl LK \\
alle Level \\
pro Carotis
\end{tabular} & \begin{tabular}{|c|} 
Anzahl LK II- \\
IV pro \\
Carotis
\end{tabular} & $\begin{array}{l}\text { größte LK: } \\
\text { Größe pro } \\
\text { Carotis }\end{array}$ & $\begin{array}{l}\text { Carotis-LK: } \\
\text { Anzahl pro } \\
\text { Carotis }\end{array}$ & $\begin{array}{c}\text { Carotis-LK: } \\
\text { Größe pro } \\
\text { Carotis }\end{array}$ \\
\hline \multirow[t]{8}{*}{ Gesunde Carotis } & \multicolumn{2}{|l|}{$\mathrm{N}$} & 46 & 46 & 46 & 46 & 46 \\
\hline & \multirow[t]{2}{*}{ Normalparameter $^{\mathrm{a}}$} & Mittelwert & 15,22 & 9,28 & 8,696 & 3,17 & 14,3000 \\
\hline & & Std.-Abweichung & 5,951 & 3,868 & 5,6698 & 1,970 & 9,38611 \\
\hline & \multirow[t]{3}{*}{ Größte Differenzen } & Absolut & 0,093 & 0,132 & 0,118 & 0,137 & 0,105 \\
\hline & & Positiv & 0,080 & 0,132 & 0,118 & 0,137 & 0,105 \\
\hline & & Negativ & $-0,093$ & $-0,074$ & $-0,088$ & $-0,097$ & $-0,064$ \\
\hline & \multicolumn{2}{|c|}{ Kolmogorov-Smirnov Z } & 0,630 & 0,899 & 0,797 & 0,932 & 0,710 \\
\hline & \multicolumn{2}{|l|}{$\mathrm{p}$-Wert } & 0,822 & 0,395 & 0,549 & 0,350 & 0,694 \\
\hline \multirow{8}{*}{$\begin{array}{l}\text { Gesunde Carotis mit } \\
\text { Stenose auf anderer } \\
\text { Seite }\end{array}$} & \multicolumn{2}{|l|}{$\mathrm{N}$} & 28 & 28 & 28 & 28 & 28 \\
\hline & \multirow[t]{2}{*}{ Normalparameter ${ }^{a}$} & Mittlwert & 15,39 & 9,79 & 8,261 & 2,89 & 13,2000 \\
\hline & & Std.-Abweichung & 6,573 & 4,954 & 5,3244 & 1,729 & 7,83813 \\
\hline & \multirow[t]{3}{*}{ Größte Differenzen } & Absolut & 0,155 & 0,119 & 0,118 & 0,233 & 0,139 \\
\hline & & Positiv & 0,155 & 0,119 & 0,118 & 0,233 & 0,139 \\
\hline & & Negativ & $-0,072$ & $-0,109$ & $-0,105$ & $-0,132$ & $-0,124$ \\
\hline & \multicolumn{2}{|c|}{ Kolmogorov-Smirnov Z } & 0,822 & 0,628 & 0,625 & 1,233 & 0,735 \\
\hline & \multicolumn{2}{|l|}{$\mathrm{p}$-Wert } & 0,509 & 0,825 & 0,829 & 0,096 & 0,652 \\
\hline \multirow[t]{8}{*}{ Carotis-Stenose } & \multicolumn{2}{|l|}{$\mathrm{N}$} & 58 & 58 & 58 & 58 & 58 \\
\hline & \multirow[t]{2}{*}{ Normalparameter $^{\mathrm{a}}$} & Mittelwert & 14,59 & 8,53 & 7,195 & 2,93 & 13,4655 \\
\hline & & Std.-Abweichung & 6,728 & 4,500 & 4,7847 & 1,945 & 9,05820 \\
\hline & \multirow[t]{3}{*}{ Größte Differenzen } & Absolut & 0,115 & 0,151 & 0,124 & 0,176 & 0,124 \\
\hline & & Positiv & 0,115 & 0,151 & 0,123 & 0,176 & 0,124 \\
\hline & & Negativ & $-0,101$ & $-0,109$ & $-0,124$ & $-0,109$ & $-0,069$ \\
\hline & \multicolumn{2}{|c|}{ Kolmogorov-Smirnov Z } & 0,877 & 1,148 & 0,943 & 1,337 & 0,941 \\
\hline & \multicolumn{2}{|l|}{$\mathrm{p}$-Wert } & 0,425 & 0,144 & 0,336 & 0,056 & 0,339 \\
\hline
\end{tabular}

a. Es besteht Normalverteilung.

Tab. 10 Prüfung der Normalverteilung zur Hypothese „Carotisstenosen haben mehr Lymphknoten auf der Seite der Stenose" für alle Level, Level II-IV, Größe größte Lymphknoten, Anzahl und Größe CarotisLymphknoten auf die Stenoseseite bezogen 
Beschreibende Statistik

\begin{tabular}{|c|c|c|c|c|c|c|}
\hline & $\begin{array}{l}\text { Carotis Stenose / Gesund / } \\
\text { Gesund mit Stenose }\end{array}$ & $\mathrm{N}$ & Minimum & Maximum & Mittelwert & Std.-Abweichung \\
\hline \multirow{3}{*}{$\begin{array}{l}\text { Anzahl LK alle Level pro } \\
\text { Carotis }\end{array}$} & Gesunde Carotis & 46 & 4 & 29 & 15,22 & 5,951 \\
\hline & $\begin{array}{l}\text { Gesunde Carotis mit Stenose } \\
\text { auf anderer Seite }\end{array}$ & 28 & 5 & 31 & 15,39 & 6,573 \\
\hline & Carotis-Stenose & 58 & 6 & 35 & 14,59 & 6,728 \\
\hline \multirow[t]{3}{*}{ Anzahl LK II-IV pro Carotis } & Gesunde Carotis & 46 & 3 & 19 & 9,28 & 3,868 \\
\hline & $\begin{array}{l}\text { Gesunde Carotis mit Stenose } \\
\text { auf anderer Seite }\end{array}$ & 28 & 3 & 20 & 9,79 & 4,954 \\
\hline & Carotis-Stenose & 58 & 3 & 21 & 8,53 & 4,500 \\
\hline \multirow[t]{3}{*}{ größte LK: Größe pro Carotis } & Gesunde Carotis & 46 & 0,0 & 22,5 & 8,696 & 5,6698 \\
\hline & $\begin{array}{l}\text { Gesunde Carotis mit Stenose } \\
\text { auf anderer Seite }\end{array}$ & 28 & 0,0 & 15,9 & 8,261 & 5,3244 \\
\hline & Carotis-Stenose & 58 & 0,0 & 18,2 & 7,195 & 4,7847 \\
\hline \multirow[t]{3}{*}{ Carotis-LK: Anzahl pro Carotis } & Gesunde Carotis & 46 & 0 & 9 & 3,17 & 1,970 \\
\hline & $\begin{array}{l}\text { Gesunde Carotis mit Stenose } \\
\text { auf anderer Seite }\end{array}$ & 28 & 0 & 7 & 2,89 & 1,729 \\
\hline & Carotis-Stenose & 58 & 0 & 8 & 2,93 & 1,945 \\
\hline \multirow[t]{3}{*}{ Carotis-LK: Größe pro Carotis } & Gesunde Carotis & 46 & 0,00 & 41,70 & 14,3000 & 9,38611 \\
\hline & $\begin{array}{l}\text { Gesunde Carotis mit Stenose } \\
\text { auf anderer Seite }\end{array}$ & 28 & 0,00 & 28,40 & 13,2000 & 7,83813 \\
\hline & Carotis-Stenose & 58 & 0,00 & 42,00 & 13,4655 & 9,05820 \\
\hline \multirow[t]{3}{*}{ Stichprobenumfang } & Gesunde Carotis & 46 & & & & \\
\hline & $\begin{array}{l}\text { Gesunde Carotis mit Stenose } \\
\text { auf anderer Seite }\end{array}$ & 28 & & & & \\
\hline & Carotis-Stenose & 58 & & & & \\
\hline
\end{tabular}

Tab. 11 Beschreibende Statistik zur Hypothese „Carotisstenosen haben mehr Lymphknoten auf der Seite der Stenose" für alle Level, Level II-IV, Größe größte Lymphknoten, Anzahl und Größe Carotis-Lymphknoten auf die Stenoseseite bezogen

ANOVA

\begin{tabular}{|c|c|c|c|c|c|c|}
\hline & & Quadratsumme & Freiheitsgrad & $\begin{array}{c}\text { Mittlere } \\
\text { Quadratsumme }\end{array}$ & $\mathrm{F}$ & $p$-Wert \\
\hline \multirow[t]{3}{*}{ Anzahl LK alle Level pro Carotis } & Zwischen den Gruppen & 16,358 & 2 & \multirow{3}{*}{$\begin{array}{r}8,179 \\
41,400\end{array}$} & \multirow[t]{3}{*}{0,198} & \multirow[t]{3}{*}{0,821} \\
\hline & Innerhalb der Gruppen & 5340,574 & 129 & & & \\
\hline & Total & 5356,932 & 131 & & & \\
\hline \multirow[t]{3}{*}{ Anzahl LK II-IV pro Carotis } & Zwischen den Gruppen & 33,044 & 2 & 16,522 & \multirow[t]{3}{*}{0,856} & \multirow[t]{3}{*}{0,427} \\
\hline & Innerhalb der Gruppen & 2490,471 & 129 & 19,306 & & \\
\hline & Total & 2523,515 & 131 & & & \\
\hline \multirow[t]{3}{*}{ größte LK: Größe pro Carotis } & Zwischen den Gruppen & 61,351 & 2 & 30,675 & \multirow[t]{3}{*}{1,125} & \multirow[t]{3}{*}{0,328} \\
\hline & Innerhalb der Gruppen & 3516,954 & 129 & 27,263 & & \\
\hline & Total & 3578,305 & 131 & & & \\
\hline \multirow[t]{3}{*}{ Carotis-LK: Anzahl pro Carotis } & Zwischen den Gruppen & 1,981 & 2 & 0,991 & \multirow[t]{3}{*}{0,271} & \multirow[t]{3}{*}{0,763} \\
\hline & Innerhalb der Gruppen & 471,011 & 129 & 3,651 & & \\
\hline & Total & 472,992 & 131 & & & \\
\hline \multirow[t]{3}{*}{ Carotis-LK: Größe pro Carotis } & Zwischen den Gruppen & 26,749 & 2 & 13,374 & \multirow[t]{3}{*}{0,168} & \multirow[t]{3}{*}{0,846} \\
\hline & Innerhalb der Gruppen & 10300,151 & 129 & 79,846 & & \\
\hline & Total & 10326,900 & 131 & & & \\
\hline
\end{tabular}

Tab. 12 Varianzanalyse zur Hypothese „Carotisstenosen haben mehr Lymphknoten auf der Seite der Stenose“ für alle Level, Level II-IV, Größe größte Lymphknoten, Anzahl und Größe Carotis-Lymphknoten auf die Stenoseseite bezogen 


\section{"Symptomatische Carotisstenosen haben mehr LK auf der Seite der Stenose."}

\section{Alle Level, Level II-IV, Größe größter LK, Anzahl Carotis-LK, Größe Carotis-LK, bezogen auf Patienten}

Ein-Stichproben Kolmogorov-Smirnov Test

\begin{tabular}{|c|c|c|c|c|c|c|c|}
\hline \multicolumn{3}{|c|}{ klinische Symptomatik bei Gesund \& Stenose } & $\begin{array}{l}\text { Anzahl LK } \\
\text { alle Level }\end{array}$ & $\begin{array}{c}\text { Anzahl LK II- } \\
\text { IV }\end{array}$ & $\begin{array}{l}\text { größte LK: } \\
\text { Größe [mm] }\end{array}$ & $\begin{array}{l}\text { Carotis-LK: } \\
\text { Anzahl }\end{array}$ & $\begin{array}{l}\text { Carotis-LK: } \\
\text { Größe [mm] }\end{array}$ \\
\hline \multirow[t]{8}{*}{ Gesund } & \multicolumn{2}{|l|}{$\mathrm{N}$} & 23 & 23 & 23 & 23 & 23 \\
\hline & \multirow[t]{2}{*}{ Normalparameter ${ }^{\mathrm{a}}$} & Mittelwert & 30,43 & 18,57 & 17,391 & 6,35 & 28,600 \\
\hline & & Std.-Abweichung & 10,879 & 6,821 & 5,8554 & 3,537 & 16,5173 \\
\hline & \multirow[t]{3}{*}{ Größte Differenzen } & Absolut & 0,101 & 0,118 & 0,187 & 0,146 & 0,114 \\
\hline & & Positiv & 0,101 & 0,097 & 0,130 & 0,146 & 0,114 \\
\hline & & Negativ & $-0,064$ & $-0,118$ & $-0,187$ & $-0,095$ & $-0,095$ \\
\hline & \multicolumn{2}{|c|}{ Kolmogorov-Smirnov Z } & 0,483 & 0,564 & 0,896 & 0,702 & 0,545 \\
\hline & \multicolumn{2}{|l|}{$\mathrm{p}$-Wert } & 0,974 & 0,908 & 0,399 & 0,709 & 0,928 \\
\hline \multirow{8}{*}{$\begin{array}{l}\text { Stenose }+ \\
\text { asymptomatisch }\end{array}$} & \multicolumn{2}{|l|}{$\mathrm{N}$} & 12 & 12 & 12 & 12 & 12 \\
\hline & \multirow[t]{2}{*}{ Normalparameter ${ }^{\mathrm{a}}$} & Mittelwert & 29,33 & 17,33 & 13,450 & 6,67 & 28,775 \\
\hline & & Std.-Abweichung & 10,924 & 8,532 & 7,3204 & 2,934 & 13,3074 \\
\hline & \multirow[t]{3}{*}{ Größte Differenzen } & Absolut & 0,198 & 0,235 & 0,201 & 0,215 & 0,148 \\
\hline & & Positiv & 0,187 & 0,235 & 0,176 & 0,215 & 0,133 \\
\hline & & Negativ & $-0,198$ & $-0,178$ & $-0,201$ & $-0,122$ & $-0,148$ \\
\hline & \multicolumn{2}{|c|}{ Kolmogorov-Smirnov Z } & 0,686 & 0,815 & 0,695 & 0,745 & 0,514 \\
\hline & \multicolumn{2}{|l|}{$\mathrm{p}$-Wert } & 0,734 & 0,520 & 0,720 & 0,636 & 0,955 \\
\hline \multirow{8}{*}{$\begin{array}{l}\text { Stenose + } \\
\text { symptomatisch }\end{array}$} & \multicolumn{2}{|l|}{$\mathrm{N}$} & 31 & 31 & 31 & 31 & 31 \\
\hline & \multirow[t]{2}{*}{ Normalparameter ${ }^{\mathrm{a}}$} & Mittelwert & 29,84 & 18,10 & 15,716 & 5,52 & 25,977 \\
\hline & & Std.-Abweichung & 13,399 & 9,071 & 6,9981 & 3,539 & 17,1629 \\
\hline & \multirow[t]{3}{*}{ Größte Differenzen } & Absolut & 0,178 & 0,191 & 0,198 & 0,214 & 0,179 \\
\hline & & Positiv & 0,178 & 0,191 & 0,129 & 0,214 & 0,179 \\
\hline & & Negativ & $-0,104$ & $-0,111$ & $-0,198$ & $-0,128$ & $-0,101$ \\
\hline & \multicolumn{2}{|c|}{ Kolmogorov-Smirnov Z } & 0,990 & 1,064 & 1,101 & 1,193 & 0,996 \\
\hline & \multicolumn{2}{|l|}{$\mathrm{p}$-Wert } & 0,281 & 0,208 & 0,177 & 0,116 & 0,274 \\
\hline
\end{tabular}

a. Es besteht Normalverteilung.

Tab. 13 Prüfung der Normalverteilung zur Hypothese „Symptomatische Carotisstenosen haben mehr Lymphknoten auf der Seite der Stenose" für alle Level, Level II-IV, Größe größte Lymphknoten, Anzahl und Größe Carotis-Lymphknoten bezogen auf Patienten 
Beschreibende Statistik

\begin{tabular}{|c|c|c|c|c|c|c|}
\hline & $\begin{array}{l}\text { klinische Symptomatik bei } \\
\text { Gesund \& Stenose }\end{array}$ & $\mathrm{N}$ & Minimum & Maximum & Mittelwert & Std.-Abweichung \\
\hline \multirow[t]{3}{*}{ Anzahl LK alle Level } & Stenose + asymptomatisch & 12 & 14 & 49 & 29,33 & 10,924 \\
\hline & Stenose + symptomatisch & 31 & 13 & 70 & 29,84 & 13,399 \\
\hline & Gesund & 23 & 11 & 56 & 30,43 & 10,879 \\
\hline \multirow[t]{3}{*}{ Anzahl LK II-IV } & Stenose + asymptomatisch & 12 & 7 & 31 & 17,33 & 8,532 \\
\hline & Stenose + symptomatisch & 31 & 7 & 42 & 18,10 & 9,071 \\
\hline & Gesund & 23 & 7 & 36 & 18,57 & 6,821 \\
\hline \multirow[t]{3}{*}{ größte LK: Größe [mm] } & Stenose + asymptomatisch & 12 & 0,0 & 22,1 & 13,450 & 7,3204 \\
\hline & Stenose + symptomatisch & 31 & 0,0 & 24,7 & 15,716 & 6,9981 \\
\hline & Gesund & 23 & 0,0 & 24,0 & 17,391 & 5,8554 \\
\hline \multirow[t]{3}{*}{ Carotis-LK: Anzahl } & Stenose + asymptomatisch & 12 & 2 & 11 & 6,67 & 2,934 \\
\hline & Stenose + symptomatisch & 31 & 0 & 13 & 5,52 & 3,539 \\
\hline & Gesund & 23 & 0 & 14 & 6,35 & 3,537 \\
\hline \multirow[t]{3}{*}{ Carotis-LK: Größe [mm] } & Stenose + asymptomatisch & 12 & 8,1 & 51,2 & 28,775 & 13,3074 \\
\hline & Stenose + symptomatisch & 31 & 0,0 & 63,4 & 25,977 & 17,1629 \\
\hline & Gesund & 23 & 0,0 & 60,6 & 28,600 & 16,5173 \\
\hline \multirow[t]{3}{*}{ Stichprobenumfang } & Stenose + asymptomatisch & 12 & & & & \\
\hline & Stenose + symptomatisch & 31 & & & & \\
\hline & Gesund & 23 & & & & \\
\hline
\end{tabular}

Tab. 14 Beschreibende Statistik zur Hypothese „Symptomatische Carotisstenosen haben mehr Lymphknoten auf der Seite der Stenose“ für alle Level, Level II-IV, Größe größte Lymphknoten, Anzahl und Größe CarotisLymphknoten bezogen auf Patienten

\begin{tabular}{|c|c|c|c|c|c|c|}
\hline \multicolumn{7}{|c|}{ ANOVA } \\
\hline & & Quadratsumme & Freiheitsgrad & $\begin{array}{c}\text { Mittlere } \\
\text { Quadratsumme }\end{array}$ & $\mathrm{F}$ & $p$-Wert \\
\hline \multirow[t]{3}{*}{ Anzahl LK alle Level } & Zwischen den Gruppen & 10,351 & 2 & 5,176 & 0,035 & 0,966 \\
\hline & Innerhalb der Gruppen & 9302,512 & 63 & 147,659 & & \\
\hline & Total & 9312,864 & 65 & & & \\
\hline \multirow[t]{3}{*}{ Anzahl LK II-IV } & Zwischen den Gruppen & 12,002 & 2 & 6,001 & 0,088 & 0,916 \\
\hline & Innerhalb der Gruppen & 4293,029 & 63 & 68,143 & & \\
\hline & Total & 4305,030 & 65 & & & \\
\hline \multirow[t]{3}{*}{ größte LK: Größe [mm] } & Zwischen den Gruppen & 124,220 & 2 & 62,110 & 1,391 & 0,256 \\
\hline & Innerhalb der Gruppen & 2812,950 & 63 & 44,650 & & \\
\hline & Total & 2937,170 & 65 & & & \\
\hline \multirow[t]{3}{*}{ Carotis-LK: Anzahl } & Zwischen den Gruppen & 15,359 & 2 & 7,679 & 0,649 & 0,526 \\
\hline & Innerhalb der Gruppen & 745,626 & 63 & 11,835 & & \\
\hline & Total & 760,985 & 65 & & & \\
\hline \multirow[t]{3}{*}{ Carotis-LK: Größe [mm] } & Zwischen den Gruppen & 118,543 & 2 & 59,272 & 0,222 & 0,801 \\
\hline & Innerhalb der Gruppen & 16786,977 & 63 & 266,460 & & \\
\hline & Total & 16905,520 & 65 & & & \\
\hline
\end{tabular}

Tab. 15 Varianzanalyse zur Hypothese „Symptomatische Carotisstenosen haben mehr Lymphknoten auf der Seite der Stenose“ für alle Level, Level II-IV, Größe größte Lymphknoten, Anzahl und Größe CarotisLymphknoten bezogen auf Patienten 
Alle Level, Level II-IV, Größe größte LK, Anzahl Carotis-LK, Größe Carotis-LK pro Carotis

Ein-Stichproben Kolmogorov-Smirnov Test

\begin{tabular}{|c|c|c|c|c|c|c|c|}
\hline \multicolumn{3}{|c|}{ Klinische Symptomatik nach Carotiden } & \begin{tabular}{c|} 
Anzahl LK \\
alle Level \\
nach \\
Carotiden \\
und \\
Symptomatik \\
\end{tabular} & \begin{tabular}{|} 
Anzahl LK II- \\
IV nach \\
Carotiden \\
und \\
Symptomatik
\end{tabular} & \begin{tabular}{|c|} 
größte LK: \\
Größe nach \\
Carotiden \\
und \\
Symptomatik
\end{tabular} & $\begin{array}{c}\text { Carotis-LK: } \\
\text { Anzahl nach } \\
\text { Carotiden } \\
\text { und } \\
\text { Symptomatik }\end{array}$ & $\begin{array}{l}\text { Carotis-LK: } \\
\text { Größe nach } \\
\text { Carotiden } \\
\text { und } \\
\text { Symptomatik }\end{array}$ \\
\hline \multirow[t]{8}{*}{ Gesund } & \multicolumn{2}{|l|}{$\mathrm{N}$} & 46 & 46 & 46 & 46 & 46 \\
\hline & \multirow[t]{2}{*}{ Normalparameter $^{\mathrm{a}}$} & Mittlwert & 15,22 & 9,28 & 8,696 & 3,17 & 14,300 \\
\hline & & Std.-Abweichung & 5,951 & 3,868 & 5,6698 & 1,970 & 9,3861 \\
\hline & \multirow[t]{3}{*}{ Größte Differenzen } & Absolut & 0,093 & 0,132 & 0,118 & 0,137 & 0,105 \\
\hline & & Positiv & 0,080 & 0,132 & 0,118 & 0,137 & 0,105 \\
\hline & & Negativ & $-0,093$ & $-0,074$ & $-0,088$ & $-0,097$ & $-0,064$ \\
\hline & \multicolumn{2}{|c|}{ Kolmogorov-Smirnov Z } & 0,630 & 0,899 & 0,797 & 0,932 & 0,710 \\
\hline & \multicolumn{2}{|l|}{$\mathrm{p}$-Wert } & 0,822 & 0,395 & 0,549 & 0,350 & 0,694 \\
\hline \multirow{8}{*}{$\begin{array}{l}\text { Gesund mit } \\
\text { symptomatischer } \\
\text { Stenose auf der } \\
\text { Gegenseite }\end{array}$} & \multicolumn{2}{|l|}{$\mathrm{N}$} & 22 & 22 & 22 & 22 & 22 \\
\hline & \multirow[t]{2}{*}{ Normalparameter ${ }^{\mathrm{a}}$} & Mittelwert & 15,64 & 10,14 & 8,727 & 2,77 & 13,041 \\
\hline & & Std.-Abweichung & 6,765 & 4,843 & 5,1394 & 1,602 & 7,7044 \\
\hline & \multirow[t]{3}{*}{ Größte Differenzen } & Absolut & 0,141 & 0,157 & 0,140 & 0,231 & 0,144 \\
\hline & & Positiv & 0,141 & 0,157 & 0,140 & 0,231 & 0,144 \\
\hline & & Negativ & $-0,121$ & $-0,114$ & $-0,128$ & $-0,187$ & $-0,110$ \\
\hline & \multicolumn{2}{|c|}{ Kolmogorov-Smirnov Z } & 0,661 & 0,734 & 0,656 & 1,082 & 0,676 \\
\hline & \multicolumn{2}{|l|}{$\mathrm{p}$-Wert } & 0,774 & 0,654 & 0,783 & 0,192 & 0,750 \\
\hline \multirow{8}{*}{$\begin{array}{l}\text { Gesund mit } \\
\text { asymptomatischer } \\
\text { Stenose auf der } \\
\text { Gegenseite }\end{array}$} & \multicolumn{2}{|l|}{$\mathrm{N}$} & 6 & 6 & 6 & 6 & 6 \\
\hline & \multirow[t]{2}{*}{ Normalparameter $^{\mathrm{a}}$} & Mittelwert & 14,50 & 8,50 & 6,550 & 3,33 & 13,783 \\
\hline & & Std.-Abweichung & 6,317 & 5,612 & 6,1383 & 2,251 & 9,0517 \\
\hline & \multirow[t]{3}{*}{ Größte Differenzen } & Absolut & 0,198 & 0,234 & 0,190 & 0,226 & 0,287 \\
\hline & & Positiv & 0,198 & 0,234 & 0,190 & 0,226 & 0,287 \\
\hline & & Negativ & $-0,152$ & $-0,164$ & $-0,143$ & $-0,150$ & $-0,197$ \\
\hline & \multicolumn{2}{|c|}{ Kolmogorov-Smirnov Z } & 0,486 & 0,572 & 0,466 & 0,552 & 0,704 \\
\hline & \multicolumn{2}{|l|}{$\mathrm{p}$-Wert } & 0,972 & 0,899 & 0,982 & 0,920 & 0,704 \\
\hline \multirow{8}{*}{$\begin{array}{l}\text { Symptomatische } \\
\text { Stenose }\end{array}$} & \multicolumn{2}{|l|}{$\mathrm{N}$} & 40 & 40 & 40 & 40 & 40 \\
\hline & \multirow[t]{2}{*}{ Normalparameter $^{\mathrm{a}}$} & Mittelwert & 14,52 & 8,45 & 7,380 & 2,75 & 12,960 \\
\hline & & Std.-Abweichung & 7,289 & 4,663 & 4,6482 & 2,157 & 9,9652 \\
\hline & \multirow[t]{3}{*}{ Größte Differenzen } & Absolut & 0,174 & 0,172 & 0,137 & 0,211 & 0,161 \\
\hline & & Positiv & 0,174 & 0,172 & 0,119 & 0,211 & 0,161 \\
\hline & & Negativ & $-0,121$ & $-0,121$ & $-0,137$ & $-0,101$ & $-0,097$ \\
\hline & \multicolumn{2}{|c|}{ Kolmogorov-Smirnov Z } & 1,101 & 1,088 & 0,866 & 1,334 & 1,021 \\
\hline & \multicolumn{2}{|l|}{$p$-Wert } & 0,177 & 0,187 & 0,442 & 0,057 & 0,248 \\
\hline Asymptomatische & $\mathrm{N}$ & & 18 & 18 & 18 & 18 & 18 \\
\hline ose & Normalparameter $^{\mathrm{a}}$ & Mittelwert & 14,72 & 8,72 & 6,783 & 3,33 & 14,589 \\
\hline & & Std.-Abweichung & 5,464 & 4,240 & 5,1897 & 1,328 & 6,7347 \\
\hline & Größte Differenzen & Absolut & 0,148 & 0,184 & 0,173 & 0,210 & 0,133 \\
\hline & & Positiv & 0,141 & 0,184 & 0,173 & 0,210 & 0,133 \\
\hline & & Negativ & $-0,148$ & $-0,121$ & $-0,110$ & $-0,123$ & $-0,081$ \\
\hline & Kolmogorov-Smirno & & 0,628 & 0,781 & 0,734 & 0,892 & 0,566 \\
\hline & $p$-Wert & & 0,825 & 0,576 & 0,654 & 0,404 & 0,906 \\
\hline
\end{tabular}

a. Es besteht Normalverteilung. Lymphknoten auf der Seite der Stenose“ für alle Level, Level II-IV, Größe größte Lymphknoten, Anzahl und Größe Carotis-Lymphknoten pro Carotis 
Beschreibende Statistik

\begin{tabular}{|c|c|c|c|c|c|c|}
\hline & $\begin{array}{l}\text { Klinische Symptomatik nach } \\
\text { Carotiden }\end{array}$ & $\mathrm{N}$ & Minimum & Maximum & Mittelwert & Std.-Abweichung \\
\hline \multirow{5}{*}{$\begin{array}{l}\text { Anzahl LK alle Level nach } \\
\text { Carotiden und Symptomatik }\end{array}$} & Gesund & 46 & 4 & 29 & 15,22 & 5,951 \\
\hline & $\begin{array}{l}\text { Gesund mit symptomatischer } \\
\text { Stenose auf der Gegenseite }\end{array}$ & 22 & 5 & 31 & 15,64 & 6,765 \\
\hline & $\begin{array}{l}\text { Gesund mit asymptomatischer } \\
\text { Stenose auf der Gegenseite }\end{array}$ & 6 & 8 & 24 & 14,50 & 6,317 \\
\hline & Symptomatische Stenose & 40 & 6 & 35 & 14,52 & 7,289 \\
\hline & Asymptomatische Stenose & 18 & 6 & 25 & 14,72 & 5,464 \\
\hline \multirow{5}{*}{$\begin{array}{l}\text { Anzahl LK II-IV nach } \\
\text { Carotiden und Symptomatik }\end{array}$} & Gesund & 46 & 3 & 19 & 9,28 & 3,868 \\
\hline & $\begin{array}{l}\text { Gesund mit symptomatischer } \\
\text { Stenose auf der Gegenseite }\end{array}$ & 22 & 3 & 20 & 10,14 & 4,843 \\
\hline & $\begin{array}{l}\text { Gesund mit asymptomatischer } \\
\text { Stenose auf der Gegenseite }\end{array}$ & 6 & 3 & 18 & 8,50 & 5,612 \\
\hline & Symptomatische Stenose & 40 & 3 & 21 & 8,45 & 4,663 \\
\hline & Asymptomatische Stenose & 18 & 3 & 17 & 8,72 & 4,240 \\
\hline \multirow{5}{*}{$\begin{array}{l}\text { größte LK: Größe nach } \\
\text { Carotiden und Symptomatik }\end{array}$} & Gesund & 46 & 0,0 & 22,5 & 8,696 & 5,6698 \\
\hline & $\begin{array}{l}\text { Gesund mit symptomatischer } \\
\text { Stenose auf der Gegenseite }\end{array}$ & 22 & 0,0 & 15,9 & 8,727 & 5,1394 \\
\hline & $\begin{array}{l}\text { Gesund mit asymptomatischer } \\
\text { Stenose auf der Gegenseite }\end{array}$ & 6 & 0,0 & 15,1 & 6,550 & 6,1383 \\
\hline & Symptomatische Stenose & 40 & 0,0 & 18,2 & 7,380 & 4,6482 \\
\hline & Asymptomatische Stenose & 18 & 0,0 & 17,6 & 6,783 & 5,1897 \\
\hline \multirow{5}{*}{$\begin{array}{l}\text { Carotis-LK: Anzahl nach } \\
\text { Carotiden und Symptomatik }\end{array}$} & Gesund & 46 & 0 & 9 & 3,17 & 1,970 \\
\hline & $\begin{array}{l}\text { Gesund mit symptomatischer } \\
\text { Stenose auf der Gegenseite }\end{array}$ & 22 & 0 & 6 & 2,77 & 1,602 \\
\hline & $\begin{array}{l}\text { Gesund mit asymptomatischer } \\
\text { Stenose auf der Gegenseite }\end{array}$ & 6 & 1 & 7 & 3,33 & 2,251 \\
\hline & Symptomatische Stenose & 40 & 0 & 8 & 2,75 & 2,157 \\
\hline & Asymptomatische Stenose & 18 & 1 & 6 & 3,33 & 1,328 \\
\hline \multirow{5}{*}{$\begin{array}{l}\text { Carotis-LK: Größe nach } \\
\text { Jarotiden und Symptomatik }\end{array}$} & Gesund & 46 & 0,0 & 41,7 & 14,300 & 9,3861 \\
\hline & $\begin{array}{l}\text { Gesund mit symptomatischer } \\
\text { Stenose auf der Gegenseite }\end{array}$ & 22 & 0,0 & 28,4 & 13,041 & 7,7044 \\
\hline & $\begin{array}{l}\text { Gesund mit asymptomatischer } \\
\text { Stenose auf der Gegenseite }\end{array}$ & 6 & 4,4 & 26,2 & 13,783 & 9,0517 \\
\hline & Symptomatische Stenose & 40 & 0,0 & 42,0 & 12,960 & 9,9652 \\
\hline & Asymptomatische Stenose & 18 & 3,7 & 27,5 & 14,589 & 6,7347 \\
\hline \multirow[t]{5}{*}{ Stichprobenumfang } & Gesund & 46 & & & & \\
\hline & $\begin{array}{l}\text { Gesund mit symptomatischer } \\
\text { Stenose auf der Gegenseite }\end{array}$ & 22 & & & & \\
\hline & $\begin{array}{l}\text { Gesund mit asymptomatischer } \\
\text { Stenose auf der Gegenseite }\end{array}$ & 6 & & & & \\
\hline & Symptomatische Stenose & 40 & & & & \\
\hline & Asymptomatische Stenose & 18 & & & & \\
\hline
\end{tabular}

Tab. 17 Beschreibende Statistik zur Hypothese „Symptomatische Carotisstenosen haben mehr Lymphknoten auf der Seite der Stenose“ für alle Level, Level II-IV, Größe größte Lymphknoten, Anzahl und Größe CarotisLymphknoten pro Carotis 


\begin{tabular}{|c|c|c|c|c|c|c|}
\hline \multicolumn{7}{|c|}{ ANOVA } \\
\hline & & Quadratsumme & Freiheitsgrad & \begin{tabular}{c|} 
Mittlere \\
Quadratsumme
\end{tabular} & $\mathrm{F}$ & $\mathrm{p}$-Wert \\
\hline \multirow{3}{*}{$\begin{array}{l}\text { Anzahl LK alle Level nach } \\
\text { Carotiden und Symptomatik }\end{array}$} & Zwischen den Gruppen & 22,929 & 4 & \multirow{3}{*}{$\begin{array}{r}5,732 \\
42,000\end{array}$} & \multirow[t]{3}{*}{0,136} & \multirow[t]{3}{*}{0,969} \\
\hline & Innerhalb der Gruppen & 5334,003 & 127 & & & \\
\hline & Total & 5356,932 & 131 & & & \\
\hline \multirow{3}{*}{$\begin{array}{l}\text { Anzahl LK II-IV nach Carotiden } \\
\text { und Symptomatik }\end{array}$} & Zwischen den Gruppen & 46,587 & 4 & 11,647 & \multirow[t]{3}{*}{0,597} & \multirow[t]{3}{*}{0,665} \\
\hline & Innerhalb der Gruppen & 2476,928 & 127 & 19,503 & & \\
\hline & Total & 2523,515 & 131 & & & \\
\hline \multirow{3}{*}{$\begin{array}{l}\text { größte LK: Größe nach } \\
\text { Carotiden und Symptomatik }\end{array}$} & Zwischen den Gruppen & 88,118 & 4 & 22,030 & \multirow[t]{3}{*}{0,802} & \multirow[t]{3}{*}{0,526} \\
\hline & Innerhalb der Gruppen & 3490,187 & 127 & 27,482 & & \\
\hline & Total & 3578,305 & 131 & & & \\
\hline \multirow{3}{*}{$\begin{array}{l}\text { Carotis-LK: Anzahl nach } \\
\text { Carotiden und Symptomatik }\end{array}$} & Zwischen den Gruppen & 7,687 & 4 & 1,922 & \multirow[t]{3}{*}{0,525} & \multirow[t]{3}{*}{0,718} \\
\hline & Innerhalb der Gruppen & 465,306 & 127 & 3,664 & & \\
\hline & Total & 472,992 & 131 & & & \\
\hline \multirow{3}{*}{$\begin{array}{l}\text { Carotis-LK: Größe nach } \\
\text { Carotiden und Symptomatik }\end{array}$} & Zwischen den Gruppen & 62,285 & 4 & 15,571 & \multirow[t]{3}{*}{0,193} & \multirow[t]{3}{*}{0,942} \\
\hline & Innerhalb der Gruppen & 10264,615 & 127 & 80,824 & & \\
\hline & Total & 10326,900 & 131 & & & \\
\hline
\end{tabular}

Tab. 18 Varianzanalyse zur Hypothese „Symptomatische Carotisstenosen haben mehr Lymphknoten auf der Seite der Stenose" für alle Level, Level II-IV, Größe größte Lymphknoten, Anzahl und Größe CarotisLymphknoten pro Carotis 


\section{„Ulzerierte Carotisplaques haben mehr und/oder größere Lymphknoten (auf der Seite des Ulkus).“}

Alle Level, Level II-IV, Größe größte LK, Anzahl \& Größe Carotis-LK, bezogen auf Patienten

\begin{tabular}{|c|c|c|c|c|c|c|c|}
\hline \multicolumn{8}{|c|}{ Ein-Stichproben Kolmogorov-Smirnov Test } \\
\hline \multicolumn{3}{|l|}{ Ulzeration } & $\begin{array}{l}\text { Anzahl LK } \\
\text { alle Level }\end{array}$ & $\begin{array}{c}\text { Anzahl LK II- } \\
\text { IV }\end{array}$ & $\begin{array}{l}\text { größte LK: } \\
\text { Größe }[\mathrm{mm}]\end{array}$ & $\begin{array}{l}\text { Carotis-LK: } \\
\text { Anzahl }\end{array}$ & $\begin{array}{l}\text { Carotis-LK: } \\
\text { Größe [mm] }\end{array}$ \\
\hline \multirow[t]{8}{*}{ Gesund } & \multicolumn{2}{|l|}{$N$} & 23 & 23 & 23 & 23 & 23 \\
\hline & \multirow[t]{2}{*}{ Normalparameter ${ }^{\mathrm{a}}$} & Mittelwert & 30,43 & 18,57 & 17,391 & 6,35 & 28,600 \\
\hline & & Std.-Abweichung & 10,879 & 6,821 & 5,8554 & 3,537 & 16,5173 \\
\hline & \multirow[t]{3}{*}{ Größte Differenzen } & Absolut & 0,101 & 0,118 & 0,187 & 0,146 & 0,114 \\
\hline & & Positiv & 0,101 & 0,097 & 0,130 & 0,146 & 0,114 \\
\hline & & Negativ & $-0,064$ & $-0,118$ & $-0,187$ & $-0,095$ & $-0,095$ \\
\hline & \multicolumn{2}{|c|}{ Kolmogorov-Smirnov Z } & 0,483 & 0,564 & 0,896 & 0,702 & 0,545 \\
\hline & \multicolumn{2}{|l|}{$p$-Wert } & 0,974 & 0,908 & 0,399 & 0,709 & 0,928 \\
\hline \multirow{8}{*}{$\begin{array}{l}\text { Stenose ohne } \\
\text { Ulkus }\end{array}$} & \multicolumn{2}{|l|}{$N$} & 19 & 19 & 19 & 19 & 19 \\
\hline & \multirow[t]{2}{*}{ Normalparameter ${ }^{\mathrm{a}}$} & Mittelwert & 27,63 & 17,00 & 16,032 & 5,53 & 25,358 \\
\hline & & Std.-Abweichung & 11,534 & 8,609 & 5,6578 & 3,323 & 15,3240 \\
\hline & \multirow[t]{3}{*}{ Größte Differenzen } & Absolut & 0,203 & 0,178 & 0,202 & 0,203 & 0,196 \\
\hline & & Positiv & 0,203 & 0,178 & 0,124 & 0,203 & 0,196 \\
\hline & & Negativ & $-0,119$ & $-0,123$ & $-0,202$ & $-0,144$ & $-0,130$ \\
\hline & \multicolumn{2}{|c|}{ Kolmogorov-Smirnov Z } & 0,883 & 0,775 & 0,879 & 0,886 & 0,852 \\
\hline & \multicolumn{2}{|l|}{$\mathrm{p}$-Wert } & 0,417 & 0,585 & 0,422 & 0,412 & 0,462 \\
\hline \multirow[t]{8}{*}{ Ulkus } & \multicolumn{2}{|l|}{$\mathrm{N}$} & 24 & 24 & 24 & 24 & 24 \\
\hline & \multirow[t]{2}{*}{ Normalparameter ${ }^{a}$} & Mittelwert & 31,33 & 18,58 & 14,333 & 6,08 & 27,867 \\
\hline & & Std.-Abweichung & 13,451 & 9,122 & 8,0657 & 3,488 & 16,8871 \\
\hline & \multirow[t]{3}{*}{ Größte Differenzen } & Absolut & 0,143 & 0,153 & 0,185 & 0,205 & 0,145 \\
\hline & & Positiv & 0,143 & 0,153 & 0,165 & 0,205 & 0,145 \\
\hline & & Negativ & $-0,086$ & $-0,102$ & $-0,185$ & $-0,129$ & $-0,074$ \\
\hline & \multicolumn{2}{|c|}{ Kolmogorov-Smirnov Z } & 0,703 & 0,750 & 0,907 & 1,006 & 0,713 \\
\hline & \multicolumn{2}{|l|}{$\mathrm{p}-$ Wert } & 0,707 & 0,627 & 0,383 & 0,264 & 0,690 \\
\hline
\end{tabular}

a. Es besteht Normalverteilung.

Tab. 19 Prüfung der Normalverteilung zur Hypothese „Ulzerierte Carotisplaques haben mehr und/oder größere Lymphknoten (auf der Seite des Ulkus)“ für alle Level, Level II-IV, Größe größte Lymphknoten, Anzahl und Größe Carotis-Lymphknoten bezogen auf Patienten 


\begin{tabular}{|ll|r|r|r|r|r|}
\hline \multicolumn{1}{|c|}{ Beschreibende Statistik } \\
\hline Anzahl LK alle Level & Ulzeration & Minimum & Maximum & Mittelwert & Std.-Abweichung \\
& Gesund & 23 & 11 & 56 & 30,43 & 10,879 \\
& Stenose ohne Ulkus & 19 & 14 & 51 & 27,63 & 11,534 \\
& Ulkus & 24 & 13 & 70 & 31,33 & 13,451 \\
\hline Anzahl LK II-IV & Gesund & 23 & 7 & 36 & 18,57 & 6,821 \\
& Stenose ohne Ulkus & 19 & 7 & 36 & 17,00 & 8,609 \\
& Ulkus & 24 & 7 & 42 & 18,58 & 9,122 \\
\hline größte LK: Größe [mm] & Gesund & 23 & 0,0 & 24,0 & 17,391 & 5,8554 \\
& Stenose ohne Ulkus & 19 & 5,2 & 23,2 & 16,032 & 5,6578 \\
& Ulkus & 24 & 0,0 & 24,7 & 14,333 & 8,0657 \\
\hline Carotis-LK: Anzahl & Gesund & 23 & 0 & 14 & 6,35 & 3,537 \\
& Stenose ohne Ulkus & 19 & 2 & 13 & 5,53 & 3,323 \\
& Ulkus & 24 & 0 & 12 & 6,08 & 3,488 \\
\hline Carotis-LK: Größe [mm] & Gesund & 23 & 0,0 & 60,6 & 28,600 & 16,5173 \\
& Stenose ohne Ulkus & 19 & 8,1 & 60,5 & 25,358 & 15,3240 \\
& Ulkus & 24 & 0,0 & 63,4 & 27,867 & 16,8871 \\
\hline Gtichprobenumfang & Gesund & 23 & & & & \\
& Stenose ohne Ulkus & 19 & & & & \\
& Ulkus & 24 & & & & \\
\hline
\end{tabular}

Tab. 20 Beschreibende Statistik zur Hypothese „Ulzerierte Carotisplaques haben mehr und/oder größere Lymphknoten (auf der Seite des Ulkus)“ für alle Level, Level II-IV, Größe größte Lymphknoten, Anzahl und Größe Carotis-Lymphknoten bezogen auf Patienten

ANOVA

\begin{tabular}{|c|c|c|c|c|c|c|}
\hline & & Quadratsumme & Freiheitsgrad & $\begin{array}{c}\text { Mittlere } \\
\text { Quadratsumme }\end{array}$ & $\mathrm{F}$ & $\mathrm{p}$-Wert \\
\hline \multirow[t]{3}{*}{ Anzahl LK alle Level } & Zwischen den Gruppen & 153,457 & 2 & 76,729 & \multirow[t]{3}{*}{0,528} & \multirow[t]{3}{*}{0,593} \\
\hline & Innerhalb der Gruppen & 9159,407 & 63 & 145,387 & & \\
\hline & Total & 9312,864 & 65 & & & \\
\hline \multirow[t]{3}{*}{ Anzahl LK II-IV } & Zwischen den Gruppen & 33,545 & 2 & 16,772 & \multirow[t]{3}{*}{0,247} & \multirow[t]{3}{*}{0,782} \\
\hline & Innerhalb der Gruppen & 4271,486 & 63 & 67,801 & & \\
\hline & Total & 4305,030 & 65 & & & \\
\hline \multirow[t]{3}{*}{ größte LK: Größe [mm] } & Zwischen den Gruppen & 110,378 & 2 & 55,189 & \multirow[t]{3}{*}{1,230} & \multirow[t]{3}{*}{0,299} \\
\hline & Innerhalb der Gruppen & 2826,793 & 63 & 44,870 & & \\
\hline & Total & 2937,170 & 65 & & & \\
\hline \multirow[t]{3}{*}{ Carotis-LK: Anzahl } & Zwischen den Gruppen & 7,197 & 2 & 3,599 & \multirow[t]{3}{*}{0,301} & \multirow[t]{3}{*}{0,741} \\
\hline & Innerhalb der Gruppen & 753,788 & 63 & 11,965 & & \\
\hline & Total & 760,985 & 65 & & & \\
\hline \multirow[t]{3}{*}{ Carotis-LK: Größe [mm] } & Zwischen den Gruppen & 117,580 & 2 & 58,790 & \multirow[t]{3}{*}{0,221} & \multirow[t]{3}{*}{0,803} \\
\hline & Innerhalb der Gruppen & 16787,940 & 63 & 266,475 & & \\
\hline & Total & 16905,520 & 65 & & & \\
\hline
\end{tabular}

Tab. 21 Varianzanalyse zur Hypothese „Ulzerierte Carotisplaques haben mehr und/oder größere Lymphknoten (auf der Seite des Ulkus)“ für alle Level, Level II-IV, Größe größte Lymphknoten, Anzahl und Größe Carotis-Lymphknoten bezogen auf Patienten 
Alle Level, Level II-IV, Größe größte LK, Anzahl \& Größe Carotis-LK, bezogen auf Carotiden

\begin{tabular}{|c|c|c|c|c|c|c|c|}
\hline \multicolumn{8}{|c|}{ Ein-Stichproben Kolmogorov-Smirnov Test } \\
\hline \multicolumn{3}{|c|}{ Ulzeration/Gesund nach Carotiden } & $\begin{array}{l}\text { Anzahl LK } \\
\text { alle Level } \\
\text { nach } \\
\text { Carotiden } \\
\text { und } \\
\text { Ulzeration }\end{array}$ & $\begin{array}{l}\text { Anzahl LK II- } \\
\text { IV nach } \\
\text { Carotiden } \\
\text { und } \\
\text { Ulzeration }\end{array}$ & $\begin{array}{c}\text { größte LK: } \\
\text { Größe nach } \\
\text { Carotiden } \\
\text { und } \\
\text { Ulzeration }\end{array}$ & $\begin{array}{l}\text { Carotis-LK: } \\
\text { Anzahl nach } \\
\text { Carotiden } \\
\text { und } \\
\text { Ulzeration }\end{array}$ & $\begin{array}{c}\text { Carotis-LK: } \\
\text { Größe nach } \\
\text { Carotiden } \\
\text { und } \\
\text { Ulzeration }\end{array}$ \\
\hline \multirow[t]{8}{*}{ Gesunde Carotis } & \multicolumn{2}{|l|}{$\mathrm{N}$} & 74 & 74 & 74 & 74 & 74 \\
\hline & \multirow[t]{2}{*}{ Normalparameter $^{a}$} & Mittelwert & 15,28 & 9,47 & 8,531 & 3,07 & 13,884 \\
\hline & & Std.-Abweichung & 6,150 & 4,285 & 5,5088 & 1,875 & 8,7931 \\
\hline & \multirow[t]{3}{*}{ Größte Differenzen } & Absolut & 0,099 & 0,118 & 0,101 & 0,175 & 0,112 \\
\hline & & Positiv & 0,099 & 0,118 & 0,101 & 0,175 & 0,112 \\
\hline & & Negativ & $-0,066$ & $-0,071$ & $-0,068$ & $-0,109$ & $-0,061$ \\
\hline & \multicolumn{2}{|c|}{ Kolmogorov-Smirnov Z } & 0,856 & 1,011 & 0,872 & 1,505 & 0,963 \\
\hline & \multicolumn{2}{|l|}{$p$-Wert } & 0,457 & 0,258 & 0,432 & 0,022 & 0,312 \\
\hline \multirow{8}{*}{$\begin{array}{l}\text { Stenosierte Carotis } \\
\text { ohne Ulkus }\end{array}$} & \multicolumn{2}{|l|}{$\mathrm{N}$} & 30 & 30 & 30 & 30 & 30 \\
\hline & \multirow[t]{2}{*}{ Normalparameter $^{\mathrm{a}}$} & Mittelwert & 13,10 & 8,07 & 7,283 & 2,80 & 12,603 \\
\hline & & Std.-Abweichung & 5,833 & 4,093 & 4,8650 & 1,901 & 8,1643 \\
\hline & \multirow[t]{3}{*}{ Größte Differenzen } & Absolut & 0,169 & 0,143 & 0,133 & 0,225 & 0,161 \\
\hline & & Positiv & 0,169 & 0,143 & 0,133 & 0,225 & 0,161 \\
\hline & & Negativ & $-0,112$ & $-0,127$ & $-0,101$ & $-0,105$ & $-0,071$ \\
\hline & \multicolumn{2}{|c|}{ Kolmogorov-Smirnov Z } & 0,926 & 0,784 & 0,727 & 1,231 & 0,883 \\
\hline & \multicolumn{2}{|l|}{$\mathrm{p}$-Wert } & 0,357 & 0,570 & 0,665 & 0,096 & 0,417 \\
\hline \multirow{8}{*}{$\begin{array}{l}\text { Stenosierte Carotis } \\
\text {,nit Ulkus }\end{array}$} & \multicolumn{2}{|l|}{$\mathrm{N}$} & 28 & 28 & 28 & 28 & 28 \\
\hline & \multirow[t]{2}{*}{ Normalparameter ${ }^{a}$} & Mittelwert & 16,18 & 9,04 & 7,100 & 3,07 & 14,389 \\
\hline & & Std.-Abweichung & 7,344 & 4,925 & 4,7844 & 2,017 & 9,9957 \\
\hline & \multirow[t]{3}{*}{ Größte Differenzen } & Absolut & 0,136 & 0,196 & 0,159 & 0,167 & 0,122 \\
\hline & & Positiv & 0,136 & 0,196 & 0,156 & 0,167 & 0,122 \\
\hline & & Negativ & $-0,106$ & $-0,110$ & $-0,159$ & $-0,119$ & $-0,081$ \\
\hline & \multicolumn{2}{|c|}{ Kolmogorov-Smirnov Z } & 0,720 & 1,037 & 0,843 & 0,882 & 0,648 \\
\hline & \multicolumn{2}{|l|}{$\mathrm{p}$-Wert } & 0,677 & 0,232 & 0,475 & 0,418 & 0,795 \\
\hline
\end{tabular}

a. Es besteht Normalverteilung.

Tab. 22 Prüfung der Normalverteilung zur Hypothese „Ulzerierte Carotisplaques haben mehr und/oder größere Lymphknoten (auf der Seite des Ulkus)“ für alle Level, Level II-IV, Größe größte Lymphknoten, Anzahl und Größe Carotis-Lymphknoten bezogen auf Carotiden 


\begin{tabular}{|c|c|c|c|c|c|c|}
\hline \multicolumn{7}{|c|}{ Beschreibende Statistik } \\
\hline & $\begin{array}{l}\text { Ulzeration/Gesund nach } \\
\text { Carotiden }\end{array}$ & $\mathrm{N}$ & Minimum & Maximum & Mittelwert & Std.-Abweichung \\
\hline \multirow{3}{*}{$\begin{array}{l}\text { Anzahl LK alle Level nach } \\
\text { Carotiden und Ulzeration }\end{array}$} & Gesunde Carotis & 74 & 4 & 31 & 15,28 & 6,150 \\
\hline & $\begin{array}{l}\text { Stenosierte Carotis ohne } \\
\text { Ulkus }\end{array}$ & 30 & 6 & 28 & 13,10 & 5,833 \\
\hline & Stenosierte Carotis mit Ulkus & 28 & 7 & 35 & 16,18 & 7,344 \\
\hline \multirow{3}{*}{$\begin{array}{l}\text { Anzahl LK II-IV nach } \\
\text { Carotiden und Ulzeration }\end{array}$} & Gesunde Carotis & 74 & 3 & 20 & 9,47 & 4,285 \\
\hline & $\begin{array}{l}\text { Stenosierte Carotis ohne } \\
\text { Ulkus }\end{array}$ & 30 & 3 & 19 & 8,07 & 4,093 \\
\hline & Stenosierte Carotis mit Ulkus & 28 & 3 & 21 & 9,04 & 4,925 \\
\hline \multirow{3}{*}{$\begin{array}{l}\text { größte LK: Größe nach } \\
\text { Carotiden und Ulzeration }\end{array}$} & Gesunde Carotis & 74 & 0,0 & 22,5 & 8,531 & 5,5088 \\
\hline & $\begin{array}{l}\text { Stenosierte Carotis ohne } \\
\text { Ulkus }\end{array}$ & 30 & 0,0 & 18,2 & 7,283 & 4,8650 \\
\hline & Stenosierte Carotis mit Ulkus & 28 & 0,0 & 17,6 & 7,100 & 4,7844 \\
\hline \multirow{3}{*}{$\begin{array}{l}\text { Carotis-LK: Anzahl nach } \\
\text { Carotiden und Ulzeration }\end{array}$} & Gesunde Carotis & 74 & 0 & 9 & 3,07 & 1,875 \\
\hline & $\begin{array}{l}\text { Stenosierte Carotis ohne } \\
\text { Ulkus }\end{array}$ & 30 & 0 & 8 & 2,80 & 1,901 \\
\hline & Stenosierte Carotis mit Ulkus & 28 & 0 & 8 & 3,07 & 2,017 \\
\hline \multirow{3}{*}{$\begin{array}{l}\text { Carotis-LK: Größe nach } \\
\text { Carotiden und Ulzeration }\end{array}$} & Gesunde Carotis & 74 & 0,0 & 41,7 & 13,884 & 8,7931 \\
\hline & $\begin{array}{l}\text { Stenosierte Carotis ohne } \\
\text { Ulkus }\end{array}$ & 30 & 0,0 & 32,1 & 12,603 & 8,1643 \\
\hline & Stenosierte Carotis mit Ulkus & 28 & 0,0 & 42,0 & 14,389 & 9,9957 \\
\hline \multirow[t]{3}{*}{ Stichprobenumfang } & Gesunde Carotis & 74 & & & & \\
\hline & $\begin{array}{l}\text { Stenosierte Carotis ohne } \\
\text { Ulkus }\end{array}$ & 30 & & & & \\
\hline & Stenosierte Carotis mit Ulkus & 28 & & & & \\
\hline
\end{tabular}

Tab. 23 Beschreibende Statistik zur Hypothese „Ulzerierte Carotisplaques haben mehr und/oder größere Lymphknoten (auf der Seite des Ulkus)“ für alle Level, Level II-IV, Größe größte Lymphknoten, Anzahl und Größe Carotis-Lymphknoten bezogen auf Carotiden

ANOVA

\begin{tabular}{|c|c|c|c|c|c|c|}
\hline & & Quadratsumme & Freiheitsgrad & $\begin{array}{c}\text { Mittlere } \\
\text { Quadratsumme }\end{array}$ & $\mathrm{F}$ & $\mathrm{p}$-Wert \\
\hline \multirow{3}{*}{$\begin{array}{l}\text { Anzahl LK alle Level nach } \\
\text { Carotiden und Ulzeration }\end{array}$} & Zwischen den Gruppen & 153,084 & 2 & 76,542 & \multirow[t]{3}{*}{1,897} & \multirow[t]{3}{*}{0,154} \\
\hline & Innerhalb der Gruppen & 5203,848 & 129 & 40,340 & & \\
\hline & Total & 5356,932 & 131 & & & \\
\hline \multirow{3}{*}{$\begin{array}{l}\text { Anzahl LK II-IV nach Carotiden } \\
\text { und Ulzeration }\end{array}$} & Zwischen den Gruppen & 42,238 & 2 & 21,119 & \multirow[t]{3}{*}{1,098} & \multirow[t]{3}{*}{0,337} \\
\hline & Innerhalb der Gruppen & 2481,277 & 129 & 19,235 & & \\
\hline & Total & 2523,515 & 131 & & & \\
\hline \multirow{3}{*}{$\begin{array}{l}\text { größte LK: Größe nach } \\
\text { Carotiden und Ulzeration }\end{array}$} & Zwischen den Gruppen & 58,545 & 2 & 29,272 & \multirow[t]{3}{*}{1,073} & \multirow[t]{3}{*}{0,345} \\
\hline & Innerhalb der Gruppen & 3519,760 & 129 & 27,285 & & \\
\hline & Total & 3578,305 & 131 & & & \\
\hline \multirow{3}{*}{$\begin{array}{l}\text { Carotis-LK: Anzahl nach } \\
\text { Carotiden und Ulzeration }\end{array}$} & Zwischen den Gruppen & 1,673 & 2 & 0,837 & \multirow[t]{3}{*}{0,229} & \multirow[t]{3}{*}{0,796} \\
\hline & Innerhalb der Gruppen & 471,319 & 129 & 3,654 & & \\
\hline & Total & 472,992 & 131 & & & \\
\hline \multirow{3}{*}{$\begin{array}{l}\text { Carotis-LK: Größe nach } \\
\text { Carotiden und Ulzeration }\end{array}$} & Zwischen den Gruppen & 51,883 & 2 & 25,942 & \multirow[t]{3}{*}{0,326} & \multirow[t]{3}{*}{0,723} \\
\hline & Innerhalb der Gruppen & 10275,017 & 129 & 79,651 & & \\
\hline & Total & 10326,900 & 131 & & & \\
\hline
\end{tabular}

Tab. 24 Varianzanalyse zur Hypothese „Ulzerierte Carotisplaques haben mehr und/oder größere Lymphknoten (auf der Seite des Ulkus)“ für alle Level, Level II-IV, Größe größte Lymphknoten, Anzahl und Größe Carotis-Lymphknoten bezogen auf Carotiden 


\section{„Es besteht ein Zusammenhang zwischen dem Grad einer Carotisstenose und der Anzahl bzw. Größe der zervikalen Lymphknoten."}

Ein-Stichproben Kolmogorov-Smirnov Test

\begin{tabular}{|c|c|c|c|c|c|c|c|}
\hline \multicolumn{3}{|c|}{ ECST (65-100) nach Carotiden } & $\begin{array}{c}\text { Anzahl LK } \\
\text { alle Level } \\
\text { pro Carotis }\end{array}$ & $\begin{array}{c}\text { Anzahl LK II- } \\
\text { IV pro } \\
\text { Carotis }\end{array}$ & $\begin{array}{c}\text { größte LK: } \\
\text { Größe pro } \\
\text { Carotis }\end{array}$ & $\begin{array}{l}\text { Carotis-LK: } \\
\text { Anzahl pro } \\
\text { Carotis }\end{array}$ & $\begin{array}{c}\text { Carotis-LK: } \\
\text { Größe pro } \\
\text { Carotis }\end{array}$ \\
\hline \multirow[t]{8}{*}{ Gesund } & \multicolumn{2}{|l|}{$\mathrm{N}$} & 46 & 46 & 46 & 46 & 46 \\
\hline & \multirow[t]{2}{*}{ Normalparameter $^{\mathrm{a}}$} & Mittelwert & 15,22 & 9,28 & 8,696 & 3,17 & 14,300 \\
\hline & & Std.-Abweichung & 5,951 & 3,868 & 5,6698 & 1,970 & 9,3861 \\
\hline & \multirow[t]{3}{*}{ Größte Differenzen } & Absolut & 0,093 & 0,132 & 0,118 & 0,137 & 0,105 \\
\hline & & Positiv & 0,080 & 0,132 & 0,118 & 0,137 & 0,105 \\
\hline & & Negativ & $-0,093$ & $-0,074$ & $-0,088$ & $-0,097$ & $-0,064$ \\
\hline & \multicolumn{2}{|c|}{ Kolmogorov-Smirnov Z } & 0,630 & 0,899 & 0,797 & 0,932 & 0,710 \\
\hline & \multicolumn{2}{|l|}{$\mathrm{p}$-Wert } & 0,822 & 0,395 & 0,549 & 0,350 & 0,694 \\
\hline \multirow{8}{*}{$\begin{array}{l}\text { Gesund mit Stenose } \\
\text { auf Gegenseite }\end{array}$} & \multicolumn{2}{|l|}{$\mathrm{N}$} & 28 & 28 & 28 & 28 & 28 \\
\hline & \multirow[t]{2}{*}{ Normalparameter ${ }^{\mathrm{a}}$} & Mittelwert & 15,39 & 9,79 & 8,261 & 2,89 & 13,200 \\
\hline & & Std.-Abweichung & 6,573 & 4,954 & 5,3244 & 1,729 & 7,8381 \\
\hline & \multirow[t]{3}{*}{ Größte Differenzen } & Absolut & 0,155 & 0,119 & 0,118 & 0,233 & 0,139 \\
\hline & & Positiv & 0,155 & 0,119 & 0,118 & 0,233 & 0,139 \\
\hline & & Negativ & $-0,072$ & $-0,109$ & $-0,105$ & $-0,132$ & $-0,124$ \\
\hline & \multicolumn{2}{|c|}{ Kolmogorov-Smirnov Z } & 0,822 & 0,628 & 0,625 & 1,233 & 0,735 \\
\hline & \multicolumn{2}{|l|}{$\mathrm{p}$-Wert } & 0,509 & 0,825 & 0,829 & 0,096 & 0,652 \\
\hline \multirow[t]{8}{*}{ ECST $65-81 \%$} & \multicolumn{2}{|l|}{$\mathrm{N}$} & 17 & 17 & 17 & 17 & 17 \\
\hline & \multirow[t]{2}{*}{ Normalparameter $^{\mathrm{a}}$} & Mittelwert & 16,18 & 9,29 & 7,576 & 3,82 & 16,876 \\
\hline & & Std.-Abweichung & 8,263 & 5,371 & 4,8244 & 1,944 & 7,9761 \\
\hline & \multirow[t]{3}{*}{ Größte Differenzen } & Absolut & 0,179 & 0,183 & 0,196 & 0,170 & 0,088 \\
\hline & & Positiv & 0,179 & 0,183 & 0,196 & 0,170 & 0,088 \\
\hline & & Negativ & $-0,109$ & $-0,121$ & $-0,186$ & $-0,101$ & $-0,081$ \\
\hline & \multicolumn{2}{|c|}{ Kolmogorov-Smirnov Z } & 0,738 & 0,756 & 0,807 & 0,700 & 0,363 \\
\hline & \multicolumn{2}{|l|}{$\mathrm{p}$-Wert } & 0,647 & 0,617 & 0,533 & 0,712 & 0,999 \\
\hline \multirow[t]{8}{*}{ ECST $82-99 \%$} & \multicolumn{2}{|l|}{$\mathrm{N}$} & 24 & 24 & 24 & 24 & 24 \\
\hline & \multirow[t]{2}{*}{ Normalparameter $^{\mathrm{a}}$} & Mittelwert & 14,17 & 8,58 & 7,288 & 2,79 & 13,100 \\
\hline & & Std.-Abweichung & 5,387 & 4,032 & 4,8955 & 1,911 & 8,8339 \\
\hline & \multirow[t]{3}{*}{ Größte Differenzen } & Absolut & 0,155 & 0,197 & 0,165 & 0,207 & 0,158 \\
\hline & & Positiv & 0,155 & 0,197 & 0,140 & 0,207 & 0,158 \\
\hline & & Negativ & $-0,137$ & $-0,128$ & $-0,165$ & $-0,131$ & $-0,087$ \\
\hline & \multicolumn{2}{|c|}{ Kolmogorov-Smirnov Z } & 0,761 & 0,968 & 0,806 & 1,012 & 0,772 \\
\hline & \multicolumn{2}{|l|}{$\mathrm{p}$-Wert } & 0,608 & 0,306 & 0,534 & 0,257 & 0,590 \\
\hline ECST $100 \%$ & $\mathrm{~N}$ & & 17 & 17 & 17 & 17 & 17 \\
\hline & Normalparameter $^{\mathrm{a}}$ & Mittelwert & 13,59 & 7,71 & 6,682 & 2,24 & 10,571 \\
\hline & & Std.-Abweichung & 6,874 & 4,312 & 4,8357 & 1,751 & 9,7490 \\
\hline & Größte Differenzen & Absolut & 0,245 & 0,212 & 0,152 & 0,201 & 0,202 \\
\hline & & Positiv & 0,245 & 0,212 & 0,152 & 0,201 & 0,202 \\
\hline & & Negativ & $-0,135$ & $-0,148$ & $-0,119$ & $-0,152$ & $-0,139$ \\
\hline & Kolmogorov-Smirno & & 1,011 & 0,874 & 0,626 & 0,827 & 0,834 \\
\hline & $p$-Wert & & 0,258 & 0,429 & 0,828 & 0,501 & 0,489 \\
\hline
\end{tabular}

a. Es besteht Normalverteilung.

Tab. 25 Prüfung der Normalverteilung zur Hypothese „Es besteht ein Zusammenhang zwischen dem Grad einer Carotisstenose und der Anzahl bzw. Größe der zervikalen Lymphknoten“ für alle Level, Level II-IV, Größe größte Lymphknoten, Anzahl und Größe Carotis-Lymphknoten 
Beschreibende Statistik

\begin{tabular}{|c|c|c|c|c|c|c|}
\hline & $\begin{array}{l}\text { ECST (65-100) nach } \\
\text { Carotiden }\end{array}$ & $\mathrm{N}$ & Minimum & Maximum & Mittelwert & Std.-Abweichung \\
\hline \multirow{5}{*}{$\begin{array}{l}\text { Anzahl LK alle Level pro } \\
\text { Carotis }\end{array}$} & Gesund & 46 & 4 & 29 & 15,22 & 5,951 \\
\hline & $\begin{array}{l}\text { Gesund mit Stenose auf } \\
\text { Gegenseite }\end{array}$ & 28 & 5 & 31 & 15,39 & 6,573 \\
\hline & ECST $65-81 \%$ & 17 & 6 & 35 & 16,18 & 8,263 \\
\hline & ECST $82-99 \%$ & 24 & 6 & 25 & 14,17 & 5,387 \\
\hline & ECST $100 \%$ & 17 & 6 & 35 & 13,59 & 6,874 \\
\hline \multirow[t]{5}{*}{ Anzahl LK II-IV pro Carotis } & Gesund & 46 & 3 & 19 & 9,28 & 3,868 \\
\hline & $\begin{array}{l}\text { Gesund mit Stenose auf } \\
\text { Gegenseite }\end{array}$ & 28 & 3 & 20 & 9,79 & 4,954 \\
\hline & ECST $65-81 \%$ & 17 & 3 & 21 & 9,29 & 5,371 \\
\hline & ECST $82-99 \%$ & 24 & 4 & 17 & 8,58 & 4,032 \\
\hline & ECST $100 \%$ & 17 & 3 & 21 & 7,71 & 4,312 \\
\hline \multirow[t]{5}{*}{ größte LK: Größe pro Carotis } & Gesund & 46 & 0,0 & 22,5 & 8,696 & 5,6698 \\
\hline & $\begin{array}{l}\text { Gesund mit Stenose auf } \\
\text { Gegenseite }\end{array}$ & 28 & 0,0 & 15,9 & 8,261 & 5,3244 \\
\hline & ECST $65-81 \%$ & 17 & 0,0 & 18,2 & 7,576 & 4,8244 \\
\hline & ECST $82-99 \%$ & 24 & 0,0 & 17,6 & 7,288 & 4,8955 \\
\hline & ECST $100 \%$ & 17 & 0,0 & 15,1 & 6,682 & 4,8357 \\
\hline \multirow[t]{5}{*}{ Carotis-LK: Anzahl pro Carotis } & Gesund & 46 & 0 & 9 & 3,17 & 1,970 \\
\hline & $\begin{array}{l}\text { Gesund mit Stenose auf } \\
\text { Gegenseite }\end{array}$ & 28 & 0 & 7 & 2,89 & 1,729 \\
\hline & ECST $65-81 \%$ & 17 & 1 & 8 & 3,82 & 1,944 \\
\hline & ECST $82-99 \%$ & 24 & 0 & 8 & 2,79 & 1,911 \\
\hline & ECST $100 \%$ & 17 & 0 & 7 & 2,24 & 1,751 \\
\hline \multirow[t]{5}{*}{ Carotis-LK: Größe pro Carotis } & Gesund & 46 & 0,0 & 41,7 & 14,300 & 9,3861 \\
\hline & $\begin{array}{l}\text { Gesund mit Stenose auf } \\
\text { Gegenseite }\end{array}$ & 28 & 0,0 & 28,4 & 13,200 & 7,8381 \\
\hline & ECST $65-81 \%$ & 17 & 3,7 & 32,1 & 16,876 & 7,9761 \\
\hline & ECST 82-99\% & 24 & 0,0 & 37,8 & 13,100 & 8,8339 \\
\hline & ECST $100 \%$ & 17 & 0,0 & 42,0 & 10,571 & 9,7490 \\
\hline \multirow[t]{5}{*}{ Stichprobenumfang } & Gesund & 46 & & & & \\
\hline & $\begin{array}{l}\text { Gesund mit Stenose auf } \\
\text { Gegenseite }\end{array}$ & 28 & & & & \\
\hline & ECST $65-81 \%$ & 17 & & & & \\
\hline & ECST $82-99 \%$ & 24 & & & & \\
\hline & ECST $100 \%$ & 17 & & & & \\
\hline
\end{tabular}

Tab. 26 Beschreibende Statistik zur Hypothese „Es besteht ein Zusammenhang zwischen dem Grad einer Carotisstenose und der Anzahl bzw. Größe der zervikalen Lymphknoten“ für alle Level, Level II-IV, Größe größte Lymphknoten, Anzahl und Größe Carotis-Lymphknoten 
ANOVA

\begin{tabular}{|c|c|c|c|c|c|c|}
\hline & & Quadratsumme & Freiheitsgrad & $\begin{array}{c}\text { Mittlere } \\
\text { Quadratsumme }\end{array}$ & $\mathrm{F}$ & p-Wert \\
\hline \multirow[t]{3}{*}{ Anzahl LK alle Level pro Carotis } & Zwischen den Gruppen & 80,506 & 4 & 20,126 & 0,484 & 0,747 \\
\hline & Innerhalb der Gruppen & 5276,426 & 127 & 41,547 & & \\
\hline & Total & 5356,932 & 131 & & & \\
\hline \multirow[t]{3}{*}{ Anzahl LK II-IV pro Carotis } & Zwischen den Gruppen & 54,583 & 4 & 13,646 & 0,702 & 0,592 \\
\hline & Innerhalb der Gruppen & 2468,933 & 127 & 19,440 & & \\
\hline & Total & 2523,515 & 131 & & & \\
\hline \multirow[t]{3}{*}{ größte LK: Größe pro Carotis } & Zwischen den Gruppen & 68,498 & 4 & 17,124 & 0,620 & 0,649 \\
\hline & Innerhalb der Gruppen & 3509,807 & 127 & 27,636 & & \\
\hline & Total & 3578,305 & 131 & & & \\
\hline \multirow[t]{3}{*}{ Carotis-LK: Anzahl pro Carotis } & Zwischen den Gruppen & 24,217 & 4 & 6,054 & 1,713 & 0,151 \\
\hline & Innerhalb der Gruppen & 448,775 & 127 & 3,534 & & \\
\hline & Total & 472,992 & 131 & & & \\
\hline \multirow[t]{3}{*}{ Carotis-LK: Größe pro Carotis } & Zwischen den Gruppen & 370,214 & 4 & 92,554 & 1,181 & 0,323 \\
\hline & Innerhalb der Gruppen & 9956,686 & 127 & 78,399 & & \\
\hline & Total & 10326,900 & 131 & & & \\
\hline
\end{tabular}

Tab. 27 Varianzanalyse zur Hypothese „Es besteht ein Zusammenhang zwischen dem Grad einer Carotisstenose und der Anzahl bzw. Größe der zervikalen Lymphknoten“ für alle Level, Level II-IV, Größe größte Lymphknoten, Anzahl und Größe Carotis-Lymphknoten 
„Es besteht ein Zusammenhang zwischen den Begleiterkrankungen eines Stenosepatienten und der Anzahl bzw. Größe seiner zervikalen Lymphknoten."

\section{Arterieller Hypertonus}

Ein-Stichproben Kolmogorov-Smirnov Test

\begin{tabular}{|c|c|c|c|c|c|c|c|}
\hline \multicolumn{3}{|c|}{ Hypertonus bei Stenose \& Gesund } & $\begin{array}{l}\text { Anzahl LK } \\
\text { alle Level }\end{array}$ & $\begin{array}{c}\text { Anzahl LK II- } \\
\text { IV }\end{array}$ & $\begin{array}{l}\text { größte LK: } \\
\text { Größe [mm] }\end{array}$ & $\begin{array}{c}\text { Carotis-LK: } \\
\text { Anzahl }\end{array}$ & $\begin{array}{l}\text { Carotis-LK: } \\
\text { Größe [mm] }\end{array}$ \\
\hline \multirow[t]{8}{*}{ Gesund } & \multicolumn{2}{|l|}{$\mathrm{N}$} & 15 & 15 & 15 & 15 & 15 \\
\hline & \multirow[t]{2}{*}{ Normalparameter $^{\mathrm{a}}$} & Mittelwert & 30,27 & 18,27 & 17,020 & 6,13 & 26,513 \\
\hline & & Std.-Abweichung & 12,395 & 8,022 & 6,0710 & 3,871 & 17,0534 \\
\hline & \multirow[t]{3}{*}{ Größte Differenzen } & Absolut & 0,121 & 0,116 & 0,224 & 0,115 & 0,182 \\
\hline & & Positiv & 0,121 & 0,116 & 0,158 & 0,115 & 0,182 \\
\hline & & Negativ & $-0,083$ & $-0,080$ & $-0,224$ & $-0,086$ & $-0,103$ \\
\hline & \multicolumn{2}{|c|}{ Kolmogorov-Smirnov Z } & 0,469 & 0,449 & 0,869 & 0,445 & 0,706 \\
\hline & \multicolumn{2}{|l|}{$\mathrm{p}$-Wert } & 0,980 & 0,988 & 0,437 & 0,989 & 0,701 \\
\hline \multirow{8}{*}{$\begin{array}{l}\text { Stenose + } \\
\text { Normotonus }\end{array}$} & \multicolumn{2}{|l|}{$\mathrm{N}$} & 14 & 14 & 14 & 14 & 14 \\
\hline & \multirow[t]{2}{*}{ Normalparameter $^{\mathrm{a}}$} & Mittelwert & 29,71 & 17,14 & 15,743 & 5,21 & 23,986 \\
\hline & & Std.-Abweichung & 13,909 & 9,330 & 7,9835 & 3,118 & 16,0422 \\
\hline & \multirow[t]{3}{*}{ Größte Differenzen } & Absolut & 0,163 & 0,207 & 0,306 & 0,170 & 0,211 \\
\hline & & Positiv & 0,163 & 0,207 & 0,159 & 0,170 & 0,211 \\
\hline & & Negativ & $-0,129$ & $-0,138$ & $-0,306$ & $-0,102$ & $-0,106$ \\
\hline & \multicolumn{2}{|c|}{ Kolmogorov-Smirnov Z } & 0,611 & 0,774 & 1,146 & 0,637 & 0,790 \\
\hline & \multicolumn{2}{|l|}{$\mathrm{p}$-Wert } & 0,849 & 0,587 & 0,145 & 0,812 & 0,560 \\
\hline \multirow{8}{*}{$\begin{array}{l}\text { Stenose + } \\
\text { Hypertonus }\end{array}$} & \multicolumn{2}{|l|}{$\mathrm{N}$} & 29 & 29 & 29 & 29 & 29 \\
\hline & \multirow[t]{2}{*}{ Normalparameter $^{\mathrm{a}}$} & Mittelwert & 29,69 & 18,24 & 14,766 & 6,14 & 28,097 \\
\hline & & Std.-Abweichung & 12,227 & 8,725 & 6,7228 & 3,523 & 16,1990 \\
\hline & \multirow[t]{3}{*}{ Größte Differenzen } & Absolut & 0,132 & 0,153 & 0,164 & 0,178 & 0,140 \\
\hline & & Positiv & 0,132 & 0,153 & 0,164 & 0,178 & 0,140 \\
\hline & & Negativ & $-0,086$ & $-0,101$ & $-0,130$ & $-0,123$ & $-0,095$ \\
\hline & \multicolumn{2}{|c|}{ Kolmogorov-Smirnov Z } & 0,711 & 0,824 & 0,881 & 0,961 & 0,756 \\
\hline & \multicolumn{2}{|l|}{$\mathrm{p}$-Wert } & 0,692 & 0,505 & 0,419 & 0,315 & 0,618 \\
\hline \multirow{8}{*}{$\begin{array}{l}\text { Gesund + } \\
\text { Hypertonus }\end{array}$} & \multicolumn{2}{|l|}{$\mathrm{N}$} & 8 & 8 & 8 & 8 & 8 \\
\hline & \multirow[t]{2}{*}{ Normalparameter $^{a}$} & Mittelwert & 30,75 & 19,12 & 18,088 & 6,75 & 32,512 \\
\hline & & Std.-Abweichung & 8,031 & 4,121 & 5,7613 & 3,012 & 15,7790 \\
\hline & \multirow[t]{3}{*}{ Größte Differenzen } & Absolut & 0,116 & 0,300 & 0,268 & 0,214 & 0,130 \\
\hline & & Positiv & 0,113 & 0,181 & 0,152 & 0,214 & 0,130 \\
\hline & & Negativ & $-0,116$ & $-0,300$ & $-0,268$ & $-0,161$ & $-0,124$ \\
\hline & \multicolumn{2}{|c|}{ Kolmogorov-Smirnov Z } & 0,328 & 0,850 & 0,758 & 0,605 & 0,369 \\
\hline & \multicolumn{2}{|l|}{$\mathrm{p}$-Wert } & 1,000 & 0,466 & 0,613 & 0,857 & 0,999 \\
\hline
\end{tabular}

a. Es besteht Normalverteilung.

Tab. 28 Prüfung der Normalverteilung zur Hypothese „Es besteht ein Zusammenhang zwischen den Begleiterkrankungen eines Stenosepatienten und der Anzahl bzw. Größe seiner zervikalen Lymphknoten“ für alle Level, Level II-IV, Größe größte Lymphknoten, Anzahl und Größe Carotis-Lymphknoten bezogen auf arterielle Hypertonie 
Beschreibende Statistik

\begin{tabular}{|c|c|c|c|c|c|c|}
\hline & $\begin{array}{l}\text { Hypertonus bei Stenose \& } \\
\text { Gesund }\end{array}$ & $\mathrm{N}$ & Minimum & Maximum & Mittelwert & Std.-Abweichung \\
\hline \multirow[t]{4}{*}{ Anzahl LK alle Level } & Gesund & 15 & 11 & 56 & 30,27 & 12,395 \\
\hline & Stenose + Normotonus & 14 & 14 & 70 & 29,71 & 13,909 \\
\hline & Stenose + Hypertonus & 29 & 13 & 56 & 29,69 & 12,227 \\
\hline & Gesund + Hypertonus & 8 & 19 & 43 & 30,75 & 8,031 \\
\hline \multirow[t]{4}{*}{ Anzahl LK II-IV } & Gesund & 15 & 7 & 36 & 18,27 & 8,022 \\
\hline & Stenose + Normotonus & 14 & 7 & 42 & 17,14 & 9,330 \\
\hline & Stenose + Hypertonus & 29 & 7 & 36 & 18,24 & 8,725 \\
\hline & Gesund + Hypertonus & 8 & 13 & 24 & 19,12 & 4,121 \\
\hline \multirow[t]{4}{*}{ größte LK: Größe [mm] } & Gesund & 15 & 0,0 & 23,1 & 17,020 & 6,0710 \\
\hline & Stenose + Normotonus & 14 & 0,0 & 23,7 & 15,743 & 7,9835 \\
\hline & Stenose + Hypertonus & 29 & 5,1 & 24,7 & 14,766 & 6,7228 \\
\hline & Gesund + Hypertonus & 8 & 5,8 & 24,0 & 18,088 & 5,7613 \\
\hline \multirow[t]{4}{*}{ Carotis-LK: Anzahl } & Gesund & 15 & 0 & 14 & 6,13 & 3,871 \\
\hline & Stenose + Normotonus & 14 & 0 & 11 & 5,21 & 3,118 \\
\hline & Stenose + Hypertonus & 29 & 2 & 13 & 6,14 & 3,523 \\
\hline & Gesund + Hypertonus & 8 & 3 & 12 & 6,75 & 3,012 \\
\hline \multirow[t]{4}{*}{ Carotis-LK: Größe [mm] } & Gesund & 15 & 0,0 & 60,6 & 26,513 & 17,0534 \\
\hline & Stenose + Normotonus & 14 & 0,0 & 63,4 & 23,986 & 16,0422 \\
\hline & Stenose + Hypertonus & 29 & 6,9 & 62,1 & 28,097 & 16,1990 \\
\hline & Gesund + Hypertonus & 8 & 11,1 & 58,8 & 32,512 & 15,7790 \\
\hline \multirow[t]{4}{*}{ Stichprobenumfang } & Gesund & 15 & & & & \\
\hline & Stenose + Normotonus & 14 & & & & \\
\hline & Stenose + Hypertonus & 29 & & & & \\
\hline & Gesund + Hypertonus & 8 & & & & \\
\hline
\end{tabular}

Tab. 29 Beschreibende Statistik zur Hypothese „Es besteht ein Zusammenhang zwischen den Begleiterkrankungen eines Stenosepatienten und der Anzahl bzw. Größe seiner zervikalen Lymphknote." für alle Level, Level II-IV, Größe größte Lymphknoten, Anzahl und Größe Carotis-Lymphknoten bezogen auf arterielle Hypertonie

\begin{tabular}{|c|c|c|c|c|c|c|}
\hline \multicolumn{7}{|c|}{ ANOVA } \\
\hline & & Quadratsumme & Freiheitsgrad & \begin{tabular}{|c|} 
Mittlere \\
Quadratsumme
\end{tabular} & $\mathrm{F}$ & $p$-Wert \\
\hline \multirow[t]{3}{*}{ Anzahl LK alle Level } & Zwischen den Gruppen & 9,366 & 3 & 3,122 & 0,021 & 0,996 \\
\hline & Innerhalb der Gruppen & 9303,497 & 62 & 150,056 & & \\
\hline & Total & 9312,864 & 65 & & & \\
\hline \multirow[t]{3}{*}{ Anzahl LK II-IV } & Zwischen den Gruppen & 22,197 & 3 & 7,399 & 0,107 & 0,956 \\
\hline & Innerhalb der Gruppen & 4282,833 & 62 & 69,078 & & \\
\hline & Total & 4305,030 & 65 & & & \\
\hline \multirow[t]{3}{*}{ größte LK: Größe [mm] } & Zwischen den Gruppen & 94,758 & 3 & 31,586 & 0,689 & 0,562 \\
\hline & Innerhalb der Gruppen & 2842,413 & 62 & 45,845 & & \\
\hline & Total & 2937,170 & 65 & & & \\
\hline \multirow[t]{3}{*}{ Carotis-LK: Anzahl } & Zwischen den Gruppen & 13,946 & 3 & 4,649 & 0,386 & 0,764 \\
\hline & Innerhalb der Gruppen & 747,039 & 62 & 12,049 & & \\
\hline & Total & 760,985 & 65 & & & \\
\hline \multirow[t]{3}{*}{ Carotis-LK: Größe [mm] } & Zwischen den Gruppen & 398,167 & 3 & 132,722 & 0,498 & 0,685 \\
\hline & Innerhalb der Gruppen & 16507,353 & 62 & 266,248 & & \\
\hline & Total & 16905,520 & 65 & & & \\
\hline
\end{tabular}

Tab. 30 Varianzanalyse zur Hypothese „Es besteht ein Zusammenhang zwischen den Begleiterkrankungen eines Stenosepatienten und der Anzahl bzw. Größe seiner zervikalen Lymphknoten“ für alle Level, Level II-IV, Größe größte Lymphknoten, Anzahl und Größe Carotis-Lymphknoten bezogen auf arterielle Hypertonie 


\section{Nikotinabusus}

Ein-Stichproben Kolmogorov-Smirnov Test

\begin{tabular}{|c|c|c|c|c|c|c|c|}
\hline \multicolumn{3}{|c|}{ Nikotin bei Stenose \& Gesund } & $\begin{array}{l}\text { Anzahl LK } \\
\text { alle Level }\end{array}$ & $\begin{array}{c}\text { Anzahl LK II- } \\
\text { IV }\end{array}$ & $\begin{array}{l}\text { größte LK: } \\
\text { Größe [mm] }\end{array}$ & $\begin{array}{c}\text { Carotis-LK: } \\
\text { Anzahl }\end{array}$ & $\begin{array}{l}\text { Carotis-LK: } \\
\text { Größe [mm] }\end{array}$ \\
\hline \multirow[t]{8}{*}{ Gesund } & $\mathrm{N}$ & & 21 & 21 & 21 & 21 & 21 \\
\hline & \multirow[t]{2}{*}{ Normalparameter ${ }^{a}$} & Mittelwert & 29,81 & 18,29 & 16,995 & 6,43 & 28,438 \\
\hline & & Std.-Abweichung & 11,039 & 7,086 & 5,9840 & 3,613 & 16,7958 \\
\hline & \multirow[t]{3}{*}{ Größte Differenzen } & Absolut & 0,112 & 0,108 & 0,179 & 0,141 & 0,125 \\
\hline & & Positiv & 0,112 & 0,108 & 0,121 & 0,141 & 0,125 \\
\hline & & Negativ & $-0,058$ & $-0,078$ & $-0,179$ & $-0,087$ & $-0,106$ \\
\hline & \multicolumn{2}{|c|}{ Kolmogorov-Smirnov Z } & 0,515 & 0,496 & 0,821 & 0,648 & 0,572 \\
\hline & \multicolumn{2}{|l|}{$\mathrm{p}$-Wert } & 0,954 & 0,966 & 0,511 & 0,796 & 0,899 \\
\hline \multirow{8}{*}{$\begin{array}{l}\text { Stenose ohne } \\
\text { iVikotinabusus }\end{array}$} & \multicolumn{2}{|l|}{$\mathrm{N}$} & 30 & 30 & 30 & 30 & 30 \\
\hline & \multirow[t]{2}{*}{ Normalparameter ${ }^{\mathrm{a}}$} & Mittelwert & 29,90 & 17,43 & 14,293 & 5,67 & 25,930 \\
\hline & & Std.-Abweichung & 13,309 & 9,250 & 7,3210 & 3,262 & 16,1448 \\
\hline & \multirow[t]{3}{*}{ Größte Differenzen } & Absolut & 0,110 & 0,178 & 0,193 & 0,159 & 0,166 \\
\hline & & Positiv & 0,110 & 0,178 & 0,153 & 0,159 & 0,166 \\
\hline & & Negativ & $-0,102$ & $-0,130$ & $-0,193$ & $-0,108$ & $-0,086$ \\
\hline & \multicolumn{2}{|c|}{ Kolmogorov-Smirnov Z } & 0,604 & 0,975 & 1,055 & 0,873 & 0,910 \\
\hline & \multicolumn{2}{|l|}{$\mathrm{p}$-Wert } & 0,859 & 0,297 & 0,215 & 0,432 & 0,379 \\
\hline \multirow{8}{*}{$\begin{array}{l}\text { Stenose \& } \\
\text { Nikotinabusus }\end{array}$} & \multicolumn{2}{|l|}{$\mathrm{N}$} & 13 & 13 & 13 & 13 & 13 \\
\hline & \multirow[t]{2}{*}{ Normalparameter $^{\mathrm{a}}$} & Mittelwert & 29,23 & 18,92 & 16,908 & 6,23 & 28,669 \\
\hline & & Std.-Abweichung & 11,403 & 8,026 & 6,3691 & 3,767 & 16,3951 \\
\hline & \multirow[t]{3}{*}{ Größte Differenzen } & Absolut & 0,193 & 0,216 & 0,183 & 0,262 & 0,184 \\
\hline & & Positiv & 0,193 & 0,216 & 0,150 & 0,262 & 0,184 \\
\hline & & Negativ & $-0,132$ & $-0,117$ & $-0,183$ & $-0,131$ & $-0,111$ \\
\hline & \multicolumn{2}{|c|}{ Kolmogorov-Smirnov Z } & 0,696 & 0,778 & 0,662 & 0,943 & 0,664 \\
\hline & \multicolumn{2}{|l|}{$\mathrm{p}$-Wert } & 0,718 & 0,580 & 0,774 & 0,336 & 0,769 \\
\hline \multirow{8}{*}{$\begin{array}{l}\text { Gesund \& } \\
\text { Nikotinabusus }\end{array}$} & \multicolumn{2}{|l|}{$\mathrm{N}$} & 2 & 2 & 2 & 2 & 2 \\
\hline & \multirow[t]{2}{*}{ Normalparameter $^{\mathrm{a}}$} & Mittelwert & 37,00 & 21,50 & 21,550 & 5,50 & 30,300 \\
\hline & & Std.-Abweichung & 8,485 & 0,707 & 0,4950 & 3,536 & 18,8090 \\
\hline & \multirow[t]{3}{*}{ Größte Differenzen } & Absolut & 0,260 & 0,260 & 0,260 & 0,260 & 0,260 \\
\hline & & Positiv & 0,260 & 0,260 & 0,260 & 0,260 & 0,260 \\
\hline & & Negativ & $-0,260$ & $-0,260$ & $-0,260$ & $-0,260$ & $-0,260$ \\
\hline & \multicolumn{2}{|c|}{ Kolmogorov-Smirnov Z } & 0,368 & 0,368 & 0,368 & 0,368 & 0,368 \\
\hline & \multicolumn{2}{|l|}{$\mathrm{p}$-Wert } & 0,999 & 0,999 & 0,999 & 0,999 & 0,999 \\
\hline
\end{tabular}

a. Es besteht Normalverteilung.

Tab. 31 Prüfung der Normalverteilung zur Hypothese „Es besteht ein Zusammenhang zwischen den Begleiterkrankungen eines Stenosepatienten und der Anzahl bzw. Größe seiner zervikalen Lymphknoten" für alle Level, Level II-IV, Größe größte Lymphknoten, Anzahl und Größe Carotis-Lymphknoten bezogen auf Nikotinabusus 
Beschreibende Statistik

\begin{tabular}{|c|c|c|c|c|c|c|}
\hline & Nikotin bei Stenose \& Gesund & $\mathrm{N}$ & Minimum & Maximum & Mittelwert & Std.-Abweichung \\
\hline \multirow[t]{4}{*}{ Anzahl LK alle Level } & Gesund & 21 & 11 & 56 & 29,81 & 11,039 \\
\hline & Gesund \& Nikotinabusus & 2 & 31 & 43 & 37,00 & 8,485 \\
\hline & Stenose ohne Nikotinabusus & 30 & 13 & 70 & 29,90 & 13,309 \\
\hline & Stenose \& Nikotinabusus & 13 & 13 & 51 & 29,23 & 11,403 \\
\hline \multirow[t]{4}{*}{ Anzahl LK II-IV } & Gesund & 21 & 7 & 36 & 18,29 & 7,086 \\
\hline & Gesund \& Nikotinabusus & 2 & 21 & 22 & 21,50 & 0,707 \\
\hline & Stenose ohne Nikotinabusus & 30 & 7 & 42 & 17,43 & 9,250 \\
\hline & Stenose \& Nikotinabusus & 13 & 7 & 36 & 18,92 & 8,026 \\
\hline \multirow[t]{4}{*}{ größte LK: Größe [mm] } & Gesund & 21 & 0,0 & 24,0 & 16,995 & 5,9840 \\
\hline & Gesund \& Nikotinabusus & 2 & 21,2 & 21,9 & 21,550 & 0,4950 \\
\hline & Stenose ohne Nikotinabusus & 30 & 0,0 & 24,7 & 14,293 & 7,3210 \\
\hline & Stenose \& Nikotinabusus & 13 & 5,1 & 23,5 & 16,908 & 6,3691 \\
\hline \multirow[t]{4}{*}{ Carotis-LK: Anzahl } & Gesund & 21 & 0 & 14 & 6,43 & 3,613 \\
\hline & Gesund \& Nikotinabusus & 2 & 3 & 8 & 5,50 & 3,536 \\
\hline & Stenose ohne Nikotinabusus & 30 & 0 & 12 & 5,67 & 3,262 \\
\hline & Stenose \& Nikotinabusus & 13 & 2 & 13 & 6,23 & 3,767 \\
\hline \multirow[t]{4}{*}{ Carotis-LK: Größe [mm] } & Gesund & 21 & 0,0 & 60,6 & 28,438 & 16,7958 \\
\hline & Gesund \& Nikotinabusus & 2 & 17,0 & 43,6 & 30,300 & 18,8090 \\
\hline & Stenose ohne Nikotinabusus & 30 & 0,0 & 63,4 & 25,930 & 16,1448 \\
\hline & Stenose \& Nikotinabusus & 13 & 7,0 & 60,5 & 28,669 & 16,3951 \\
\hline \multirow[t]{4}{*}{ Sichprobenumfang } & Gesund & 21 & & & & \\
\hline & Gesund \& Nikotinabusus & 2 & & & & \\
\hline & Stenose ohne Nikotinabusus & 30 & & & & \\
\hline & Stenose \& Nikotinabusus & 13 & & & & \\
\hline
\end{tabular}

Tab. 32 Beschreibende Statistik zur Hypothese „Es besteht ein Zusammenhang zwischen den Begleiterkrankungen eines Stenosepatienten und der Anzahl bzw. Größe seiner zervikalen Lymphknoten“ für alle Level, Level II-IV, Größe größte Lymphknoten, Anzahl und Größe Carotis-Lymphknoten bezogen auf Nikotinabusus

ANOVA

\begin{tabular}{|c|c|c|c|c|c|c|}
\hline & & Quadratsumme & Freiheitsgrad & $\begin{array}{c}\text { Mittlere } \\
\text { Quadratsumme }\end{array}$ & $\mathrm{F}$ & p-Wert \\
\hline \multirow[t]{3}{*}{ Anzahl LK alle Level } & Zwischen den Gruppen & 106,618 & 3 & 35,539 & \multirow[t]{3}{*}{0,239} & \multirow[t]{3}{*}{0,869} \\
\hline & Innerhalb der Gruppen & 9206,246 & 62 & 148,488 & & \\
\hline & Total & 9312,864 & 65 & & & \\
\hline \multirow[t]{3}{*}{ Anzahl LK II-IV } & Zwischen den Gruppen & 45,955 & 3 & 15,318 & \multirow[t]{3}{*}{0,223} & \multirow[t]{3}{*}{0,880} \\
\hline & Innerhalb der Gruppen & 4259,075 & 62 & 68,695 & & \\
\hline & Total & 4305,030 & 65 & & & \\
\hline \multirow[t]{3}{*}{ größte LK: Größe [mm] } & Zwischen den Gruppen & 179,668 & 3 & 59,889 & \multirow[t]{3}{*}{1,347} & \multirow[t]{3}{*}{0,267} \\
\hline & Innerhalb der Gruppen & 2757,502 & 62 & 44,476 & & \\
\hline & Total & 2937,170 & 65 & & & \\
\hline \multirow[t]{3}{*}{ Carotis-LK: Anzahl } & Zwischen den Gruppen & 8,368 & 3 & 2,789 & \multirow[t]{3}{*}{0,230} & \multirow[t]{3}{*}{0,875} \\
\hline & Innerhalb der Gruppen & 752,617 & 62 & 12,139 & & \\
\hline & Total & 760,985 & 65 & & & \\
\hline \multirow[t]{3}{*}{ Carotis-LK: Größe [mm] } & Zwischen den Gruppen & 125,220 & 3 & 41,740 & \multirow[t]{3}{*}{0,154} & \multirow[t]{3}{*}{0,927} \\
\hline & Innerhalb der Gruppen & 16780,300 & 62 & 270,650 & & \\
\hline & Total & 16905,520 & 65 & & & \\
\hline
\end{tabular}

Tab. 33 Varianzanalyse zur Hypothese „Es besteht ein Zusammenhang zwischen den Begleiterkrankungen eines Stenosepatienten und der Anzahl bzw. Größe seiner zervikalen Lymphknoten“ für alle Level, Level II-IV, Größe größte Lymphknoten, Anzahl und Größe Carotis-Lymphknoten bezogen auf Nikotinabusus 
Hypercholesterinämie

Ein-Stichproben Kolmogorov-Smirnov Test

\begin{tabular}{|c|c|c|c|c|c|c|c|}
\hline \multicolumn{3}{|c|}{ Cholesterin bei Stenose \& Gesund } & $\begin{array}{l}\text { Anzahl LK } \\
\text { alle Level }\end{array}$ & $\begin{array}{c}\text { Anzahl LK II- } \\
\text { IV }\end{array}$ & $\begin{array}{l}\text { größte LK: } \\
\text { Größe [mm] }\end{array}$ & $\begin{array}{c}\text { Carotis-LK: } \\
\text { Anzahl }\end{array}$ & $\begin{array}{l}\text { Carotis-LK: } \\
\text { Größe [mm] }\end{array}$ \\
\hline \multirow[t]{8}{*}{ Gesund } & $\mathrm{N}$ & & 17 & 17 & 17 & 17 & 17 \\
\hline & \multirow[t]{2}{*}{ Normalparameter ${ }^{\mathrm{a}}$} & Mittelwert & 29,41 & 18,18 & 17,629 & 6,71 & 29,700 \\
\hline & & Std.-Abweichung & 11,057 & 7,691 & 5,7615 & 3,820 & 17,7055 \\
\hline & \multirow[t]{3}{*}{ Größte Differenzen } & Absolut & 0,129 & 0,118 & 0,186 & 0,132 & 0,154 \\
\hline & & Positiv & 0,129 & 0,118 & 0,134 & 0,132 & 0,154 \\
\hline & & Negativ & $-0,096$ & $-0,073$ & $-0,186$ & $-0,094$ & $-0,125$ \\
\hline & \multicolumn{2}{|c|}{ Kolmogorov-Smirnov Z } & 0,530 & 0,487 & 0,766 & 0,545 & 0,633 \\
\hline & \multicolumn{2}{|l|}{$p$-Wert } & 0,941 & 0,971 & 0,600 & 0,928 & 0,818 \\
\hline \multirow{8}{*}{$\begin{array}{l}\text { Stenose \& } \\
\text { Normocholesterinämi } \\
\text { e }\end{array}$} & \multicolumn{2}{|l|}{$\mathrm{N}$} & 24 & 24 & 24 & 24 & 24 \\
\hline & \multirow[t]{2}{*}{ Normalparameter $^{\mathrm{a}}$} & Mittelwert & 28,12 & 17,17 & 14,462 & 6,04 & 27,596 \\
\hline & & Std.-Abweichung & 13,434 & 9,644 & 7,1314 & 3,407 & 16,3146 \\
\hline & \multirow[t]{3}{*}{ Größte Differenzen } & Absolut & 0,158 & 0,215 & 0,196 & 0,172 & 0,174 \\
\hline & & Positiv & 0,158 & 0,215 & 0,157 & 0,172 & 0,174 \\
\hline & & Negativ & $-0,130$ & $-0,146$ & $-0,196$ & $-0,141$ & $-0,103$ \\
\hline & \multicolumn{2}{|c|}{ Kolmogorov-Smirnov Z } & 0,776 & 1,052 & 0,962 & 0,840 & 0,852 \\
\hline & \multicolumn{2}{|l|}{$\mathrm{p}$-Wert } & 0,584 & 0,218 & 0,313 & 0,480 & 0,462 \\
\hline \multirow{8}{*}{$\begin{array}{l}\text { Stenose \& } \\
\text { Hypercholesterinämie }\end{array}$} & \multicolumn{2}{|l|}{$\mathrm{N}$} & 19 & 19 & 19 & 19 & 19 \\
\hline & \multirow[t]{2}{*}{ Normalparameter $^{\mathrm{a}}$} & Mittelwert & 31,68 & 18,79 & 15,868 & 5,58 & 25,700 \\
\hline & & Std.-Abweichung & 11,586 & 7,843 & 7,1196 & 3,437 & 16,1463 \\
\hline & \multirow[t]{3}{*}{ Größte Differenzen } & Absolut & 0,121 & 0,228 & 0,186 & 0,198 & 0,156 \\
\hline & & Positiv & 0,121 & 0,228 & 0,126 & 0,198 & 0,156 \\
\hline & & Negativ & $-0,090$ & $-0,131$ & $-0,186$ & $-0,112$ & $-0,090$ \\
\hline & \multicolumn{2}{|c|}{ Kolmogorov-Smirnov Z } & 0,526 & 0,994 & 0,810 & 0,865 & 0,679 \\
\hline & \multicolumn{2}{|l|}{$\mathrm{p}$-Wert } & 0,945 & 0,276 & 0,528 & 0,443 & 0,745 \\
\hline \multirow{8}{*}{$\begin{array}{l}\text { Gesund \& } \\
\text { itypercholesterinämie }\end{array}$} & \multicolumn{2}{|l|}{$\mathrm{N}$} & 6 & 6 & 6 & 6 & 6 \\
\hline & \multirow[t]{2}{*}{ Normalparameter ${ }^{a}$} & Mittelwert & 33,33 & 19,67 & 16,717 & 5,33 & 25,483 \\
\hline & & Std.-Abweichung & 10,764 & 3,670 & 6,6255 & 2,582 & 13,4720 \\
\hline & \multirow[t]{3}{*}{ Größte Differenzen } & Absolut & 0,201 & 0,308 & 0,357 & 0,317 & 0,236 \\
\hline & & Positiv & 0,165 & 0,182 & 0,217 & 0,317 & 0,236 \\
\hline & & Negativ & $-0,201$ & $-0,308$ & $-0,357$ & $-0,241$ & $-0,147$ \\
\hline & \multicolumn{2}{|c|}{ Kolmogorov-Smirnov Z } & 0,492 & 0,756 & 0,873 & 0,776 & 0,577 \\
\hline & \multicolumn{2}{|l|}{$p$-Wert } & 0,969 & 0,618 & 0,430 & 0,583 & 0,893 \\
\hline
\end{tabular}

a. Es besteht Normalverteilung.

Tab. 34 Prüfung der Normalverteilung zur Hypothese „Es besteht ein Zusammenhang zwischen den Begleiterkrankungen eines Stenosepatienten und der Anzahl bzw. Größe seiner zervikalen Lymphknoten“ für alle Level, Level II-IV, Größe größte Lymphknoten, Anzahl und Größe Carotis-Lymphknoten bezogen auf Hypercholesterinämie 
Beschreibende Statistik

\begin{tabular}{|c|c|c|c|c|c|c|}
\hline & $\begin{array}{l}\text { Cholesterin bei Stenose \& } \\
\text { Gesund }\end{array}$ & $\mathrm{N}$ & Minimum & Maximum & Mittelwert & Std.-Abweichung \\
\hline \multirow[t]{4}{*}{ Anzahl LK alle Level } & Gesund & 17 & 11 & 56 & 29,41 & 11,057 \\
\hline & $\begin{array}{l}\text { Gesund \& } \\
\text { Hypercholesterinämie }\end{array}$ & 6 & 19 & 45 & 33,33 & 10,764 \\
\hline & $\begin{array}{l}\text { Stenose \& } \\
\text { Normocholesterinämie }\end{array}$ & 24 & 13 & 70 & 28,12 & 13,434 \\
\hline & $\begin{array}{l}\text { Stenose \& } \\
\text { Hypercholesterinämie }\end{array}$ & 19 & 13 & 56 & 31,68 & 11,586 \\
\hline \multirow[t]{4}{*}{ Anzahl LK II-IV } & Gesund & 17 & 7 & 36 & 18,18 & 7,691 \\
\hline & $\begin{array}{l}\text { Gesund \& } \\
\text { Hypercholesterinämie }\end{array}$ & 6 & 13 & 23 & 19,67 & 3,670 \\
\hline & $\begin{array}{l}\text { Stenose \& } \\
\text { Normocholesterinämie }\end{array}$ & 24 & 7 & 42 & 17,17 & 9,644 \\
\hline & $\begin{array}{l}\text { Stenose \& } \\
\text { Hypercholesterinämie }\end{array}$ & 19 & 10 & 36 & 18,79 & 7,843 \\
\hline \multirow[t]{4}{*}{ größte LK: Größe [mm] } & Gesund & 17 & 0,0 & 24,0 & 17,629 & 5,7615 \\
\hline & $\begin{array}{l}\text { Gesund \& } \\
\text { Hypercholesterinämie }\end{array}$ & 6 & 5,8 & 21,9 & 16,717 & 6,6255 \\
\hline & $\begin{array}{l}\text { Stenose \& } \\
\text { Normocholesterinämie }\end{array}$ & 24 & 0,0 & 23,7 & 14,462 & 7,1314 \\
\hline & $\begin{array}{l}\text { Stenose \& } \\
\text { Hypercholesterinämie }\end{array}$ & 19 & 0,0 & 24,7 & 15,868 & 7,1196 \\
\hline \multirow[t]{4}{*}{ Carotis-LK: Anzahl } & Gesund & 17 & 0 & 14 & 6,71 & 3,820 \\
\hline & $\begin{array}{l}\text { Gesund \& } \\
\text { Hypercholesterinämie }\end{array}$ & 6 & 3 & 8 & 5,33 & 2,582 \\
\hline & $\begin{array}{l}\text { Stenose \& } \\
\text { Normocholesterinämie }\end{array}$ & 24 & 2 & 12 & 6,04 & 3,407 \\
\hline & $\begin{array}{l}\text { Stenose \& } \\
\text { Hypercholesterinämie }\end{array}$ & 19 & 0 & 13 & 5,58 & 3,437 \\
\hline \multirow[t]{4}{*}{ Carotis-LK: Größe [mm] } & Gesund & 17 & 0,0 & 60,6 & 29,700 & 17,7055 \\
\hline & $\begin{array}{l}\text { Gesund \& } \\
\text { Hypercholesterinämie }\end{array}$ & 6 & 11,1 & 43,6 & 25,483 & 13,4720 \\
\hline & $\begin{array}{l}\text { Stenose \& } \\
\text { Normocholesterinämie }\end{array}$ & 24 & 7,0 & 63,4 & 27,596 & 16,3146 \\
\hline & $\begin{array}{l}\text { Stenose \& } \\
\text { Hypercholesterinämie }\end{array}$ & 19 & 0,0 & 62,1 & 25,700 & 16,1463 \\
\hline \multirow[t]{4}{*}{ Stichprobenumfang } & Gesund & 17 & & & & \\
\hline & $\begin{array}{l}\text { Gesund \& } \\
\text { Hypercholesterinämie }\end{array}$ & 6 & & & & \\
\hline & $\begin{array}{l}\text { Stenose \& } \\
\text { Normocholesterinämie }\end{array}$ & 24 & & & & \\
\hline & $\begin{array}{l}\text { Stenose \& } \\
\text { Hypercholesterinämie }\end{array}$ & 19 & & & & \\
\hline
\end{tabular}

Tab. 35 Beschreibende Statistik zur Hypothese „Es besteht ein Zusammenhang zwischen den Begleiterkrankungen eines Stenosepatienten und der Anzahl bzw. Größe seiner zervikalen Lymphknoten“ für alle Level, Level II-IV, Größe größte Lymphknoten, Anzahl und Größe Carotis-Lymphknoten bezogen auf Hypercholesterinämie 


\section{ANOVA}

\begin{tabular}{|c|c|c|c|c|c|c|}
\hline & & Quadratsumme & Freiheitsgrad & $\begin{array}{c}\text { Mittlere } \\
\text { Quadratsumme }\end{array}$ & $\mathrm{F}$ & $p$-Wert \\
\hline Anzahl LK alle Level & $\begin{array}{l}\text { Zwischen den Gruppen } \\
\text { Innerhalb der Gruppen } \\
\text { Total }\end{array}$ & $\begin{array}{r}210,682 \\
9102,181 \\
9312,864 \\
\end{array}$ & $\begin{array}{r}3 \\
62 \\
65 \\
\end{array}$ & $\begin{array}{r}70,227 \\
146,809\end{array}$ & 0,478 & 0,699 \\
\hline Anzahl LK II-IV & $\begin{array}{l}\text { Zwischen den Gruppen } \\
\text { Innerhalb der Gruppen } \\
\text { Total }\end{array}$ & $\begin{array}{r}44,735 \\
4260,295 \\
4305,030\end{array}$ & $\begin{array}{r}3 \\
62 \\
65\end{array}$ & $\begin{array}{l}14,912 \\
68,714\end{array}$ & 0,217 & 0,884 \\
\hline größte LK: Größe [mm] & $\begin{array}{l}\text { Zwischen den Gruppen } \\
\text { Innerhalb der Gruppen } \\
\text { Total }\end{array}$ & $\begin{array}{r}104,449 \\
2832,721 \\
2937,170\end{array}$ & $\begin{array}{r}3 \\
62 \\
65\end{array}$ & $\begin{array}{l}34,816 \\
45,689\end{array}$ & 0,762 & 0,520 \\
\hline Carotis-LK: Anzahl & $\begin{array}{l}\text { Zwischen den Gruppen } \\
\text { Innerhalb der Gruppen } \\
\text { Total }\end{array}$ & $\begin{array}{r}14,532 \\
746,453 \\
760,985\end{array}$ & $\begin{array}{r}3 \\
62 \\
65\end{array}$ & $\begin{array}{r}4,844 \\
12,040\end{array}$ & 0,402 & 0,752 \\
\hline Carotis-LK: Größe [mm] & $\begin{array}{l}\text { Zwischen den Gruppen } \\
\text { Innerhalb der Gruppen } \\
\text { Total }\end{array}$ & $\begin{array}{r}167,802 \\
16737,718 \\
16905,520\end{array}$ & $\begin{array}{r}3 \\
62 \\
65\end{array}$ & $\begin{array}{r}55,934 \\
269,963\end{array}$ & 0,207 & 0,891 \\
\hline
\end{tabular}

Tab. 36 Varianzanalyse zur Hypothese „Es besteht ein Zusammenhang zwischen den Begleiterkrankungen eines Stenosepatienten und der Anzahl bzw. Größe seiner zervikalen Lymphknoten“ für alle Level, Level II-IV, Größe größte Lymphknoten, Anzahl und Größe Carotis-Lymphknoten bezogen auf Hypercholesterinämie 


\section{Diabetes mellitus}

Ein-Stichproben Kolmogorov-Smirnov Test

\begin{tabular}{|c|c|c|c|c|c|c|c|}
\hline \multicolumn{3}{|c|}{ Diabetes bei Stenose \& Gesund } & $\begin{array}{l}\text { Anzahl LK } \\
\text { alle Level }\end{array}$ & $\begin{array}{c}\text { Anzahl LK II- } \\
\text { IV }\end{array}$ & $\begin{array}{l}\text { größte LK: } \\
\text { Größe [mm] }\end{array}$ & $\begin{array}{c}\text { Carotis-LK: } \\
\text { Anzahl }\end{array}$ & $\begin{array}{l}\text { Carotis-LK: } \\
\text { Größe [mm] }\end{array}$ \\
\hline \multirow[t]{8}{*}{ Gesund } & $\mathrm{N}$ & & 21 & 21 & 21 & 21 & 21 \\
\hline & \multirow[t]{2}{*}{ Normalparameter ${ }^{a}$} & Mittelwert & 31,10 & 18,71 & 17,629 & 6,24 & 27,995 \\
\hline & & Std.-Abweichung & 11,086 & 7,022 & 5,3623 & 3,404 & 15,4533 \\
\hline & \multirow[t]{3}{*}{ Größte Differenzen } & Absolut & 0,101 & 0,104 & 0,187 & 0,160 & 0,110 \\
\hline & & Positiv & 0,101 & 0,083 & 0,154 & 0,160 & 0,110 \\
\hline & & Negativ & $-0,092$ & $-0,104$ & $-0,187$ & $-0,112$ & $-0,097$ \\
\hline & \multicolumn{2}{|c|}{ Kolmogorov-Smirnov Z } & 0,462 & 0,476 & 0,856 & 0,731 & 0,504 \\
\hline & \multicolumn{2}{|l|}{$\mathrm{p}$-Wert } & 0,983 & 0,977 & 0,456 & 0,659 & 0,961 \\
\hline \multirow{8}{*}{$\begin{array}{l}\text { Stenose ohne } \\
\text { Diabetes mellitus }\end{array}$} & \multicolumn{2}{|l|}{$\mathrm{N}$} & 32 & 32 & 32 & 32 & 32 \\
\hline & \multirow[t]{2}{*}{ Normalparameter $^{\mathrm{a}}$} & Mittelwert & 26,56 & 16,12 & 14,359 & 5,16 & 23,456 \\
\hline & & Std.-Abweichung & 9,755 & 7,391 & 7,1861 & 3,163 & 14,2487 \\
\hline & \multirow[t]{3}{*}{ Größte Differenzen } & Absolut & 0,118 & 0,163 & 0,159 & 0,176 & 0,126 \\
\hline & & Positiv & 0,118 & 0,163 & 0,141 & 0,176 & 0,126 \\
\hline & & Negativ & $-0,108$ & $-0,108$ & $-0,159$ & $-0,128$ & $-0,091$ \\
\hline & \multicolumn{2}{|c|}{ Kolmogorov-Smirnov Z } & 0,665 & 0,922 & 0,898 & 0,995 & 0,711 \\
\hline & \multicolumn{2}{|l|}{$\mathrm{p}$-Wert } & 0,769 & 0,363 & 0,395 & 0,275 & 0,693 \\
\hline \multirow{8}{*}{$\begin{array}{l}\text { Stenose \& Diabetes } \\
\text { mellitus }\end{array}$} & \multicolumn{2}{|l|}{$\mathrm{N}$} & 11 & 11 & 11 & 11 & 11 \\
\hline & \multirow[t]{2}{*}{ Normalparameter ${ }^{a}$} & Mittelwert & 38,82 & 23,00 & 17,191 & 7,82 & 36,364 \\
\hline & & Std.-Abweichung & 15,880 & 10,927 & 6,6076 & 3,371 & 17,8745 \\
\hline & \multirow[t]{3}{*}{ Größte Differenzen } & Absolut & 0,140 & 0,279 & 0,264 & 0,191 & 0,243 \\
\hline & & Positiv & 0,140 & 0,279 & 0,135 & 0,162 & 0,243 \\
\hline & & Negativ & $-0,118$ & $-0,137$ & $-0,264$ & $-0,191$ & $-0,184$ \\
\hline & \multicolumn{2}{|c|}{ Kolmogorov-Smirnov Z } & 0,466 & 0,926 & 0,876 & 0,634 & 0,807 \\
\hline & \multicolumn{2}{|l|}{$\mathrm{p}$-Wert } & 0,982 & 0,358 & 0,427 & 0,817 & 0,533 \\
\hline \multirow{8}{*}{$\begin{array}{l}\text { Gesund \& Diabetes } \\
\text { nellitus }\end{array}$} & \multicolumn{2}{|l|}{$\mathrm{N}$} & 2 & 2 & 2 & 2 & 2 \\
\hline & \multirow[t]{2}{*}{ Normalparameter $^{\mathrm{a}}$} & Mittelwert & 23,50 & 17,00 & 14,900 & 7,50 & 34,950 \\
\hline & & Std.-Abweichung & 6,364 & 5,657 & 12,8693 & 6,364 & 33,7290 \\
\hline & \multirow[t]{3}{*}{ Größte Differenzen } & Absolut & 0,260 & 0,260 & 0,260 & 0,260 & 0,260 \\
\hline & & Positiv & 0,260 & 0,260 & 0,260 & 0,260 & 0,260 \\
\hline & & Negativ & $-0,260$ & $-0,260$ & $-0,260$ & $-0,260$ & $-0,260$ \\
\hline & \multicolumn{2}{|c|}{ Kolmogorov-Smirnov Z } & 0,368 & 0,368 & 0,368 & 0,368 & 0,368 \\
\hline & \multicolumn{2}{|l|}{ p-Wert } & 0,999 & 0,999 & 0,999 & 0,999 & 0,999 \\
\hline
\end{tabular}

Tab. 37 Prüfung der Normalverteilung zur Hypothese „Es besteht ein Zusammenhang zwischen den Begleiterkrankungen eines Stenosepatienten und der Anzahl bzw. Größe seiner zervikalen Lymphknoten" für alle Level, Level II-IV, Größe größte Lymphknoten, Anzahl und Größe Carotis-Lymphknoten bezogen auf Diabetes mellitus 
Beschreibende Statistik

\begin{tabular}{|c|c|c|c|c|c|c|}
\hline & $\begin{array}{l}\text { Diabetes bei Stenose \& } \\
\text { Gesund }\end{array}$ & $\mathrm{N}$ & Minimum & Maximum & Mittelwert & Std.-Abweichung \\
\hline \multirow[t]{4}{*}{ Anzahl LK alle Level } & Gesund & 21 & 11 & 56 & 31,10 & 11,086 \\
\hline & Gesund \& Diabetes mellitus & 2 & 19 & 28 & 23,50 & 6,364 \\
\hline & $\begin{array}{l}\text { Stenose ohne Diabetes } \\
\text { mellitus }\end{array}$ & 32 & 13 & 49 & 26,56 & 9,755 \\
\hline & Stenose \& Diabetes mellitus & 11 & 20 & 70 & 38,82 & 15,880 \\
\hline \multirow[t]{4}{*}{ Anzahl LK II-IV } & Gesund & 21 & 7 & 36 & 18,71 & 7,022 \\
\hline & Gesund \& Diabetes mellitus & 2 & 13 & 21 & 17,00 & 5,657 \\
\hline & $\begin{array}{l}\text { Stenose ohne Diabetes } \\
\text { mellitus }\end{array}$ & 32 & 7 & 32 & 16,12 & 7,391 \\
\hline & Stenose \& Diabetes mellitus & 11 & 10 & 42 & 23,00 & 10,927 \\
\hline \multirow[t]{4}{*}{ größte LK: Größe [mm] } & Gesund & 21 & 0,0 & 23,1 & 17,629 & 5,3623 \\
\hline & Gesund \& Diabetes mellitus & 2 & 5,8 & 24,0 & 14,900 & 12,8693 \\
\hline & $\begin{array}{l}\text { Stenose ohne Diabetes } \\
\text { mellitus }\end{array}$ & 32 & 0,0 & 23,5 & 14,359 & 7,1861 \\
\hline & Stenose \& Diabetes mellitus & 11 & 5,6 & 24,7 & 17,191 & 6,6076 \\
\hline \multirow[t]{4}{*}{ Carotis-LK: Anzahl } & Gesund & 21 & 0 & 14 & 6,24 & 3,404 \\
\hline & Gesund \& Diabetes mellitus & 2 & 3 & 12 & 7,50 & 6,364 \\
\hline & $\begin{array}{l}\text { Stenose ohne Diabetes } \\
\text { mellitus }\end{array}$ & 32 & 0 & 12 & 5,16 & 3,163 \\
\hline & Stenose \& Diabetes mellitus & 11 & 4 & 13 & 7,82 & 3,371 \\
\hline \multirow[t]{4}{*}{ Carotis-LK: Größe [mm] } & Gesund & 21 & 0,0 & 60,6 & 27,995 & 15,4533 \\
\hline & Gesund \& Diabetes mellitus & 2 & 11,1 & 58,8 & 34,950 & 33,7290 \\
\hline & $\begin{array}{l}\text { Stenose ohne Diabetes } \\
\text { mellitus }\end{array}$ & 32 & 0,0 & 56,8 & 23,456 & 14,2487 \\
\hline & Stenose \& Diabetes mellitus & 11 & 17,8 & 63,4 & 36,364 & 17,8745 \\
\hline \multirow[t]{4}{*}{ Stichprobenumfang } & Gesund & 21 & & & & \\
\hline & Gesund \& Diabetes mellitus & 2 & & & & \\
\hline & $\begin{array}{l}\text { Stenose ohne Diabetes } \\
\text { mellitus }\end{array}$ & 32 & & & & \\
\hline & Stenose \& Diabetes mellitus & 11 & & & & \\
\hline
\end{tabular}

Tab. 38 Beschreibende Statistik zur Hypothese „Es besteht ein Zusammenhang zwischen den Begleiterkrankungen eines Stenosepatienten und der Anzahl bzw. Größe seiner zervikalen Lymphknoten“ für alle Level, Level II-IV, Größe größte Lymphknoten, Anzahl und Größe Carotis-Lymphknoten bezogen auf Diabetes mellitus

\begin{tabular}{|c|c|c|c|c|c|c|}
\hline \multicolumn{7}{|c|}{ ANOVA } \\
\hline & & Quadratsumme & Freiheitsgrad & $\begin{array}{c}\text { Mittlere } \\
\text { Quadratsumme }\end{array}$ & $\mathrm{F}$ & $\mathrm{p}$-Wert \\
\hline \multirow[t]{3}{*}{ Anzahl LK alle Level } & Zwischen den Gruppen & 1343,043 & 3 & 447,681 & 3,483 & 0,021 \\
\hline & Innerhalb der Gruppen & 7969,821 & 62 & 128,545 & & \\
\hline & Total & 9312,864 & 65 & & & \\
\hline \multirow[t]{3}{*}{ Anzahl LK II-IV } & Zwischen den Gruppen & 399,245 & 3 & 133,082 & 2,113 & 0,108 \\
\hline & Innerhalb der Gruppen & 3905,786 & 62 & 62,997 & & \\
\hline & Total & 4305,030 & 65 & & & \\
\hline \multirow[t]{3}{*}{ größte LK: Größe [mm] } & Zwischen den Gruppen & 159,021 & 3 & 53,007 & 1,183 & 0,324 \\
\hline & Innerhalb der Gruppen & 2778,149 & 62 & 44,809 & & \\
\hline & Total & 2937,170 & 65 & & & \\
\hline \multirow[t]{3}{*}{ Carotis-LK: Anzahl } & Zwischen den Gruppen & 64,820 & 3 & 21,607 & 1,924 & 0,135 \\
\hline & Innerhalb der Gruppen & 696,165 & 62 & 11,228 & & \\
\hline & Total & 760,985 & 65 & & & \\
\hline \multirow[t]{3}{*}{ Carotis-LK: Größe [mm] } & Zwischen den Gruppen & 1502,961 & 3 & 500,987 & 2,017 & 0,121 \\
\hline & Within Groups & 15402,559 & 62 & 248,428 & & \\
\hline & Total & 16905,520 & 65 & & & \\
\hline
\end{tabular}

Tab. 39 Varianzanalyse zur Hypothese „Es besteht ein Zusammenhang zwischen den Begleiterkrankungen eines Stenosepatienten und der Anzahl bzw. Größe seiner zervikalen Lymphknoten“ für alle Level, Level II-IV, Größe größte Lymphknoten, Anzahl und Größe Carotis-Lymphknoten bezogen auf Diabetes mellitus 
CRP $>5 \mathrm{mg} / \mathrm{l}$

Ein-Stichproben Kolmogorov-Smirnov Test

\begin{tabular}{|c|c|c|c|c|c|c|c|}
\hline \multicolumn{3}{|c|}{ CRP > $5 \mathrm{mg} / \mathrm{l}$ bei Stenose \& Gesund } & $\begin{array}{l}\text { Anzahl LK } \\
\text { alle Level }\end{array}$ & $\begin{array}{c}\text { Anzahl LK II- } \\
\text { IV }\end{array}$ & $\begin{array}{l}\text { größte LK: } \\
\text { Größe [mm] }\end{array}$ & $\begin{array}{c}\text { Carotis-LK: } \\
\text { Anzahl }\end{array}$ & $\begin{array}{l}\text { Carotis-LK: } \\
\text { Größe [mm] }\end{array}$ \\
\hline \multirow[t]{8}{*}{ Gesund } & $\mathrm{N}$ & & 20 & 20 & 20 & 20 & 20 \\
\hline & \multirow[t]{2}{*}{ Normalparameter ${ }^{\mathrm{a}}$} & Mittelwert & 30,40 & 18,65 & 17,520 & 6,05 & 27,795 \\
\hline & & Std.-Abweichung & 11,236 & 7,110 & 5,5063 & 3,252 & 15,6547 \\
\hline & \multirow[t]{3}{*}{ Größte Differenzen } & Absolut & 0,124 & 0,129 & 0,178 & 0,124 & 0,097 \\
\hline & & Positiv & 0,124 & 0,093 & 0,133 & 0,124 & 0,097 \\
\hline & & Negativ & $-0,069$ & $-0,129$ & $-0,178$ & $-0,115$ & $-0,081$ \\
\hline & \multicolumn{2}{|c|}{ Kolmogorov-Smirnov Z } & 0,556 & 0,579 & 0,794 & 0,556 & 0,432 \\
\hline & \multicolumn{2}{|l|}{$\mathrm{p}$-Wert } & 0,917 & 0,891 & 0,554 & 0,916 & 0,992 \\
\hline \multirow{8}{*}{$\begin{array}{l}\text { Stenose ohne CRP } \\
(<5 \mathrm{mg} / \mathrm{l})\end{array}$} & \multicolumn{2}{|l|}{$\mathrm{N}$} & 28 & 28 & 28 & 28 & 28 \\
\hline & \multirow[t]{2}{*}{ Normalparameter $^{a}$} & Mittelwert & 29,14 & 17,57 & 14,761 & 5,64 & 25,729 \\
\hline & & Std.-Abweichung & 12,613 & 9,045 & 7,3172 & 3,347 & 16,5579 \\
\hline & \multirow[t]{3}{*}{ Größte Differenzen } & Absolut & 0,164 & 0,152 & 0,171 & 0,172 & 0,176 \\
\hline & & Positiv & 0,164 & 0,152 & 0,118 & 0,172 & ,0176 \\
\hline & & Negativ & $-0,117$ & $-0,121$ & $-0,171$ & $-0,118$ & $-0,108$ \\
\hline & \multicolumn{2}{|c|}{ Kolmogorov-Smirnov Z } & 0,870 & 0,802 & 0,907 & 0,909 & 0,934 \\
\hline & \multicolumn{2}{|l|}{$\mathrm{p}$-Wert } & 0,435 & 0,541 & 0,383 & 0,380 & 0,348 \\
\hline \multirow{8}{*}{$\begin{array}{l}\text { Stenose \& CRP } \\
(>5 \mathrm{mg} / \mathrm{l})\end{array}$} & \multicolumn{2}{|l|}{$\mathrm{N}$} & 15 & 15 & 15 & 15 & 15 \\
\hline & \multirow[t]{2}{*}{ Normalparameter ${ }^{a}$} & Mittelwert & 30,73 & 18,47 & 15,687 & 6,20 & 28,680 \\
\hline & & Std.-Abweichung & 13,041 & 8,692 & 6,8090 & 3,550 & 15,5037 \\
\hline & \multirow[t]{3}{*}{ Größte Differenzen } & Absolut & 0,128 & 0,230 & 0,233 & 0,232 & 0,158 \\
\hline & & Positiv & 0,128 & 0,230 & 0,187 & 0,232 & 0,158 \\
\hline & & Negativ & $-0,119$ & $-0,125$ & $-0,233$ & $-0,118$ & $-0,098$ \\
\hline & \multicolumn{2}{|c|}{ Kolmogorov-Smirnov Z } & 0,496 & 0,889 & 0,902 & 0,900 & 0,614 \\
\hline & \multicolumn{2}{|l|}{$\mathrm{p}$-Wert } & 0,966 & 0,407 & 0,390 & 0,393 & 0,846 \\
\hline \multirow{8}{*}{$\begin{array}{l}\text { Gesund \& CRP } \\
(>5 \mathrm{mg} / \mathrm{l})\end{array}$} & \multicolumn{2}{|l|}{$\mathrm{N}$} & 3 & 3 & 3 & 3 & 3 \\
\hline & \multirow[t]{2}{*}{ Normalparameter ${ }^{\mathrm{a}}$} & Mittelwert & 30,67 & 18,00 & 16,533 & 8,33 & 33,967 \\
\hline & & Std.-Abweichung & 10,116 & 5,568 & 9,3725 & 5,508 & 24,9640 \\
\hline & \multirow[t]{3}{*}{ Größte Differenzen } & Absolut & 0,368 & 0,238 & 0,338 & 0,191 & 0,227 \\
\hline & & Positiv & 0,266 & 0,238 & 0,242 & 0,191 & 0,227 \\
\hline & & Negativ & $-0,368$ & $-0,193$ & $-0,338$ & $-0,182$ & $-0,190$ \\
\hline & \multicolumn{2}{|c|}{ Kolmogorov-Smirnov Z } & 0,637 & 0,412 & 0,586 & 0,330 & 0,393 \\
\hline & \multicolumn{2}{|l|}{$\mathrm{p}$-Wert } & 0,812 & 0,996 & 0,882 & 1,000 & 0,998 \\
\hline
\end{tabular}

a. Es besteht Normalverteilung.

Tab. 40 Prüfung der Normalverteilung zur Hypothese „Es besteht ein Zusammenhang zwischen den Begleiterkrankungen eines Stenosepatienten und der Anzahl bzw. Größe seiner zervikalen Lymphknoten“ für alle Level, Level II-IV, Größe größte Lymphknoten, Anzahl und Größe Carotis-Lymphknoten bezogen auf einen CRP-Wert $>5 \mathrm{mg} / \mathrm{l}$ 
Beschreibende Statistik

\begin{tabular}{|c|c|c|c|c|c|c|}
\hline & $\begin{array}{l}\text { CRP }>5 \mathrm{mg} / \mathrm{l} \text { bei Stenose \& } \\
\text { Gesund }\end{array}$ & $\mathrm{N}$ & Minimum & Maximum & Mittelwert & Std.-Abweichung \\
\hline \multirow[t]{4}{*}{ Anzahl LK alle Level } & Gesund & 20 & 11 & 56 & 30,40 & 11,236 \\
\hline & Gesund \& CRP > $5 \mathrm{mg} / \mathrm{l}$ & 3 & 19 & 37 & 30,67 & 10,116 \\
\hline & Stenose ohne CRP $(<5 \mathrm{mg} / \mathrm{l})$ & 28 & 14 & 70 & 29,14 & 12,613 \\
\hline & Stenose \& CRP > $5 \mathrm{mg} / \mathrm{l}$ & 15 & 13 & 51 & 30,73 & 13,041 \\
\hline \multirow[t]{4}{*}{ Anzahl LK II-IV } & Gesund & 20 & 7 & 36 & 18,65 & 7,110 \\
\hline & Gesund \& CRP $>5 \mathrm{mg} / \mathrm{l}$ & 3 & 13 & 24 & 18,00 & 5,568 \\
\hline & Stenose ohne CRP $(<5 \mathrm{mg} / \mathrm{l})$ & 28 & 7 & 42 & 17,57 & 9,045 \\
\hline & Stenose \& CRP > $5 \mathrm{mg} / \mathrm{l}$ & 15 & 7 & 36 & 18,47 & 8,692 \\
\hline \multirow[t]{4}{*}{ größte LK: Größe [mm] } & Gesund & 20 & 0,0 & 24,0 & 17,520 & 5,5063 \\
\hline & Gesund \& CRP $>5 \mathrm{mg} / \mathrm{l}$ & 3 & 5,8 & 23,1 & 16,533 & 9,3725 \\
\hline & Stenose ohne CRP $(<5 \mathrm{mg} / \mathrm{l})$ & 28 & 0,0 & 24,7 & 14,761 & 7,3172 \\
\hline & Stenose \& CRP > $5 \mathrm{mg} / \mathrm{l}$ & 15 & 5,6 & 23,2 & 15,687 & 6,8090 \\
\hline \multirow[t]{4}{*}{ Carotis-LK: Anzahl } & Gesund & 20 & 0 & 12 & 6,05 & 3,252 \\
\hline & Gesund \& CRP $>5 \mathrm{mg} / \mathrm{l}$ & 3 & 3 & 14 & 8,33 & 5,508 \\
\hline & Stenose ohne CRP $(<5 \mathrm{mg} / \mathrm{l})$ & 28 & 0 & 12 & 5,64 & 3,347 \\
\hline & Stenose \& CRP > $5 \mathrm{mg} / \mathrm{l}$ & 15 & 2 & 13 & 6,20 & 3,550 \\
\hline \multirow[t]{4}{*}{ Carotis-LK: Größe [mm] } & Gesund & 20 & 0,0 & 58,8 & 27,795 & 15,6547 \\
\hline & Gesund \& CRP $>5 \mathrm{mg} / \mathrm{l}$ & 3 & 11,1 & 60,6 & 33,967 & 24,9640 \\
\hline & Stenose ohne CRP $(<5 \mathrm{mg} / \mathrm{l})$ & 28 & 0,0 & 63,4 & 25,729 & 16,5579 \\
\hline & Stenose \& CRP > $5 \mathrm{mg} / \mathrm{l}$ & 15 & 6,9 & 60,5 & 28,680 & 15,5037 \\
\hline \multirow[t]{4}{*}{ Stichprobenumfang } & Gesund & 20 & & & & \\
\hline & Gesund \& CRP $>5 \mathrm{mg} / \mathrm{l}$ & 3 & & & & \\
\hline & Stenose ohne CRP $(<5 \mathrm{mg} / \mathrm{l})$ & 28 & & & & \\
\hline & Stenose \& CRP $>5 \mathrm{mg} / \mathrm{l}$ & 15 & & & & \\
\hline
\end{tabular}

Tab. 41 Beschreibende Statistik zur Hypothese „Es besteht ein Zusammenhang zwischen den Begleiterkrankungen eines Stenosepatienten und der Anzahl bzw. Größe seiner zervikalen Lymphknoten“ für alle Level, Level II-IV, Größe größte Lymphknoten, Anzahl und Größe Carotis-Lymphknoten bezogen auf einen CRP-Wert $>5 \mathrm{mg} / \mathrm{l}$

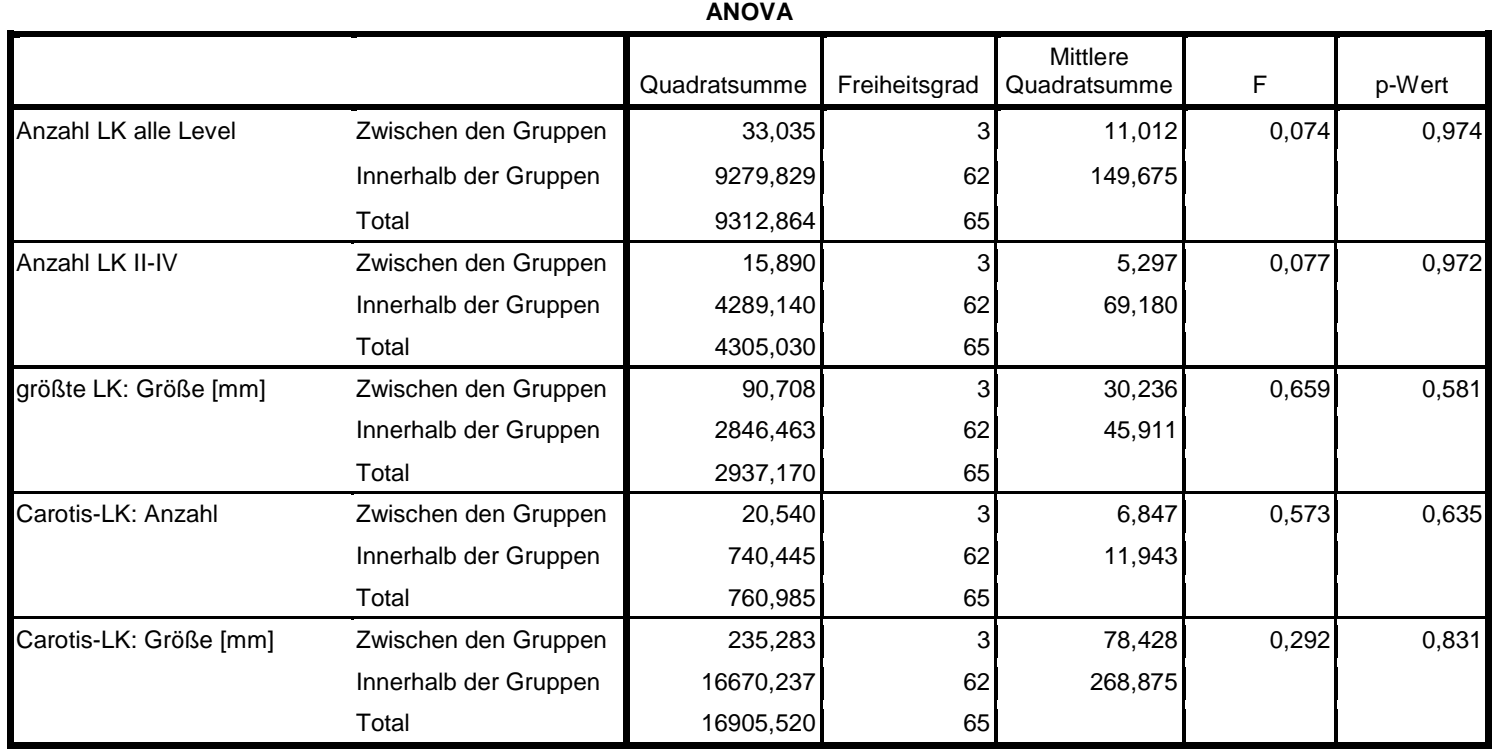

Tab. 42 Varianzanalyse zur Hypothese „Es besteht ein Zusammenhang zwischen den Begleiterkrankungen eines Stenosepatienten und der Anzahl bzw. Größe seiner zervikalen Lymphknoten“ für alle Level, Level II-IV, Größe größte Lymphknoten, Anzahl und Größe Carotis-Lymphknoten bezogen auf einen CRP-Wert > $5 \mathrm{mg} / \mathrm{l}$ 


\subsection{Formular zum Lymphknotenzählen}

Patient:

\section{Notizen:}

\begin{tabular}{|c|c|c|c|c|c|c|}
\hline \multicolumn{2}{|l|}{ Level } & $3-5 \mathrm{~mm}$ & $>5.7 \mathrm{~mm}$ & $>7-10 \mathrm{~mm}$ & $>10 \mathrm{~mm}$ & gesamt \\
\hline \multirow[t]{2}{*}{ IA } & links & & & & & \\
\hline & rechts & & & & & \\
\hline \multirow[t]{2}{*}{ IB } & links & & & & & \\
\hline & rechts & & & & & \\
\hline \multirow[t]{2}{*}{ IIA } & links & & & & & \\
\hline & rechts & & & & & \\
\hline \multirow[t]{2}{*}{ IIB } & links & & & & & \\
\hline & rechts & & & & & \\
\hline \multirow[t]{2}{*}{ III } & links & & & & & \\
\hline & rechts & & & & & \\
\hline \multirow[t]{2}{*}{ IV } & links & & & & & \\
\hline & rechts & & & & & \\
\hline \multirow[t]{2}{*}{ VA } & links & & & & & \\
\hline & rechts & & & & & \\
\hline \multirow[t]{2}{*}{ VB } & links & & & & & \\
\hline & rechts & & & & & \\
\hline \multirow[t]{2}{*}{ VI } & links & & & & & \\
\hline & rechts & & & & & \\
\hline \multicolumn{7}{|l|}{ VII } \\
\hline \multicolumn{2}{|c|}{ retrophar. } & & & & & \\
\hline \multicolumn{2}{|c|}{ gesamt } & & & & & \\
\hline
\end{tabular}

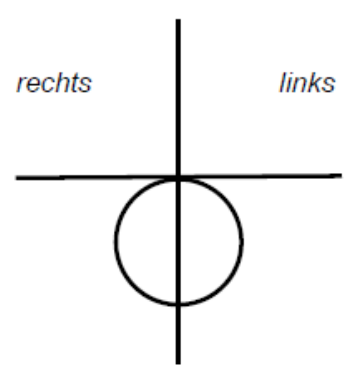

Größte LK's:

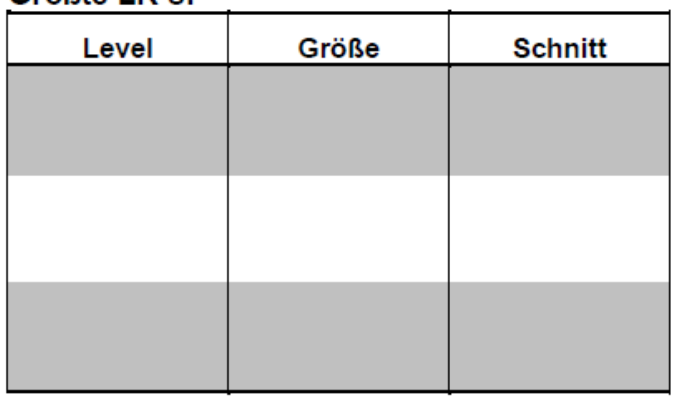

Karotisgabel:

\begin{tabular}{|l|l|l|l|}
\hline \multirow{3}{*}{ links } & Level & Größe & Schnitt \\
\cline { 2 - 4 } & & & \\
& & & \\
& & & \\
\hline rechts & & & \\
& & & \\
& & & \\
& & & \\
& & & \\
\hline
\end{tabular}

Stenose:

\begin{tabular}{|l|l|l|}
\hline & rechts & links \\
\hline NASCET & & \\
ECST & & \\
CC & & \\
\hline
\end{tabular}

$\begin{array}{ll}A= & A= \\ B= & B= \\ C= & C= \\ D= & D=\end{array}$




\subsection{Abkürzungen}

\section{Alphabetisch:}

A.:

Abb.:

ACl:

CAM:

CAS:

CC:

CD:

CEA:

CE-MRA:

CRP:

CT:

CTA:

DSA:

DWI:

ECST:

EKG:

FDG-PET-CT:

GM-CSF:

HMG-CoA-Reduktase:

HU:

ICAM-1:

IF:

IL:

i.v.:

LDL:

LK:

Lnn.:

M.:

M-CSF:

$\mathrm{Mm}$ :

MMP:

MRA:

MRT:

NASCET:

PAPP-A:

PDW:

PTA:

PWI:

ROS:

rtPA:

S.:

S.0.:

SRA:

s.u.:

Tab.:

TEA:

TNF:

TOF:

T1W:

T2W:

UPSIO:

VCAM-1:

z.B.:
Arteria

Abbildung

Arteria carotis interna

Cell adhesion molecules

Carotid artery stenting

Common Carotid Method

Cluster of Differentiation

Carotid endarterectomy

Contrast-enhanced MRA

C-reaktives Protein

Computertomographie

CT-Angiographie

Digitale Subtraktionsangiographie

Diffusion-weighted imaging

European Carotid Surgery Trial

Elektrokardiogramm

Fluoro-Desoxy-Glucose-Positronen-Emissions-Tomographie-CT

Granulocyte-macrophage colony-stimulating factor

3-Hydroxy-3-Methylglutaryl-Coenzym-A-Reduktase

Hounsfield-Unit

Inter-Cellular Adhesion Molecule 1

Interferon

Interleukin

Intravenös

Low-Density-Lipoprotein

Lymphknoten

Nodi lymphatici

Musculus

Macrophage colony stimulating factor

Musculi

Matrixmetalloproteinasen

MR-Angiographie

Magnetresonanztomographie

North American Symptomatic Carotid Endarterectomy Trial

Plasma Protein A

Proton-density-weighted

Perkutane transluminale Angioplastie

Perfusion-weighted imaging

Reaktive Sauerstoff Spezies

Alteplase

siehe

siehe oben

Scavenger Receptor

siehe unten

Tabelle

Thrombendarteriektomie

Tumornekrosefaktor

Time-of-flight

T1-weighted

T2-weighted

Ultrasmall supramagnetic iron oxide

Vascular cell adhesion molecule-1

zum Beispiel 


\section{Literaturverzeichnis}

(Alvarez Garcia et al. 2003) = Alvarez Garcia B, Ruiz C, Chacon P, Sabin JA, Matas M (2003): High-sensitivity C-reactive protein in high-grade carotid stenosis: risk marker for unstable carotid plaque. J Vasc Surg $\underline{38}$, 1018-1024

(Anderson et al. 2000) = Anderson GB, Ashforth R, Steinke DE, Ferdinandy R, Findlay JM (2000): $\mathrm{CT}$ angiography for the detection and characterization of carotid artery bifurcation disease. Stroke 31, 2168-2174

(Barnett et al. 1998) = Barnett HJ, Taylor DW, Eliasziw M, Fox AJ, Ferguson GG, Haynes RB, Rankin RN, Clagett GP, Hachinski VC, Sackett DL (1998): Benefit of carotid endarterectomy in patients with symptomatic moderate or severe stenosis. North American Symptomatic Carotid Endarterectomy Trial Collaborators. N Engl J Med 339, 1415-1425

(Bartlett et al. 2006) = Bartlett ES, Walters TD, Symons SP, Fox AJ (2006): Diagnosing carotid stenosis near-occlusion by using CT angiography. AJNR Am J Neuroradiol 27, 632-637

(Berg et al. 2005) = Berg M, Zhang Z, Ikonen A, Sipola P, Kalviainen R, Manninen H, Vanninen R (2005): Multi-detector row CT angiography in the assessment of carotid artery disease in symptomatic patients: comparison with rotational angiography and digital subtraction angiography. AJNR Am J Neuroradiol 26, $1022-1034$

(Blake und Ridker 2001) = Blake GJ, Ridker PM (2001): Novel clinical markers of vascular wall inflammation. Circ Res $\underline{89}, 763-771$

(Cannon et al. 2004) = Cannon CP, Braunwald E, McCabe CH, Rader DJ, Rouleau JL, Belder R, Joyal SV, Hill KA, Pfeffer MA, Skene AM (2004): Intensive versus moderate lipid lowering with statins after acute coronary syndromes. N Engl J Med $\underline{350}, 1495-1504$

(Denzel et al. 2005) = Denzel C, Balzer K, Muller KM, Lell M, Lang W (2005): Diagnostik der Morphologie und Oberflächenstruktur von Plaques der Arteria carotis interna. Vergleich von Sonographie, Computertomographie und Kernspintomographie. Dtsch Med Wochenschr 130, 1267-1272

(Dörner 2003) = Dörner K: Taschenlehrbuch Klinische Chemie und Hämatologie. 5. Auflage; Georg Thieme Verlag, Stuttgart 2003

(Droste et al. 1999) = Droste DW, Dittrich R, Kemény V, Schulte-Altedorneburg G, Ringelstein EB (1999): Prevalence and frequency of microembolic signals in 105 patients with extracranial carotid artery occlusive disease. J Neurol Neurosurg Psychiatry $\underline{67}, 525-528$

(Eckstein et al. 2008) = Eckstein HH, Ringleb P, Allenberg JR, Berger J, Fraedrich G, Hacke W, Hennerici M, Stingele R, Fiehler J, Zeumer H (2008): Results of the Stent-Protected Angioplasty versus Carotid Endarterectomy (SPACE) study to treat symptomatic stenoses at 2 years: a multinational, prospective, randomides trial. Lancet Neurol $\underline{7}$, 893-902

(European Carotid Surgery Trialists' Collaborative Group 1998) = European Carotid Surgery Trialists' Collaborative Group (1998): Randomised trial of endarterectomy for recently symptomatic carotid stenosis: final results of the MRC European Carotid Surgery Trial (ECST). Lancet $\underline{351}$, 1379-1387

(Fritsch und Kühnel 2003) = Fritsch H, Kühnel W: Taschenatlas der Anatomie in 3 Bänden. 8. Auflage; Georg Thieme Verlag, Stuttgart 2003 
(Fuster et al. 2005a) = Fuster V, Moreno PR, Fayad ZA, Corti R, Badimon JJ (2005): Atherothrombosis and high-risk plaque: part I: evolving concepts. J Am Coll Cardiol $\underline{46}$, 937-954

(Fuster et al. 2005b) = Fuster V, Fayad ZA, Moreno PR, Poon M, Corti R, Badimon JJ (2005): Atherothrombosis and high-risk plaque: Part II: approaches by noninvasive computed tomographic/magnetic resonance imaging. J Am Coll Cardiol 46, 1209-1218

(Geroulakos et al. 1993) = Geroulakos G, Ramaswami G, Nicolaides A, James K, Labropoulos N, Belcaro G, Holloway M (1993): Characterization of symptomatic and asymptomatic carotid plaques using high-resolution real-time ultrasonography. Br J Surg $\underline{80}, 1274-1277$

(Gor et al. 2006) $=$ Gor DM, Langer JE, Loevner LA (2006): Imaging of cervical lymph nodes in head and neck cancer: the basics. Radiol Clin North Am 44, 101-110

(Gronholdt 1999) = Gronholdt ML (1999): Ultrasound and lipoproteins as predictors of lipid-rich, rupture-prone plaques in the carotid artery. Arterioscler Thromb Vasc Biol $\underline{19}, 2-13$

(Gröschel et al. 2007) = Gröschel K, Ernemann U, Larsen J, Knauth M, Schmidt F, Artschwager J, Kastrup A (2007): Preprocedural C-reactive protein levels predict stroke and death in patients undergoing carotid stenting. AJNR Am J Neuroradiol $\underline{28}, 1743-1746$

(Hacke et al. 2008) = Hacke W, Kaste M, Bluhmki E, Brozman M, Dávalos A, Guidetti D, Larrue V, Lees KR, Medeghri Z, Machnig T (2008): Thrombolysis with Alteplase 3 to 4.5 Hours after Acute Ischemic Stroke. N Engl J Med $\underline{359}, 1317-1329$

(Halliday et al. 2010) $=$ Halliday A, Harrison M, Hayter E, Kong X, Mansfield A, Marro J, Pan H, Peto R, Potter J, Rahimi K (2010): 10-year stroke prevention after successful carotid endarterectomy for asymptomatic stenosis (ACST-1): a multicentre randomized trial. Lancet $\underline{376}$, 1074-1084

(Hatsukami et al. 2000) = Hatsukami TS, Ross R, Polissar NL, Yuan C (2000): Visualization of fibrous cap thickness and rupture in human atherosclerotic carotid plaque in vivo with highresolution magnetic resonance imaging. Circulation 102, 959-964

$($ Herold 2006) $=$ Herold G: Innere Medizin 2007. 1. Auflage; Herold Verlag, 2006

(Hofer 2006) = Hofer M: CT-Kursbuch. 5. Auflage; Didamed Verlag, Düsseldorf 2006

$($ Hohlweg-Majert et al. 2009) $=$ Hohlweg-Majert B, Metzger MC, Voss PJ, Holzle F, Wolff KD, Schulze D (2009): Preoperative cervical lymph node size evaluation in patients with malignant head/neck tumors: comparison between ultrasound and computer tomography. J Cancer Res Clin Oncol 135(6), 753-759

(Hunt et al. 2002) = Hunt JL, Fairman R, Mitchell ME, Carpenter JP, Golden M, Khalapyan T, Wolfe M, Neschis D, Milner R, Scoll B (2002): Bone formation in carotid plaques: a clinicopathological study. Stroke $\underline{33}, 1214-1419$

(Kastrup et al. 2008) = Kastrup A, Schnaudigel S, Wasser K, Groschel K (2008): Carotid artery disease: stenting versus endarterectomy. Curr Atheroscler Rep 10, 391-397

(Kerwin et al. 2006) $=$ Kerwin WS, O'Brien KD, Ferguson MS, Polissar N, Hatsukami TS, Yuan C (2006): Inflammation in carotid atherosclerotic plaque: a dynamic contrast-enhanced MR imaging study. Radiology 241, 459-468

(Koelemay et al. 2004) = Koelemay MJW, Nederkoorn PJ, Reitsma JB, Majoie CB (2004): Systematic review of computed tomographic angiography for assessment of carotid artery disease. Stroke $\underline{35}, 2306-2312$ 
(Krupinski et al. 2006) $=$ Krupinski J, Turu MM, Martinez-Gonzalez J, Carvajal A, Juan-Babot JO, Iborra E, Slevin M, Rubio F, Badimon L (2006): Endogenous expression of C-reactive protein is increased in active (ulcerated noncomplicated) human carotid artery plaques. Stroke $\underline{37}$, 1200-1204

(Lammie et al. 2000) = Lammie GA, Wardlaw J, Allan P, Ruckley CV, Peek R, Signorini DF (2000): What pathological components indicate carotid atheroma activity and can these be identified reliably using ultrasound?. Eur J Ultrasound $\underline{11}, 77-86$

(Lell et al. 2006) $=$ Lell MM, Anders K, Uder M, Klotz E, Ditt H, Vega-Higuera F, Boskamp T, Bautz WA, Tomandl BF (2006): New techniques in CT angiography. Radiographics 26 Suppl 1, 45-62

(Lell et al. 2007) $=$ Lell M, Fellner C, Baum U, Hothorn T, Steiner R, Lang W, Bautz W, Fellner FA (2007): Evaluation of carotid artery stenosis with multisection CT and MR imaging: influence of imaging modality and postprocessing. AJNR Am J Neuroradiol $\underline{28}, 104-110$

(Libby 2002) = Libby P (2002): Inflammation in atherosclerosis. Nature $\underline{420}, 868-874$

(Libby 2008) = Libby P (2008): The molecular mechanisms of the thrombotic complications of atherosclerosis. J Intern Med 263, 517-527

(Libby und Sasiela 2006) = Libby P, Sasiela W (2006): Plaque stabilization: Can we turn theory into evidence?. Am J Cardiol $\underline{98}, 26 \mathrm{P}-33 \mathrm{P}$

(Lovett et al. 2004) = Lovett JK, Gallagher PJ, Hands LJ, Walton J, Rothwell PM (2004): Histological correlates of carotid plaque surface morphology on lumen contrast imaging. Circulation $\underline{110}, 2190-2197$

(Lüllmann-Rauch 2003) = Lüllmann-Rauch R: Histologie. 1. Auflage; Georg Thieme Verlag, Stuttgart 2003

(Markus et al. 2010) = Markus HS, King A, Shipley M, Topakian R, Cullinane M, Rheihill S, Bornstein NM, Schaafsma A (2010): Asymptomatic embolisation for prediction of stroke in the Asymptomatic Carotid Emboli Study (ACES): a prospective observational study. Lancet Neurol $\underline{9}$, 663-671

(Mathiesen et al. 2001) = Mathiesen EB, Bonaa KH, Joakimsen O (2001): Echolucent plaques are associated with high risk of ischemic cerebrovascular events in carotid stenosis: the troms $\varnothing$ study. Circulation $\underline{103}$, 2171-2175

(Mayranpaa et al. 2006) = Mayranpaa MI, Heikkila HM, Lindstedt KA, Walls AF, Kovanen PT (2006): Desquamation of human coronary artery endothelium by human mast cell proteases: implications for plaque erosion. Coron Artery Dis $\underline{17}, 611-621$

(McKinney et al. 2005) = McKinney AM, Casey SO, Teksam M, Lucato LT, Smith M, Truwit CL, Kieffer S (2005): Carotid bifurcation calcium and correlation with percent stenosis of the internal carotid artery on CT angiography. Neuroradiology $\underline{47}, 1-9$

(MRC Asymptomatic Carotid Surgery Trial (ACST) Collaborative Group 2004) = MRC Asymptomatic Carotid Surgery Trial (ACST) Collaborative Group (2004): Prevention of disabling and fatal strokes by successful carotid endarterectomy in patients without recent neurological symptoms: randomised controlled trial. Lancet $\underline{363}, 1491-1502$

(Naghavi et al. 2003) = Naghavi M, Libby P, Falk E, Casscells SW, Litovsky S, Rumberger J, Badimon JJ, Stefanadis C, Moreno P, Pasterkamp G (2003): From vulnerable plaque to vulnerable patient: a call for new definitions and risk assessment strategies: Part II. Circulation 108, 1772-1778 
(Nandalur et al. 2005) $=$ Nandalur KR, Baskurt E, Hagspiel KD, Phillips CD, Kramer CM (2005): Calcified carotid atherosclerotic plaque is associated less with ischemic symptoms than is noncalcified plaque on MDCT. AJR Am J Roentgenol 184, 295-298

(Nandalur et al. 2006) = Nandalur KR, Baskurt E, Hagspiel KD, Finch M, Phillips CD, Bollampally SR, Kramer CM (2006): Carotid artery calcification on CT may independently predict stroke risk. AJR Am J Roentgenol 186, 547-552

(Nederkoorn et al. 2003) $=$ Nederkoorn PJ, Van der Graaf Y, Hunink MGM (2003): Duplex ultrasound and magnetic resonance angiography compared with digital subtraction angiography in carotid artery stenosis: a systematic review. Stroke $\underline{34}, 1324-1332$

(Nighoghossian et al. 2005) = Nighoghossian N, Derex L, Douek P (2005): The vulnerable carotid artery plaque: current imaging methods and new perspectives. Stroke $\underline{36}, 2764-2772$

(North American Symptomatic Carotid Endarterectomy Trial Collaborators 1991) $=$ North American Symptomatic Carotid Endarterectomy Trial Collaborators (1991): Beneficial effect of carotid endarterectomy in symptomatic patients with high-grade carotid stenosis. North American Symptomatic Carotid Endarterectomy Trial Collaborators. N Engl J Med $\underline{325}$, 445-453

(Oliver et al. 1999) = Oliver TB, Lammie GA, Wright AR, Wardlaw J, Patel SG, Peek R, Ruckley CV, Collie DA (1999): Atherosclerotic plaque at the carotid bifurcation: CT angiographic appearance with histopathologic correlation. AJNR Am J Neuroradiol 20, 897-901

(Poeck und Hacke 2006) = Poeck K, Hacke W: Neurologie. 12 Auflage; Springer Medizin Verlag, Heidelberg 2006

(Randoux et al. 2001) = Randoux B, Marro B, Koskas F, Duyme M, Sahel M, Zouaoui A, Marsault C (2001): Carotid artery stenosis: prospective comparison of CT, three-dimensional gadolinium-enhanced MR, and conventional angiography. Radiology 220, 179-185

(Rerkasem et al. 2002) = Rerkasem K, Shearman CP, Williams JA, Morris GE, Phillips MJ, Calder PC, Grimble RF (2002): C-reactive protein is elevated in symptomatic compared with asymptomatic patients with carotid artery disease. Eur J Vasc Endovasc Surg 23, 505-509

(Ridker 2005) = Ridker PM (2005): C-reactive protein, inflammation, and cardiovascular disease: clinical update. Tex Heart Inst J $\underline{32}, 384-386$

(Ridker et al. 2001) $=$ Ridker PM, Rifai N, Clearfield M, Downs JR, Weis SE, Miles JS, Gotto AMJ (2001): Measurement of C-reactive protein for the targeting of statin therapy in the primary prevention of acute coronary events. N Engl J Med $\underline{344}, 1959-1965$

(Ringleb et al. 2008) = Ringleb P, Schellinger PD, Hacke W (2008): Leitlinien zum Management von Patienten mit akutem Hirninfarkt oder TIA der Europäischen Schlaganfallorganisation 2008. Teil 1. Nervenarzt $\underline{79}, 936-957$

$($ Ross 1999) $=$ Ross R (1999): Atherosclerosis--an inflammatory disease. N Engl J Med $\underline{340}$, $115-126$

(Rothwell et al. 2000) $=$ Rothwell PM, Gibson R, Warlow CP (2000): Interrelation between plaque surface morphology and degree of stenosis on carotid angiograms and the risk of ischemic stroke in patients with symptomatic carotid stenosis. On behalf of the European Carotid Surgery Trialists' Collaborative Group. Stroke 31, 615-621

(Saam et al. 2006) = Saam T, Cai J, Ma L, Cai Y, Ferguson MS, Polissar NL, Hatsukami TS, Yuan C (2006): Comparison of symptomatic and asymptomatic atherosclerotic carotid plaque features with in vivo MR imaging. Radiology $\underline{240}$, 464-472 
(Saam et al. 2007) = Saam T, Hatsukami TS, Takaya N, Chu B, Underhill H, Kerwin WS, Cai J, Ferguson MS, Yuan C (2007): The vulnerable, or high-risk, atherosclerotic plaque: noninvasive MR imaging for characterization and assessment. Radiology 244, 64-77

(Saba et al. 2007) = Saba L, Caddeo G, Sanfilippo R, Montisci R, Mallarini G (2007): CT and ultrasound in the study of ulcerated carotid plaque compared with surgical results: potentialities and advantages of multidetector row CT angiography. AJNR Am J Neuroradiol 28, 1061-1066

(Schellinger et al. 2008) = Schellinger PD, Ringleb P, Hacke W (2008): Leitlinien zum Management von Patienten mit akutem Hirninfarkt oder TIA der Europäischen Schlaganfallorganisation 2008 : Teil 2. Nervenarzt $\underline{79}, 1180-4,1186-8,1190-1201$

(Schillinger et al. 2005) = Schillinger M, Exner M, Mlekusch W, Sabeti S, Amighi J, Nikowitsch R, Timmel E, Kickinger B, Minar C, Pones M (2005): Inflammation and Carotid Artery--Risk for Atherosclerosis Study (ICARAS). Circulation 111, 2203-2209

(Schönbeck und Libby 2004) = Schönbeck U, Libby $P$ (2004): Inflammation, immunity, and HMG-CoA reductase inhibitors: statins as antiinflammatory agents?. Circulation $\underline{109}$, II18-26

(Sidhu und Allan 1997) = Sidhu PS, Allan PL (1997): The extended role of carotid artery ultrasound. Clin Radiol $\underline{52}, 643-653$

(Silvennoinen et al. 2007) = Silvennoinen HM, Ikonen S, Soinne L, Railo M, Valanne L (2007): CT angiographic analysis of carotid artery stenosis: comparison of manual assessment, semiautomatic vessel analysis, and digital subtraction angiography. AJNR Am J Neuroradiol $\underline{28}, 97-103$

(Som et al. 2000) = Som PM, Curtin HD, Mancuso AA (2000): Imaging-based nodal classification for evaluation of neck metastatic adenopathy. AJR Am J Roentgenol 174, 837-844

(Spagnoli et al. 2007) = Spagnoli LG, Bonanno E, Sangiorgi G, Mauriello A (2007): Role of inflammation in atherosclerosis. J Nucl Med $\underline{48}, 1800-1815$

(Sumi et al. 2001) = Sumi M, Ohki M, Nakamura T (2001): Comparison of sonography and CT for differentiating benign from malignant cervical lymph nodes in patients with squamous cell carcinoma of the head and neck. AJR Am J Roentgenol 176, 1019-1024

(Takaya et al. 2006) = Takaya N, Yuan C, Chu B, Saam T, Underhill H, Cai J, Tran N, Polissar NL, Isaac C, Ferguson MS (2006): Association between carotid plaque characteristics and subsequent ischemic cerebrovascular events: a prospective assessment with MRI--initial results. Stroke $\underline{37}$, 818-823

(Tang et al. 2006) = Tang T, Howarth SPS, Miller SR, Trivedi R, Graves MJ, King-Im JU, Li ZY, Brown AP, Kirkpatrick PJ, Gaunt ME (2006): Assessment of inflammatory burden contralateral to the symptomatic carotid stenosis using high-resolution ultrasmall, superparamagnetic iron oxideenhanced MRI. Stroke $\underline{37}, 2266-2270$

(Thakore et al. 2007) = Thakore AH, Guo C, Larson MG, Corey D, Wang TJ, Vasan RS, D'Agostino RBS, Lipinska I, Keaney JFJ, Benjamin EJ (2007): Association of multiple inflammatory markers with carotid intimal medial thickness and stenosis (from the Framingham Heart Study). Am $J$ Cardiol 99, 1598-1602

(Trivedi et al. 2004) = Trivedi RA, U-King-Im J, Graves MJ, Horsley J, Goddard M, Kirkpatrick PJ, Gillard JH (2004): MRI-derived measurements of fibrous-cap and lipid-core thickness: the potential for identifying vulnerable carotid plaques in vivo. Neuroradiology $\underline{46}, 738-743$ 
(U-King-Im et al. 2004) = U-King-Im JMKS, Trivedi RA, Cross JJ, Higgins NJP, Hollingworth W, Graves M, Joubert I, Kirkpatrick PJ, Antoun NM, Gillard JH (2004): Measuring carotid stenosis on contrast-enhanced magnetic resonance angiography: diagnostic performance and reproducibility of 3 different methods. Stroke $\underline{35}, 2083-2088$

(U-King-Im et al. 2008) = U-King-Im JM, Tang TY, Patterson A, Graves MJ, Howarth S, Li Z, Trivedi R, Bowden D, Kirkpatrick PJ, Gaunt ME (2008): Characterisation of carotid atheroma in symptomatic and asymptomatic patients using high resolution MRI. J Neurol Neurosurg Psychiatry $\underline{79}, 905-912$

(Van den Brekel et al. 1990) = Van den Brekel MW, Stel HV, Castelijns JA, Nauta JJ, Van der Waal I, Valk J, Meyer CJ, Snow GB (1990): Cervical lymph node metastasis: assessment of radiologic criteria. Radiology 177 , 379-384

(Van der Meer et al. 2002) = Van der Meer IM, de Maat MPM, Bots ML, Breteler MMB, Meijer J, Kiliaan AJ, Hofman A, Witteman JCM (2002): Inflammatory mediators and cell adhesion molecules as indicators of severity of atherosclerosis: the Rotterdam Study. Arterioscler Thromb Vasc Biol $\underline{22}$, 838-842

(Virmani et al. 2000) = Virmani R, Kolodgie FD, Burke AP, Farb A, Schwartz SM (2000): Lessons from sudden coronary death: a comprehensive morphological classification scheme for atherosclerotic lesions. Arterioscler Thromb Vasc Biol 20, 1262-1275

(Virmani et al. 2006) = Virmani R, Burke AP, Farb A, Kolodgie FD (2006): Pathology of the vulnerable plaque. J Am Coll Cardiol $\underline{47}, \mathrm{C} 13-18$

(Walker et al. 2002) $=$ Walker LJ, Ismail A, McMeekin W, Lambert D, Mendelow AD, Birchall D (2002): Computed tomography angiography for the evaluation of carotid atherosclerotic plaque: correlation with histopathology of endarterectomy specimens. Stroke $\underline{33}, 977-981$

(Wang et al. 2002) = Wang TJ, Nam B, Wilson PWF, Wolf PA, Levy D, Polak JF, D'Agostino RB, O'Donnell CJ (2002): Association of C-reactive protein with carotid atherosclerosis in men and women: the Framingham Heart Study. Arterioscler Thromb Vasc Biol 22, 1662-1667

(Wardlaw 2008) = Wardlaw JM (2008): Carotid imaging for secondary stroke prevention in routine practice. Int J Stroke $\underline{3}, 20-32$

(Wardlaw et al. 2006) $=$ Wardlaw JM, Chappell FM, Best JJK, Wartolowska K, Berry E (2006): Noninvasive imaging compared with intra-arterial angiography in the diagnosis of symptomatic carotid stenosis: a meta-analysis. Lancet $\underline{367}, 1503-1512$

(Willinsky et al. 2003) = Willinsky RA, Taylor SM, TerBrugge K, Farb RI, Tomlinson G, Montanera W (2003): Neurologic complications of cerebral angiography: prospective analysis of 2,899 procedures and review of the literature. Radiology $\underline{227}, 522-528$

(Yoon et al. 2009) = Yoon DY, Hwang HS, Chang SK, Rho Y, Ahn HY, Kim JH, Lee IJ (2009): CT, MR, US,18F-FDG PET/CT, and their combined use for the assessment of cervical lymph node metastases in squamous cell carcinoma of the head and neck. Eur Radiol $\underline{19}, 634-642$

(Zacho et al. 2008) = Zacho J, Tybjaerg-Hansen A, Jensen JS, Grande P, Sillesen H, Nordestgaard BG (2008): Genetically elevated C-reactive protein and ischemic vascular disease. N Engl J Med 359, 1897-1908 


\section{Danksagungen}

Herrn Prof. Dr. med. M. Knauth möchte ich für die Überlassung des interessanten Themas, die fachkundige und nette Betreuung und die Bereitstellung des Arbeitsplatzes herzlich danken. Es war mir eine große Freude, meine Dissertation in seiner Abteilung verfassen zu dürfen.

Frau Sara M. Pilgram-Pastor möchte ich für ihre herausragende Betreuung ganz besonders danken. Jede Phase dieser Arbeit wurde von ihr intensiv, professionell und sehr engagiert begleitet. Ihr kompetenter Rat und ihre Hilfe kamen mir stets sehr zugute. Ich fühlte mich nicht nur fachlich, sondern auch menschlich hervorragend betreut.

Herrn Dr. med. Jörg Larsen danke ich für die interessante Idee zur Arbeit.

Allen Mitarbeitern und Mitarbeiterinnen des Instituts möchte ich für die sehr gute Zusammenarbeit danken. 